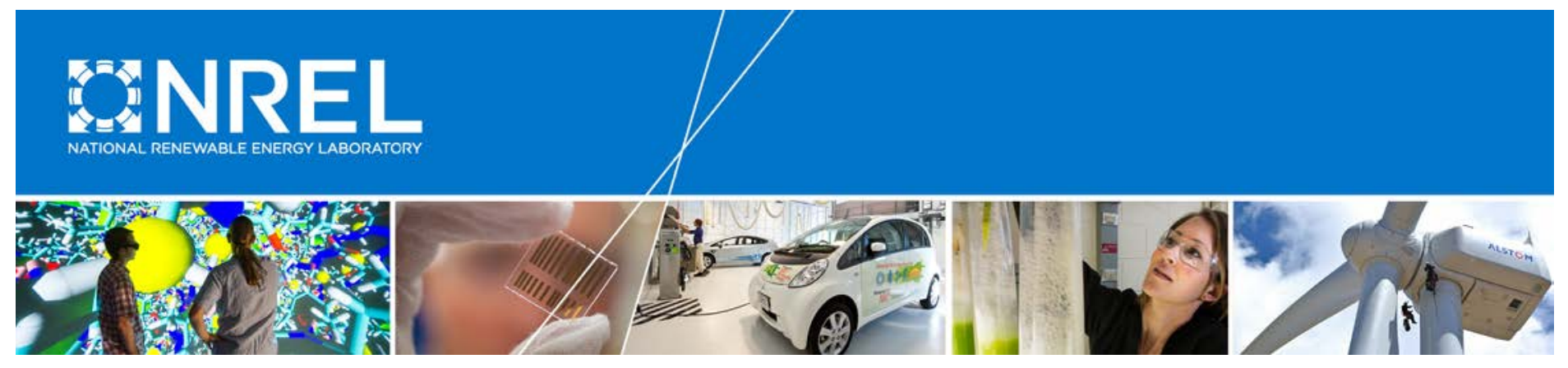

\title{
Estimating the National Carbon Abatement Potential of City Policies: A Data- Driven Approach
}

Eric O'Shaughnessy, Jenny Heeter, David Keyser, Pieter Gagnon, and Alexandra Aznar National Renewable Energy Laboratory

NREL is a national laboratory of the U.S. Department of Energy Office of Energy Efficiency \& Renewable Energy Operated by the Alliance for Sustainable Energy, LLC

This report is available at no cost from the National Renewable Energy Laboratory (NREL) at www.nrel.gov/publications.

Technical Report

NREL/TP-6A20-67101

October 2016 


\section{Estimating the National Carbon Abatement Potential of City Policies: A Data- Driven Approach}

Eric O'Shaughnessy, Jenny Heeter, David Keyser, Pieter Gagnon, and Alexandra Aznar National Renewable Energy Laboratory

Prepared under Task No. SA15.0803

NREL is a national laboratory of the U.S. Department of Energy Office of Energy Efficiency \& Renewable Energy Operated by the Alliance for Sustainable Energy, LLC

This report is available at no cost from the National Renewable Energy Laboratory (NREL) at www.nrel.gov/publications.

National Renewable Energy Laboratory 15013 Denver West Parkway Golden, CO 80401

303-275-3000 • www.nrel.gov

\section{Technical Report}

NREL/TP-6A20-67101

October 2016

Contract No. DE-AC36-08G028308 


\section{NOTICE}

This report was prepared as an account of work sponsored by an agency of the United States government. Neither the United States government nor any agency thereof, nor any of their employees, makes any warranty, express or implied, or assumes any legal liability or responsibility for the accuracy, completeness, or usefulness of any information, apparatus, product, or process disclosed, or represents that its use would not infringe privately owned rights. Reference herein to any specific commercial product, process, or service by trade name, trademark, manufacturer, or otherwise does not necessarily constitute or imply its endorsement, recommendation, or favoring by the United States government or any agency thereof. The views and opinions of authors expressed herein do not necessarily state or reflect those of the United States government or any agency thereof.

This report is available at no cost from the National Renewable Energy Laboratory (NREL) at www.nrel.gov/publications.

Available electronically at SciTech Connect http:/www.osti.gov/scitech

Available for a processing fee to U.S. Department of Energy and its contractors, in paper, from:

U.S. Department of Energy

Office of Scientific and Technical Information

P.O. Box 62

Oak Ridge, TN 37831-0062

OSTI http://www.osti.gov

Phone: 865.576.8401

Fax: 865.576.5728

Email: reports@osti.gov

Available for sale to the public, in paper, from:

U.S. Department of Commerce

National Technical Information Service

5301 Shawnee Road

Alexandria, VA 22312

NTIS http://www.ntis.gov

Phone: 800.553 .6847 or 703.605 .6000

Fax: 703.605.6900

Email: orders@ntis.gov 


\section{Acknowledgments}

This work was funded by the U.S. Department of Energy's Office of Energy Efficiency and Renewable Energy. For their thoughtful review of the document, the authors thank Derik Broekhoff and Pete Erickson of the Stockholm Environmental Institute; Russell Brooks of Transportation for America; Danielle Byrnett, David Cohan, Paul Donohoo-Vallett, Ookie Ma, Kate Marks, and Sarah Zaleski of the Department of Energy, Paul Haven of the Environmental and Energy Study Institute; JC Martel of the University of Kansas; Carlos Martin of the Urban Institute; Vrushali Mendon of the Pacific Northwest National Laboratory; and Jaquelin Cochran, Alex Dane, Megan Day, Jeff Logan, Colin McMillan, Dave Mooney, Shanti Pless, Gian Porro, and Laura Vimmerstadt of the National Renewable Energy Laboratory (NREL) as well as Tina Eichner, Mike Meshek, and Kathryn Ruckman of NREL for editorial support. 


\section{Preface}

The Office of Strategic Programs within the U.S. Department of Energy's (DOE's) Office of Energy Efficiency and Renewable Energy initiated a multi-year project called Cities Leading through Energy Analysis and Planning (Cities-LEAP). The project aims to enable cities to lead clean energy innovation and integrate strategic energy analysis into decisions by providing standardized, localized energy data and analysis. Cities-LEAP informs the implementation of city-sponsored, data-driven energy policies, programs, and projects that have the potential to impact the national energy landscape. Through Cities-LEAP, cities will be able to:

- Set data-informed climate or energy goals

- Prioritize and implement energy strategies

- Understand the potential impacts of climate or energy action plans

- Learn from peers about city energy planning best practices

- Get access to credible data and transparent, usable analytic methodologies

- Make data-driven energy decisions.

The initial Cities-LEAP technical report, "City-Level Energy Decision Making: Data Use in Energy Planning, Implementation, and Evaluation in U.S. Cities" (Aznar et al. 2015), explores how a sample of cities incorporates data into making energy-related decisions. Building on the needs identified in the initial Cities-LEAP report, the DOE and the National Renewable Energy Laboratory developed the City Energy Profile tool. ${ }^{1}$ The profiles in the tool provide estimates and actual data on city-level energy use metrics, including electricity use, natural gas use, vehicle fuel use, and vehicle miles traveled. These data allow city decision makers to better understand their energy landscape and make more strategic energy decisions. The following figure illustrates how the current report fits into the broader Cities-LEAP body of work.

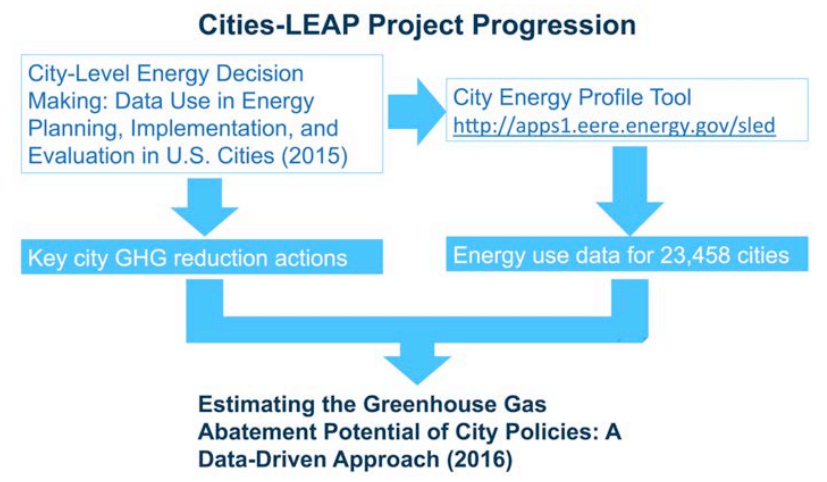

This report builds on the existing Cities-LEAP work by applying the findings from "City-Level Energy Decision Making" and data from the City Energy Profile tool to estimate the carbon abatement potential of city-led actions identified in "City-Level Energy Decision Making."

\footnotetext{
${ }^{1}$ The City Energy Profile tool can be accessed at http://apps1.eere.energy.gov/sled.
} 


\section{Executive Summary}

Cities are increasingly taking actions such as building code enforcement, urban planning, and public transit expansion to reduce emissions of carbon dioxide in their communities and municipal operations (Aznar et al. 2015; ICMA 2016). However, many cities lack the quantitative information needed to estimate policy impacts and prioritize city actions in terms of carbon abatement potential and cost effectiveness (Aznar et al. 2015). This report fills this research gap by providing methodologies to assess the carbon abatement potential of a variety of city actions. The methodologies are applied to an energy use data set of 23,458 cities compiled for the U.S. Department of Energy's City Energy Profile tool.

The analysis estimates the national carbon abatement potential of the most commonly implemented actions (Aznar et al. 2015) in six specific policy areas. The results of this analysis suggest that, in aggregate, cities could reduce nationwide carbon emissions by about 210 million metric tons of carbon dioxide $\left(\mathrm{MMT} \mathrm{CO}_{2}\right)$ per year in a "moderate abatement scenario" by 2035 and $480 \mathrm{MMT} \mathrm{CO}_{2}$ /year in a "high abatement scenario" by 2035 through these common actions typically within a city's control in the six policy areas (Figure ES-1). The aggregate carbon abatement potential of these specific areas equates to a reduction of 3\%-7\% relative to 2013 U.S. emissions. At the city level, the results suggest the average city could reduce carbon emissions by $7 \%$ (moderate) to $19 \%$ (high) relative to current city-level emissions. City carbon abatement potential is sensitive to national and state policies that affect the carbon intensity of electricity and transportation. Specifically, the U.S. Clean Power Plan and further renewable energy cost reductions could reduce city carbon emissions overall, helping cities achieve their carbon reduction goals.

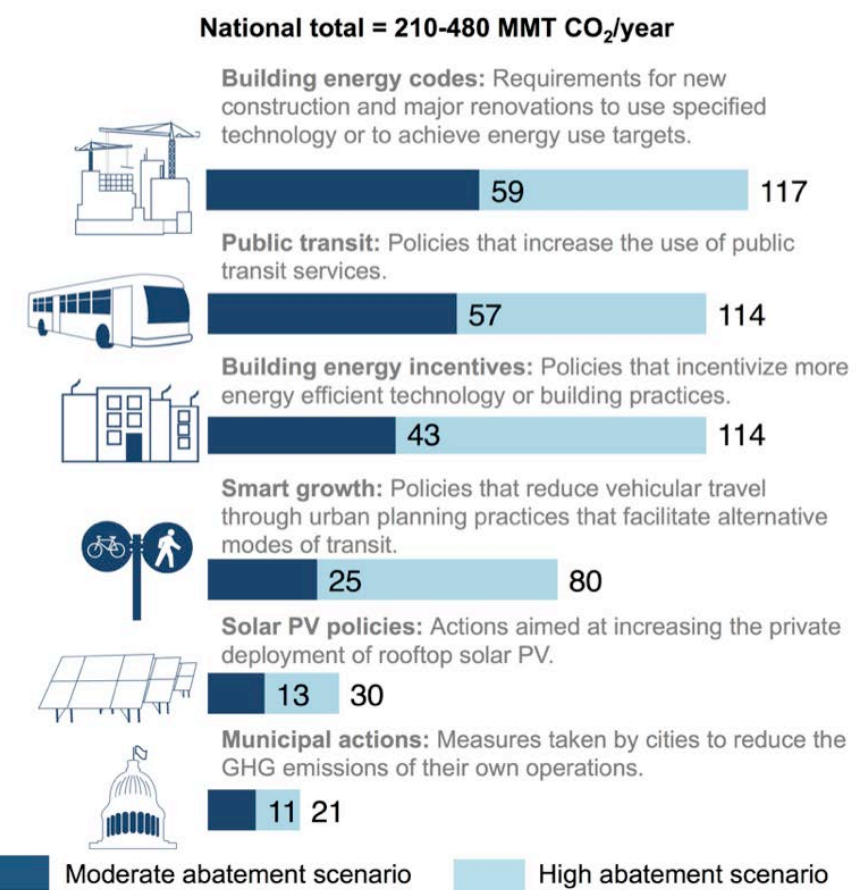

Figure ES-1. Estimated national carbon abatement potential (MMT $\mathrm{CO}_{2} /$ year) of city policy areas 
In the context of U.S. climate commitments under the $21^{\text {st }}$ session of the Conference of the Parties (COP21), the estimated national abatement potential of the city actions analyzed in this report equates to about $15 \%-35 \%$ of the remaining carbon abatement necessary to achieve the U.S. COP21 target (Figure ES-2). ${ }^{2}$ Additional city actions outside the scope of this report, such as community choice aggregation (city-level purchasing of renewable energy), zero energy districts, and multi-level governance strategies, could significantly augment the carbon abatement contributions of city actions toward national climate targets. The results suggest that cities may play a pivotal role in progress toward national climate targets.

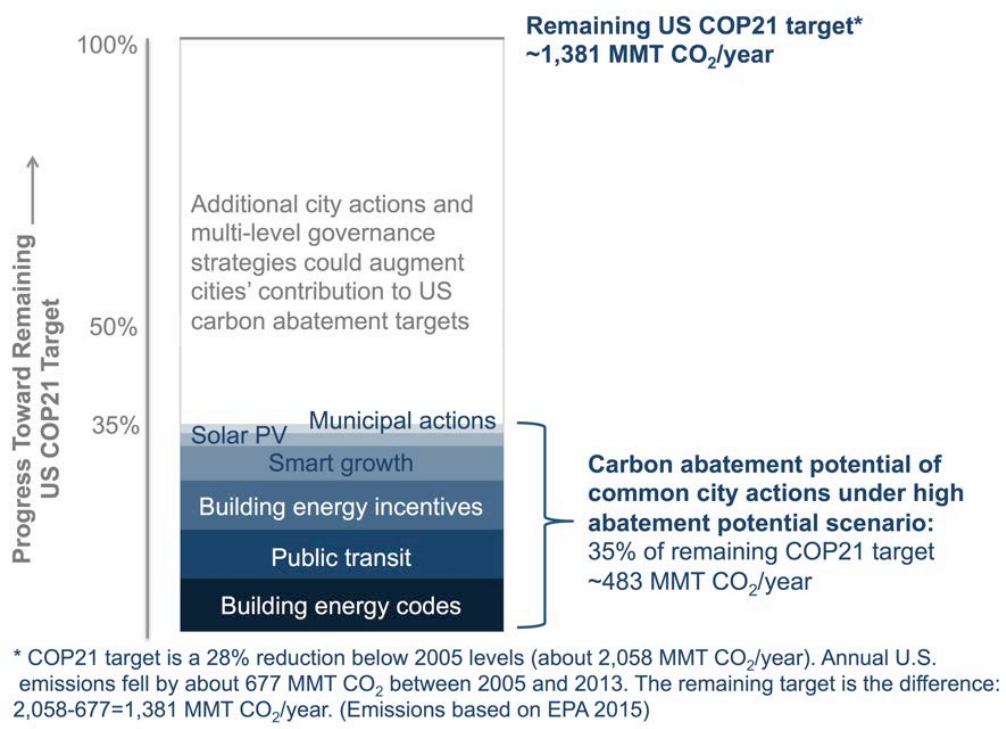

Figure ES-2. Carbon abatement potential of common city actions in the context of U.S. COP21 targets (high abatement potential scenario)

In addition to providing carbon and emissions estimates, this report estimates the national net economic impacts of policies for which cost and benefit data are available. Impact metrics include employment, worker earnings, and gross domestic product (GDP). For the policy areas studied, the economic analysis demonstrates that city carbon abatement may be achieved with only minimal and generally slightly positive economic impacts. Employment impacts range from $0.04 \%$ to $0.13 \%$ of 2015 U.S. employment during implementation and zero to $0.1 \%$ thereafter. GDP estimates show net impacts of $0.02 \%$ to $0.07 \%$ of GDP during implementation and impacts from $-0.02 \%$ to zero thereafter.

This report quantitatively demonstrates the material impact of a limited set of local policy areas on national carbon abatement potential. The magnitude of estimated carbon reductions from city policies, a 3\%-7\% reduction relative to 2013 U.S. emissions by 2035, suggests an important role for city-led actions in reaching U.S. climate goals. Multi-level governance at the city, state, and national levels could augment the carbon abatement potential of city actions and make cities a key component of long-term U.S. climate strategies.

\footnotetext{
${ }^{2}$ U.S. COP21 targets and emissions in the U.S. EPA greenhouse gas inventory are measured in terms of carbon dioxide equivalent, which includes other greenhouse gases such as methane and nitrous oxide not measured in this report.
} 


\section{Table of Contents}

1 Introduction

Scope, Terminology, and Methods......................................................................................... 3

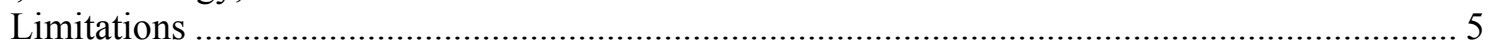

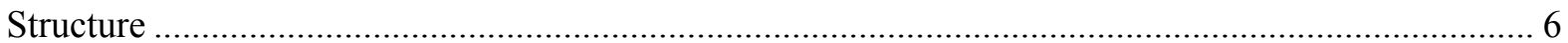

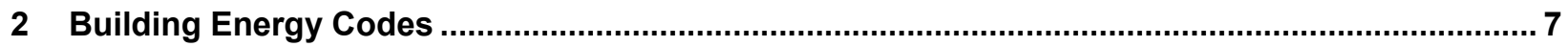

2.1 Summary of Current Building Energy Codes ............................................................. 7

2.2 Scenarios, Assumptions, and Methods for Estimating Carbon Abatement Potential of Building

Energy Codes ........................................................................................................ 8

New Construction and Major Renovation Baseline Energy Use .........................................9

Building Code Energy Realization Rate Change .......................................................... 10

Carbon Intensity of Displaced Building Energy Use ................................................... 11

Summary of Assumptions ........................................................................................ 11

2.3 Results: Carbon Abatement Potential of City Building Energy Codes .................................. 12

3 Building Energy Incentives.................................................................................................. 13

3.1 Summary of City Building Energy Incentive Policies Currently Enacted ............................. 13

Financial Incentives...................................................................................... 13

Building Energy Benchmarking ............................................................................. 14

3.2 Scenarios, Assumptions, and Methods for Estimating Carbon Abatement Potential of Building

Energy Incentives .............................................................................................. 15

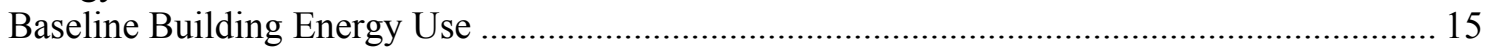

Reduction of Building Energy Use ....................................................................... 16

Program Participation Rates .................................................................................. 17

Carbon Intensity of Displaced Energy Use .............................................................. 17

Summary of Assumptions ..................................................................................... 17

3.3 Results: Carbon Abatement Potential of City Building Energy Incentives............................ 18

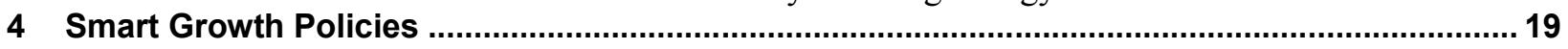

4.1 Summary of Smart Growth Policies Currently Enacted.................................................... 19

4.2 Scenarios, Assumptions, and Methods for Estimating Carbon Abatement Potential of Smart

Growth Policies ................................................................................................ 21

New Development Baseline Travel.......................................................................... 21

Percentage of Travel Affected.................................................................................... 22

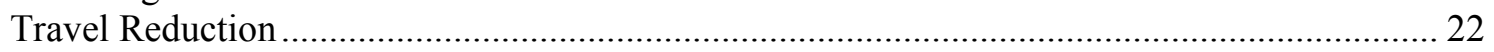

Carbon Intensity of Displaced Travel ...................................................................... 24

Summary of Assumptions ............................................................................. 24

4.3 Results: Carbon Abatement Potential of Smart Growth Policies ......................................... 24

5 Public Transit Expansion ..................................................................................................... 25

5.1 Summary of Public Transit Expansion Policies Currently Enacted ..................................... 25

5.2 Scenarios, Assumptions, and Methods for Estimating Carbon Abatement Potential of Public

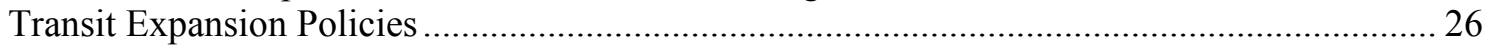

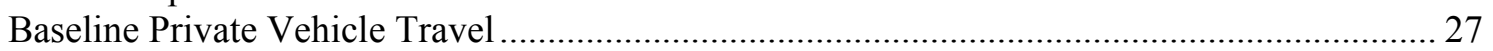

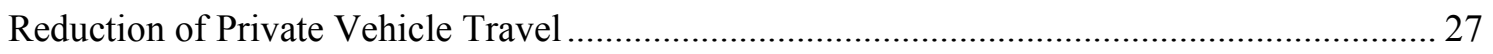

Change in Carbon Intensity from Mode Change............................................................. 29

Summary of Assumptions ....................................................................................... 30

5.3 Results: Carbon Abatement Potential of Public Transit Policies ............................................. 31

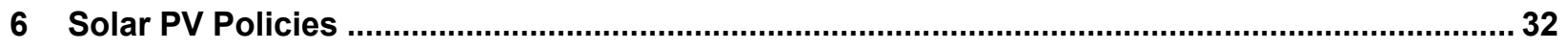

6.1 Summary of Solar PV Policies Currently Enacted ..................................................... 32

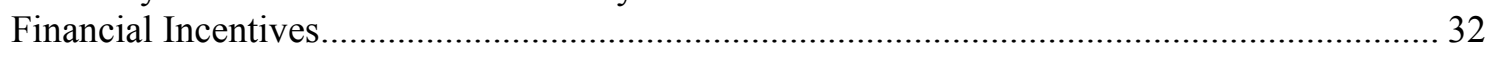

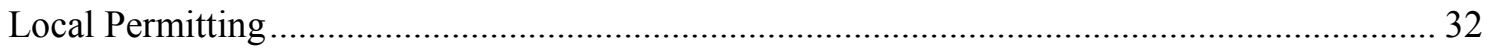

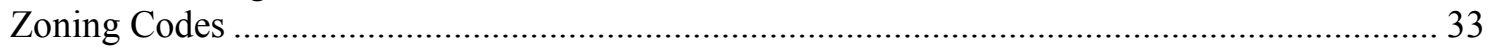




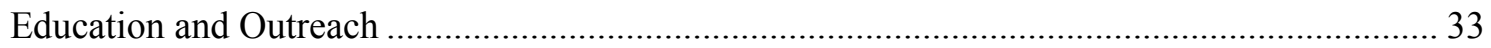

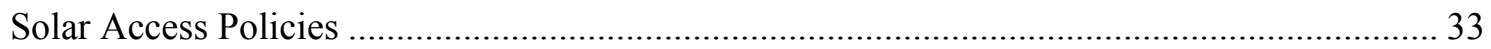

6.2 Scenarios, Assumptions, and Methods for Estimating Carbon Abatement Potential of Solar PV

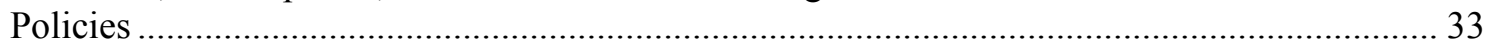

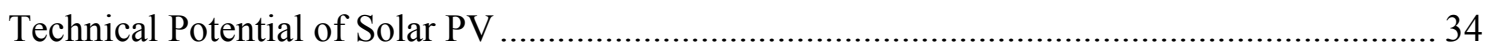

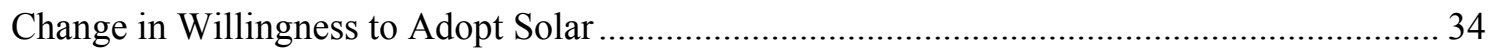

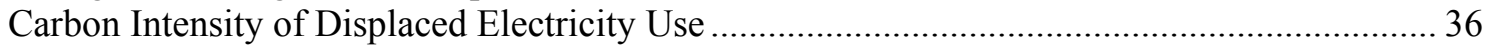

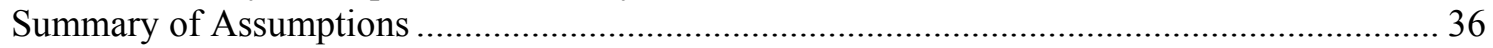

6.3 Results: Carbon Abatement Potential of City PV Policies..................................................... 37

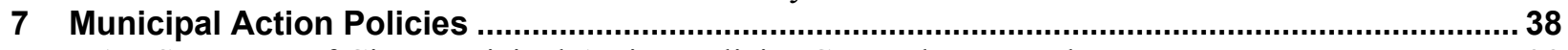

7.1 Summary of City Municipal Action Policies Currently Enacted ............................................ 38

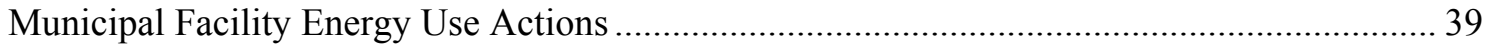

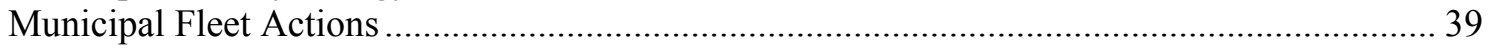

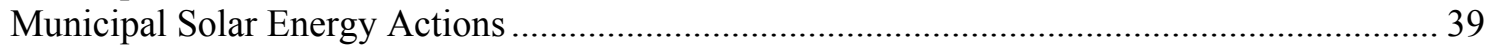

7.2 Scenarios, Assumptions, and Methods for Estimating Carbon Abatement Potential of Municipal

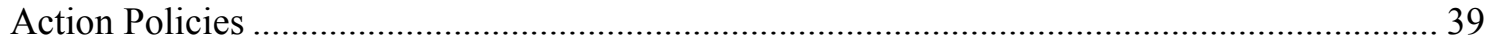

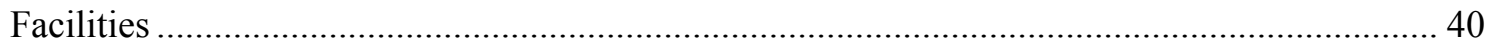

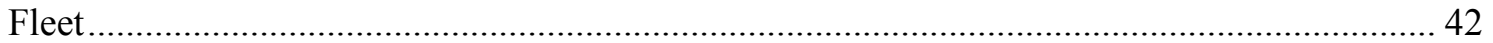

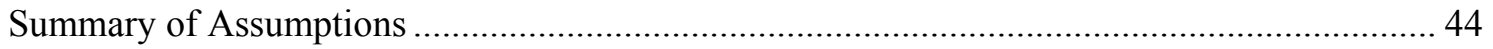

7.3 Results: Carbon Abatement Potential of Municipal Action Policies ......................................... 44

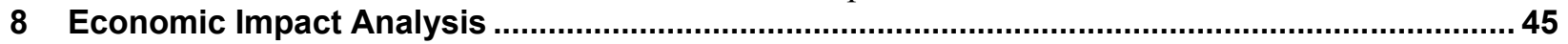

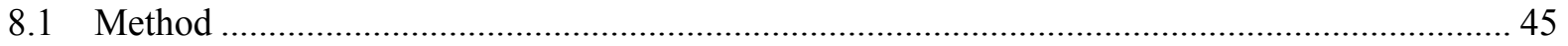

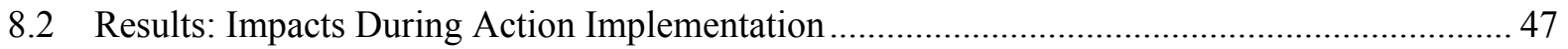

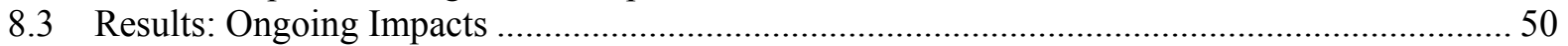

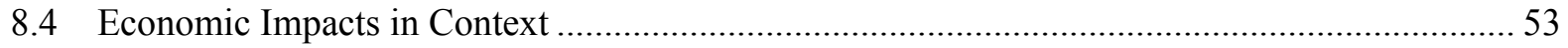

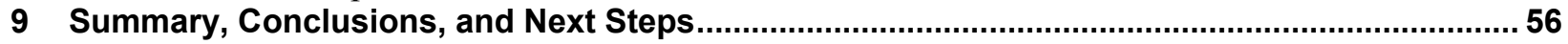

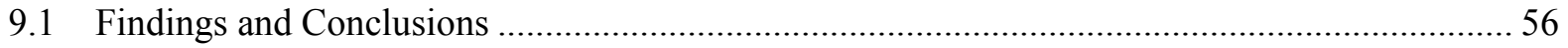

9.2 Next Steps: Using City Energy Data to Prioritize City Actions .................................................59

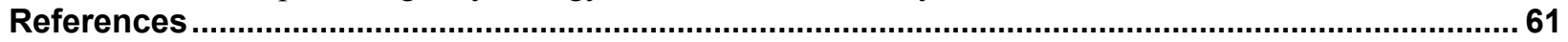

Appendix A. Supplementary Materials: Data, Methods, and Results ............................................. 68

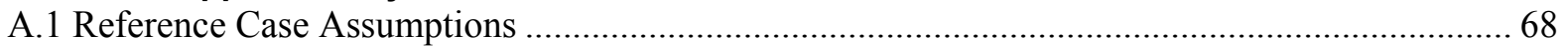

A.2 Building Energy Code Supplementary Materials: Energy Use Reductions between Building Code

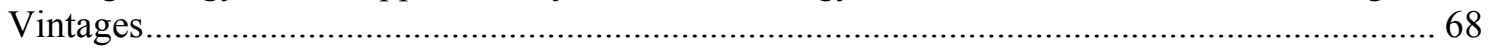

A.3 Smart Growth Supplementary Materials: Assumptions for Carbon Intensity of Displaced Travel70

A.4 Solar PV Supplementary Materials: Technical Potential Derate Factor..................................... 71

A.5 Municipal Action Supplementary Materials: Hybrid Adjustment Factor.................................... 72

Appendix B. Supplementary Materials: Cost Assumptions Used in Economic Impact Analysis .... 73

B.1 Implementation Cost Assumptions ..................................................................................... 73

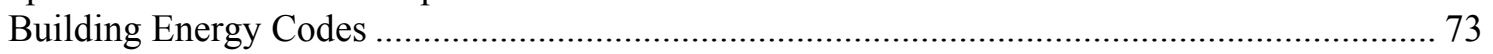

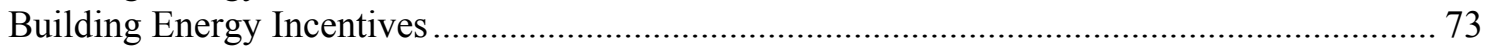

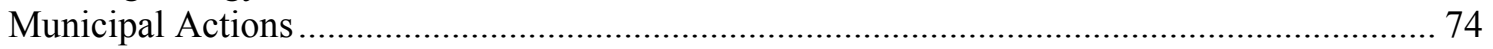

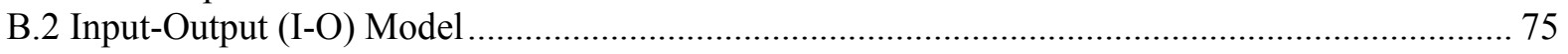

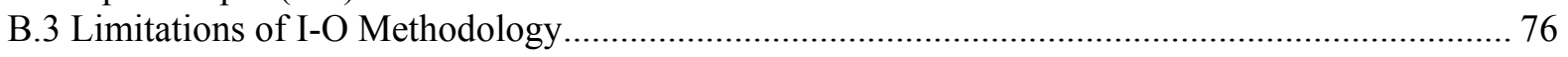

viii

This report is available at no cost from the National Renewable Energy Laboratory (NREL) at www.nrel.gov/publications. 


\section{List of Figures}

Figure ES-1. Estimated national carbon abatement potential (MMT $\mathrm{CO}_{2} /$ year) of city policy areas... $\mathrm{v}$ Figure 1. Conceptualization of carbon abatement potential estimation ........................................... 1

Figure 2. Policy areas with corresponding report sections ........................................................ 3

Figure 3. Geographic coverage of the City Energy Profile tool data ............................................. 5

Figure 4. Method for carbon abatement potential estimation of building energy codes .................. 9

Figure 5. Reductions in site energy use intensity over building code vintages (commercial

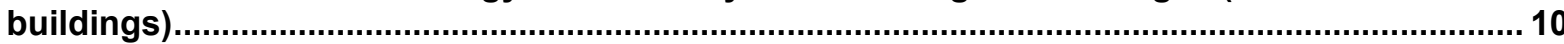

Figure 6. City-level carbon abatement potential distribution of building energy codes .................. 12

Figure 7. Method for carbon abatement potential estimation of building energy incentives ............ 15

Figure 8. City-level carbon abatement potential distribution of building energy incentives ............. 18

Figure 9. Method for carbon abatement potential estimation of smart growth policies ..................21

Figure 10. VMT reduction effect sizes from urban form studies....................................................... 23

Figure 11. City-level carbon abatement potential distribution of smart growth policies ................. 24

Figure 12. Number of public transit programs, by transit services ................................................. 25

Figure 13. Method for carbon abatement potential estimation of public transit expansion policies27

Figure 14. Carbon intensity (kg CO

Figure 15. City-level carbon abatement potential distribution of public transit expansion ............... 31

Figure 16. Method for carbon abatement potential estimation of city solar PV policies ................... 34

Figure 17. Residential solar PV willingness-to-pay curve ............................................................. 35

Figure 18. Modeled effects of city PV rebates on PV adoption ..................................................... 36

Figure 19. City-level carbon abatement potential distribution of solar PV policies......................... 37

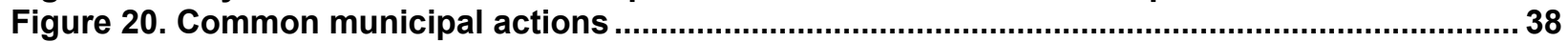

Figure 21. Method for carbon abatement potential estimation of municipal building actions ......... 40

Figure 22. Method for carbon abatement potential estimation of municipal fleet actions................ 42

Figure 23. Method for carbon abatement potential estimation of municipal solar PV actions......... 43

Figure 24. City-level carbon abatement potential distribution of municipal action policies ............ 44

Figure 25. Estimated national employment impacts during implementation of actions in three

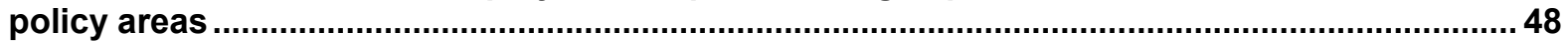

Figure 26. Estimated ongoing national employment impacts for actions in three policy areas ...... 51

Figure 27. Summary of results ..................................................................................................... 56

Figure 28. Carbon abatement potential of common city actions in the context of U.S.

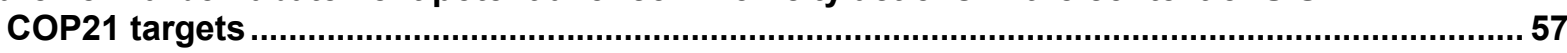

Figure 29. Carbon abatement potential as percentage of city emissions.........................................60 


\section{List of Tables}

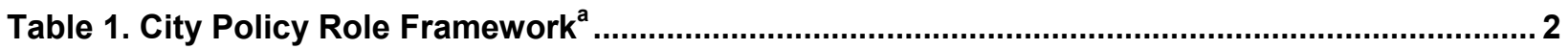

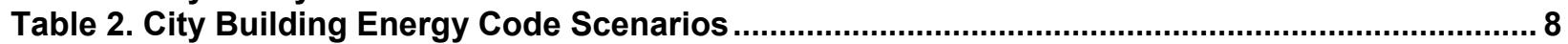

Table 3. City Financial Incentives for Building Energy Efficiency .................................................. 14

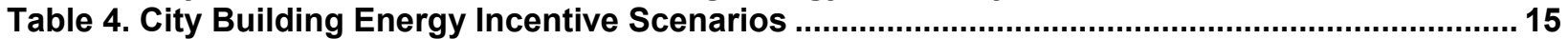

Table 5. Observed Energy Use Reductions in Benchmarking Programs ...................................... 16

Table 6. Sample of City Smart Growth Policies ................................................................................. 19

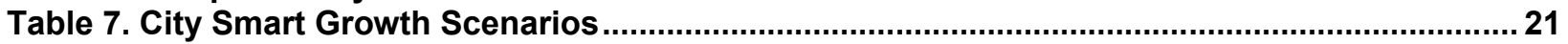

Table 8. Sample of Smart Growth Assumptions.............................................................................. 22

Table 9. Public Transit Expansion Policy Descriptions ................................................................. 26

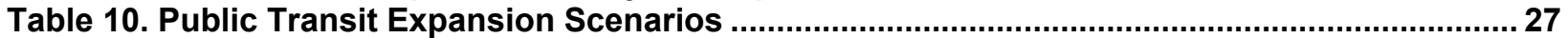

Table 11. Private Vehicle Travel Reductions Associated with Transit Expansion (Litman 2015) .... 28

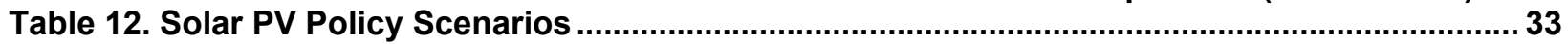

Table 13. Municipal Action Policy Scenarios ............................................................................. 40

Table 14. Economic Impact National Assumptions (\$ billions, 2015) ..............................................46

Table 15. Impacts During Implementation (Moderate Abatement Scenario) ${ }^{\mathrm{a}}$..................................... 49

Table 16. Impacts During Implementation (High Abatement Scenario) ${ }^{\mathrm{a}}$..........................................50

Table 17. Ongoing Impacts (Moderate Abatement Scenario) ${ }^{a}$..........................................................5 52

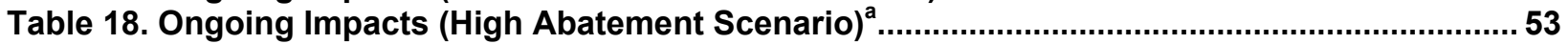

Table 19. Estimated Value Added Impacts Compared to 2015 GDP (\$ billions, 2015) ...................... 54

Table 20. Estimated Employment Impacts Compared to 2015 National Employment....................... 55

Table A-1. Estimated Energy Use Reductions from Commercial Building Code Update Studies ... 69

Table A-2. Estimated Energy Use Reductions from Residential Building Code Update Studies..... 69

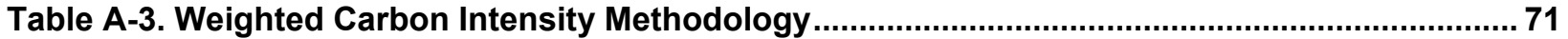

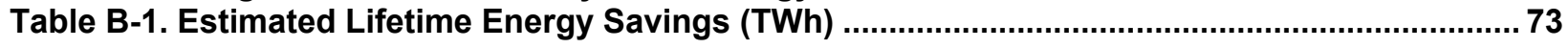

\section{List of Text Boxes}

Text Box 1. The DOE/NREL City Energy Profile Tool Data ............................................................ 5

\section{List of Equations}

Equation 1. Carbon intensity of passenger miles traveled (PMT) ................................................ 29 


\section{Introduction}

Cities are increasingly acting to reduce energy costs and emissions of carbon dioxide and other greenhouse gases in their communities and municipal operations (Aznar et al. 2015; ICMA 2016). ${ }^{3}$ Cities are well positioned to reduce carbon emissions through local actions such as building code enforcement, urban planning, and public transit that can result in reduced building and transportation energy use, reduced carbon intensity, or both ${ }^{4}$ (Erickson and Tempest 2014). However, many cities lack the quantitative information needed to estimate policy impacts and prioritize city actions in terms of carbon abatement potential and economic impacts (Aznar et al. 2015).

Carbon abatement potential refers to the quantity of carbon dioxide $\left(\mathrm{CO}_{2}\right)$ emissions that could be avoided by implementing a policy relative to a counterfactual situation where the policy is not implemented. Carbon emissions in the United States are generally projected to decline, especially in the electricity generation sector (EIA 2015). Carbon abatement potential is therefore the additional reduction achievable through carbon abatement policies (Figure 1).

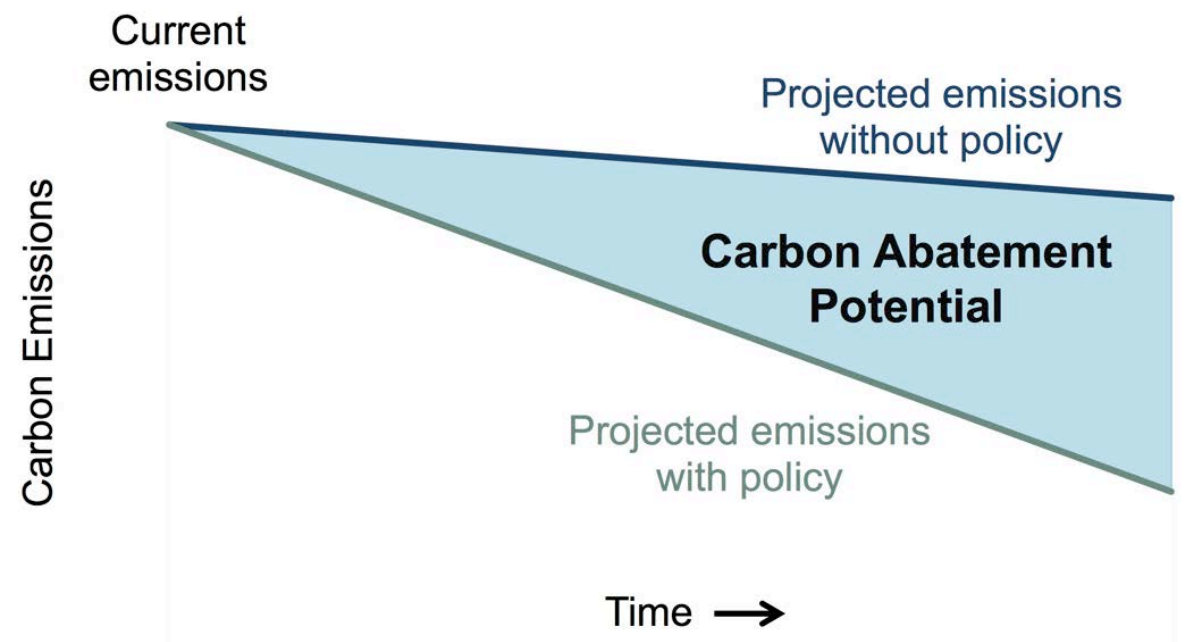

Figure 1. Conceptualization of carbon abatement potential estimation

Some existing literature assesses city policies in terms of carbon abatement potential. Some studies assess a more inclusive group of greenhouse gases (e.g., carbon dioxide, methane, and nitrous oxide) while we analyze $\mathrm{CO}_{2}$ exclusively. To avoid confusion, we use the term carbon abatement potential throughout this report. Ramaswami et al. (2012) found that a mix of voluntary and regulatory city actions could reduce emissions from the building and transportation sectors by about $1 \%$ annually. The authors found that city regulatory actions were about five times more effective in terms of carbon abatement potential than voluntary programs. Erickson and Tempest (2014) found that city actions could reduce global carbon emissions by

\footnotetext{
${ }^{3}$ The term "city" used for this analysis includes incorporated places as defined by the U.S. Census as well as minor civil divisions in New England states in order to include smaller cities and towns, and census-designated places in the State of Hawaii where there are no incorporated cities.

${ }^{4}$ Carbon intensity refers to the amount of emissions (total carbon dioxide or $\mathrm{tCO}_{2}$ ) per a unit of activity (e.g., MWh of electricity generation).
} 
about $11 \%$ by 2050 relative to a 2050 business-as-usual projection. At the city level, they found that cities could reduce local carbon emissions by about $47 \%$ by 2050 . Broekhoff, Erickson, and Lee (2015) developed a city policy role framework for assessing city actions based on cities' various roles in policy creation and implementation. Under this framework, cities can most efficiently achieve their full abatement potential through a combination of city-level (crafted and implemented primarily at the city level) and multi-level governance strategies (Table 1).

Table 1. City Policy Role Framework

\begin{tabular}{ll}
\hline City Role & Description \\
\hline Policy leader and architect & Policies crafted and implemented primarily at the city level \\
Critical implementer & $\begin{array}{l}\text { Policies adopted above the city level (e.g., state, national) that are } \\
\text { primarily implemented at the city level }\end{array}$ \\
Strategic partner & $\begin{array}{l}\text { Policies adopted at multiple levels of government involving cities as } \\
\text { implementation partners }\end{array}$ \\
\hline
\end{tabular}

${ }^{a}$ Broekhoff, Erickson, and Lee 2015

No national estimate of the carbon abatement potential of city policies has yet been made. We address this research gap by developing methodologies to estimate the carbon abatement potential of actions that cities are already taking to reduce emissions. We apply the methodologies to the U.S. Department of Energy (DOE) City Energy Profile data set to estimate the national carbon abatement potential of the most common city actions (Aznar et al. 2015). ${ }^{5}$ Further, we seek to provide cities with another critical metric with which to prioritize energyrelated actions: the economic impacts of local energy policies. Constrained by budgets, local governments weigh costs and benefits of policy implementation when constructing local sustainability (e.g., carbon-reducing) policies and program agendas; however, little information about the economic impacts of policies and programs, particularly city-to-city comparisons, exists (Aznar et al. 2015).

The methodologies we developed are easily transferable to a city-level context, and they enable a city's stakeholders to estimate the carbon abatement potential of various city policies given their city's unique characteristics. Data-driven policy prioritization could result in an accelerated nationwide carbon reduction by informing cities on how to make the deepest achievable carbon reductions as soon as possible. National estimates of the carbon abatement potential of city policies may empower cities to sustain their leadership in energy and carbon-reducing activities by quantitatively estimating the impact of collective local action in addressing global climate change.

City-level and national stakeholders may both be informed by this report. A national city action carbon abatement potential estimate will help national policymakers place city actions into a broader context of national climate policy options. This information is particularly timely after the Paris Climate Change Conference in November 2015 and given the potential contribution of cities to national carbon reduction targets. Federal agencies could create incentives for the city-

\footnotetext{
${ }^{5}$ The City Energy Profile tool can be accessed at http://apps1.eere.energy.gov/sled.
} 
level uptake of the most cost-effective actions identified, or could partner with cities to coordinate intercity carbon reduction programs.

\section{Scope, Terminology, and Methods}

Building on the findings of Aznar et al. (2015), we developed six policy areas for analysis of national carbon abatement potential (Figure 2). ${ }^{6}$ The six policy areas encompass the most common actions that cities are already taking to reduce carbon emissions, but are not meant to be comprehensive or capture all actions a city could take. Importantly, the policy areas are limited to policies that are crafted and implemented primarily at the city level (i.e., policies that do not require significant support from other levels of government). Policies that could have significant abatement potential but require significant cooperation from other authorities, such as community choice aggregation and zero energy districts, are excluded. Literature suggests that multi-level governance strategies, outside the scope of this analysis, could significantly augment city carbon abatement potential (Broekhoff, Erickson, and Lee 2015). The estimates in this report, then, do not include important actions being taken by leading-edge cities, nor do they include actions being implemented at the utility, state, or federal levels.

\section{Policy Areas}
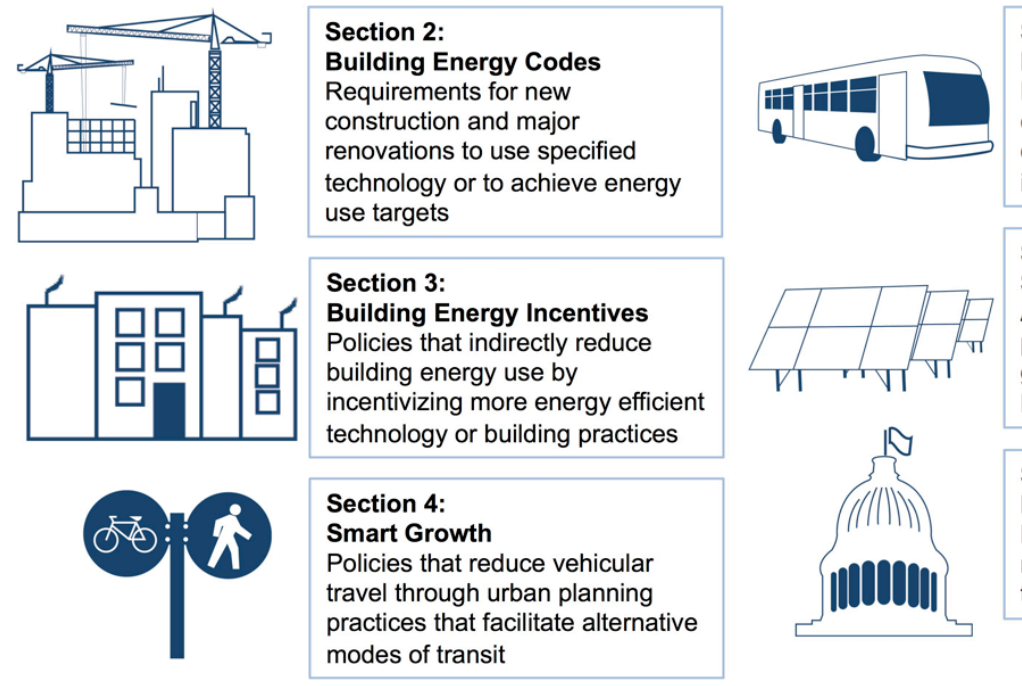

Section 5:
Public Transit Expansion
Policies that increase the use of
existing public transit services or
develop new public transit
infrastructure

Figure 2. Policy areas with corresponding report sections

Policy areas - rather than specific policies — are analyzed in order to estimate the policy impacts of incremental actions taken by cities at different stages of policy implementation. It is assumed all cities can take incremental actions to further reduce carbon emissions through a given policy area regardless of their current policy environment or progress toward carbon reduction goals. For example, cities with no existing public transit infrastructure may focus on new transit service

\footnotetext{
${ }^{6}$ Findings from the NREL city action study (Aznar et al. 2015) were further corroborated with data from the (1) American Council for an Energy-Efficient Economy's City Energy Efficiency Scorecard, (2) the DOE Clean Cities program, and (3) International City/County Management Association survey research (ICMA 2016). State-level, regional, or national-level assumptions were necessary where city-level data were unavailable; therefore, we do not present city-level estimates due to potential biases introduced from the use of supra-city level assumptions. The methodologies we developed may be applied at a local level with more complete city-level data.
} 
development, while cities with advanced transit infrastructure may focus on increasing the utilization of existing services.

The analysis for each policy is based on a specific methodology for a study period of 2020 to 2035, described by the following general structure ${ }^{7}$ :

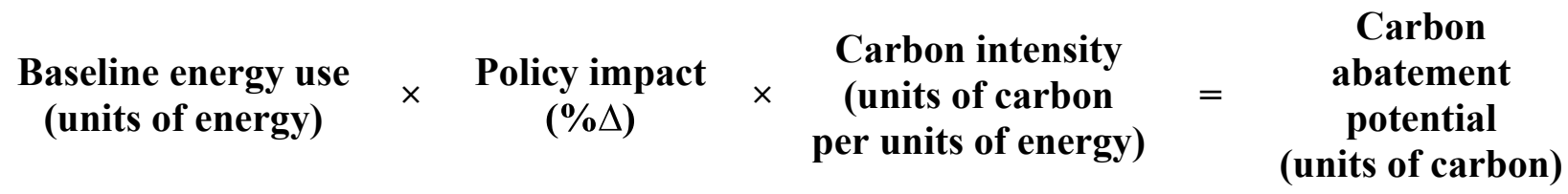

- Baseline energy use: A projection of the magnitude of energy use (e.g., MWh, mmBtu, gallons of gasoline) that would have occurred in 2035 without the policy. The term "baseline" used throughout this report always refers to an estimate of some unit in 2035 based on the 2035 reference case (see Appendix A.1).

- Policy impact: A policy's impact is generally measured as some percentage change (reduction) in energy use. In several cases this factor requires multiple inputs.

- Carbon intensity: Converts the input from units of energy into units of carbon.

Energy use data for the baselines are based on data for 23,458 cities from the DOE/NREL City Energy Profile tool (see Text Box 1).

\footnotetext{
${ }^{7}$ The only exception to this structure is the solar PV analysis, which uses a slightly more complex methodology (see Section 6).
} 


\section{Text Box 1. The DOE City Energy Profile Tool Data}

Through the Cities Leading through Energy Analysis and Planning (Cities-LEAP) project, NREL has compiled energy use data on 23,458 cities for the City Energy Profile tool. The data set includes all incorporated places in the United States, with the addition of minor civil divisions for northeastern statesConnecticut, Maine, Massachusetts, New Hampshire, New Jersey, New York, Pennsylvania, Rhode Island, and Vermont-and for counties in Hawaii (as there are no incorporated places). The data represent the energy use data of about 220 million city inhabitants, or about two-thirds of the U.S. population. The City Energy Profile tool data are publicly available, and may be obtained at http://apps1.eere.energy.gov/sled/.

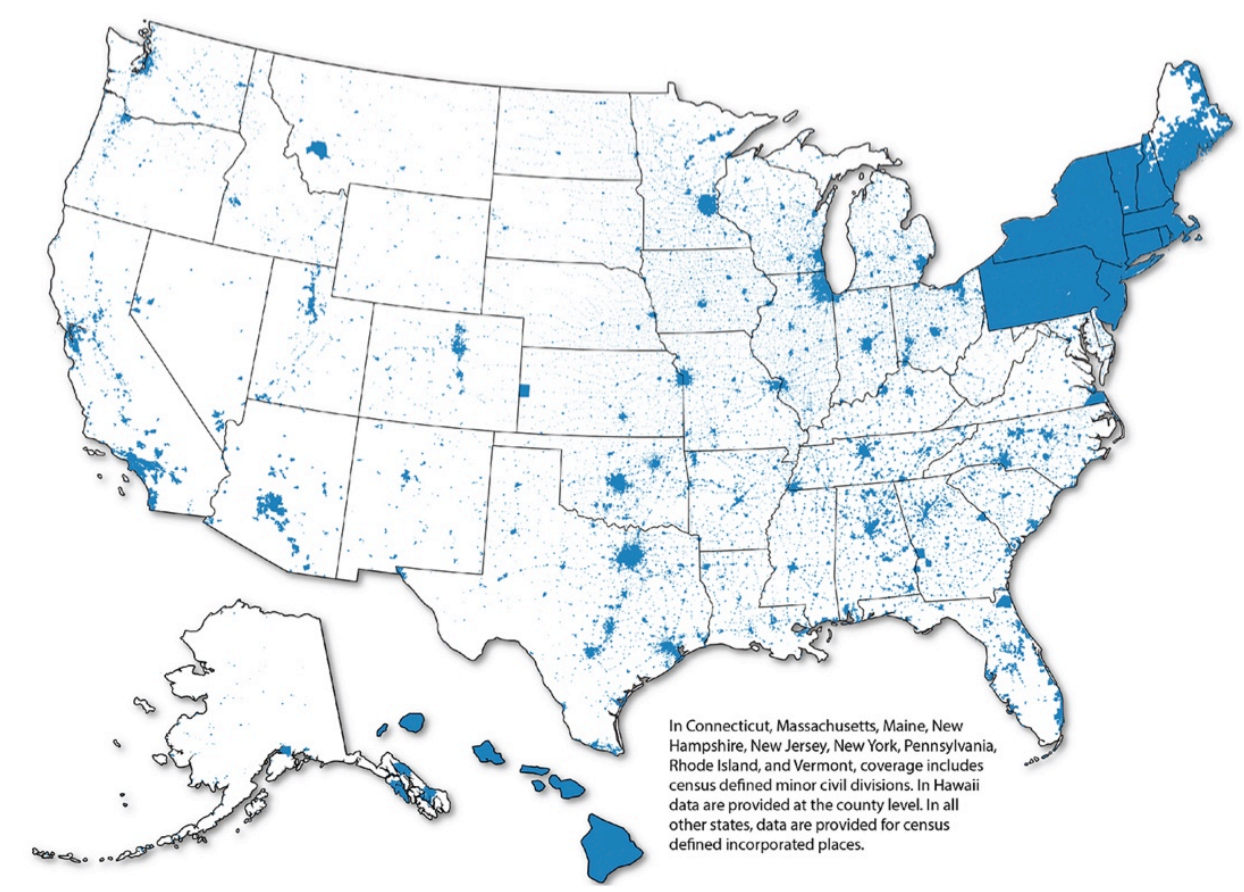

Figure 3. Geographic coverage of the City Energy Profile tool data

\section{Limitations}

This study has several limitations. First, the majority of the extant policy analysis literature provides state- or national-level estimates of the impacts of city policies on energy use. Due to this limitation, the policy impacts in this analysis are based on national-level assumptions, with state and regional adjustments where possible. The use of national-level assumptions applied to city-level data yields a valid output at the national level provided that estimation errors at the city level are not systematic. ${ }^{8}$ For this reason all results are presented at the national level. Future research on city-level estimates of the impacts of city policies on energy use is needed; additional research could build on our work by applying the methodologies at the city level with more precise city-level assumptions.

\footnotetext{
${ }^{8}$ For example, building code updates yield a $10 \%$ reduction in energy use on average at the national level. Building code updates in some cities may yield a 5\% energy use reduction, while updates in other cities may yield a $15 \%$ reduction.
} 
Second, the analysis assumes full and equal implementation by all cities. In other words, the analysis assumes that all cities will have fully implemented the policies by 2035 . This assumption may not be practical nor efficient. Multi-level governance strategies could optimize city carbon abatement actions by prioritizing action in cities with greater abatement potential. Such a scheme could possibly achieve greater carbon emissions, even without full and equal implementation.

Third, the analysis is limited in scope to actions that are currently being taken by cities; does not account for emerging policies; and does not take into account actions cities could take in combination with state, utility, or national policy implementers. Further the analysis assumes no interaction between policies. In general these limitations should result in a lower bound estimate of carbon abatement potential.

\section{Structure}

The paper is structured as follows. Sections 2-7 describe the carbon abatement potential in each of six policy areas: building energy codes, building energy incentives, smart growth policies, public transit expansion, solar photovoltaic (PV) policies, and municipal action policies. In Section 8 , estimates of the economic impacts of the policy areas are provided. The paper concludes with a comparison of carbon abatement potential within each policy area, a discussion of the estimates in the context of the city policy role framework, and a preliminary discussion of city-level variability in carbon abatement potential. The appendixes provide supplementary materials, including data and methods used in the analysis (Appendix A) and economic impact analysis (Appendix B). 


\section{Building Energy Codes}

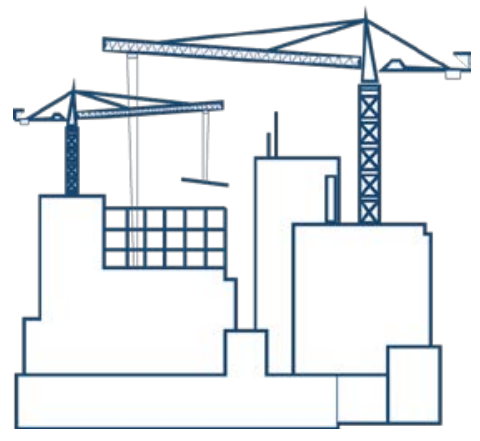

\section{Building energy codes are policies that directly reduce building energy use by requiring new construction and major renovations to use specific technologies or to achieve energy use targets.}

Building energy use - primarily electricity and natural gas consumption - accounts for about $40 \%$ of U.S. greenhouse gas emissions (EPA 2015). Cities can reduce building-related emissions through the implementation of new building energy codes or through measures to maximize energy savings from existing building energy codes. Our analysis finds that city building energy code actions can reduce building-related carbon emissions by about 60-120 MMT $\mathrm{CO}_{2} /$ year by 2035 , representing about $0.9 \%-1.9 \%$ of 2013 U.S. greenhouse gas emissions. ${ }^{9}$ It is important to note that the short-term carbon abatement potential of building energy codes is limited by the long life and slow turnover of building stock; however, the longer-term carbon abatement potential may be significantly greater (Schwartz et al. 2016).

\subsection{Summary of Current Building Energy Codes}

Building energy codes, which set minimum standards for energy consumption in new and renovated buildings, are the most common form of city-level building energy requirements. Building energy codes are a relatively cost-effective measure to improve building energy efficiency, given that the incremental cost of efficiency improvements is lowest during building design and construction (Schwartz et al. 2016). Cities are the primary enforcers of building codes, even if the building code is set at the state level (Misuriello et al. 2010; CEP 2014).

Cities can reduce energy use through "beyond code" measures. "Beyond code" refers to a city policy that requires more stringent building energy measures than called for in either the statelevel code or the most current version of the applicable model building code. Twenty-one percent (13/61) of ACEEE Scorecard cities ${ }^{10}$ have implemented a "beyond code" measure (ACEEE [American Council for an Energy-Efficient Economy] 2016).

Cities can also reduce energy use through building measures that increase energy savings from improved compliance with existing building codes. A large body of evidence suggests that under-compliance with building energy codes is prevalent (Stellberg 2013). However, the term compliance embodies many elements, including factors that do not have energy use implications, such as whether certain appliances are appropriately labeled (DOE 2015a). Further, the term compliance is used inconsistently in the literature (Schwartz et al. 2016). DOE has recently

\footnotetext{
${ }^{9}$ Based on 2013 U.S. greenhouse gas emissions (EPA 2015). EPA emissions estimates include all greenhouse gases including those not contained in this report (e.g., methane, nitrous oxide).

${ }^{10}$ The American Council for an Energy Efficient Economy (ACEEE) documents city policies in 61 "scorecard" cities. These data are used throughout this report.
} 
developed a methodology to measure the energy realization rates of residential buildings using sampled and modeled energy use intensity (EUI) rates. The new metric measures the fraction of potential energy savings from improved building energy codes that is actually realized in the code's implementation. Preliminary results from the DOE field studies of new single-family homes suggest significant energy savings potential from improving the energy performance under existing building codes (DOE 2016a).

Cities can take several measures to optimize energy savings from existing codes, including increased resources for compliance activities, conducting periodic compliance studies, and offering education and training to building designers (Schwartz et al. 2016). Third-party review policies require a private sector company to perform code compliance reviews on new construction. About 18\% (11/61) of ACEEE Scorecard cities use a third-party compliance review for code enforcement. Cities may specify certain performance metrics that third-party reviewers must assess during compliance evaluation. Third-party reviews may provide more objective compliance evaluations and use city resources more efficiently (BCAP 2008; CEP 2014).

\subsection{Scenarios, Assumptions, and Methods for Estimating Carbon Abatement Potential of Building Energy Codes}

The moderate and high abatement scenarios for the carbon abatement potential of building energy codes are summarized in Table 2 . This section describes the basis, assumptions, and methods for the two scenarios.

Table 2. City Building Energy Code Scenarios

\begin{tabular}{ll}
\hline Scenario & Description \\
\hline $\begin{array}{l}\text { Moderate abatement } \\
\text { scenario }\end{array}$ & $\begin{array}{l}\text { Cities implement beyond code measures and improve energy realization } \\
\text { rates by } 10 \text { percentage points }\end{array}$ \\
High abatement scenario & $\begin{array}{l}\text { Cities implement beyond code measures and improve energy realization } \\
\text { rates by } 20 \text { percentage points }\end{array}$ \\
\hline
\end{tabular}

The carbon abatement potential of the city policy scenarios in Table 2 is modeled as a function of three factors: new construction and major renovation baseline energy use, energy realization rate change (policy impact), and the carbon intensity of displaced building energy use (Figure 4). 


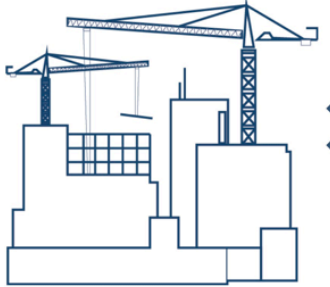

New construction and major renovation baseline energy use (mmBtu)

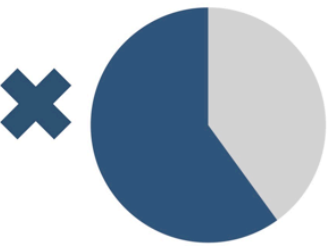

Building code energy realization rate change

(\%)

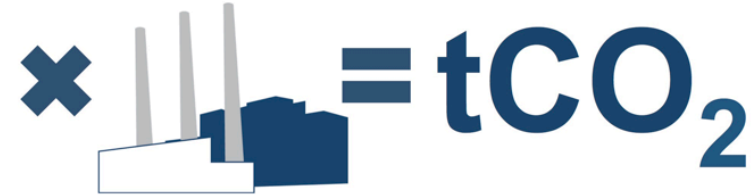

$$
\begin{aligned}
& \text { Carbon intensity } \\
& \text { of displaced } \\
& \text { energy } \\
& \text { (tCO } 2 \text { /mmBtu) }
\end{aligned}
$$

Carbon abatement potential

$\left(\mathrm{tCO}_{2}\right)$

Figure 4. Method for carbon abatement potential estimation of building energy codes

\section{New Construction and Major Renovation Baseline Energy Use}

The quantity of new construction is the primary driver of the energy use reduction potential of building code updates (Kneifel 2014). The 2011 Buildings Energy Data Book estimates that the United States will increase the residential housing stock by about $16 \%$ and commercial floor space by about $15 \%$ from 2020 to 2035 (DOE 2012). Major retrofits and renovations generally comprise about $60 \%$ of all construction (McGraw Hill 2011). Extrapolating from projections for the residential and commercial building stocks, a rough estimate for major renovations equates to about $24 \%$ and $22.5 \%$ of existing residential and commercial building stock by 2035 , respectively. ${ }^{11}$ Summing new construction and major renovations, total new residential and commercial construction is $40 \%$ and $37.5 \%$ of the existing residential and commercial building stocks, respectively. ${ }^{12}$

New construction and major renovations generally use less energy than older buildings. This is in part due to higher energy efficiencies required by updated building codes. In general, the literature suggests that updated building codes reduce building energy use by about $10 \%$ on average (Figure 5) (see Section A.2 of Appendix A). About half of the residential and commercial building stock was constructed before 1980 (DOE 2012; EIA 2012). Given that several building code updates occur per decade, most new construction and major renovations are several codes out of date. Based on this literature, it is assumed that new construction and major renovations use $27 \%$ less energy than existing buildings in the baseline (i.e., before any additional city policy actions), the equivalent energy use reduction of three building code updates. Applying this assumption to assumed new construction and major renovation building stocks yields a baseline new construction and major renovation baseline energy use of about $28 \%$ of current building energy use. ${ }^{13}$

\footnotetext{
${ }^{11}$ Assuming residential and commercial major renovations are 1.5 times new construction levels. Residential renovations $=1.5 \times 0.15=0.24$, and commercial renovations $=1.5 \times 0.16=0.225$. Assumes linear growth in new construction and major renovations from 2020 to 2035.

${ }^{12}$ Residential: $16 \%$ (new construction) $+24 \%$ (major renovations) $=40 \%$. Commercial: $15 \%$ (new construction) + $22.5 \%$ (major renovations) $=37.5 \%$.

${ }^{13}$ Assuming new buildings and major renovations use $73 \%$ as much energy as existing buildings, baseline residential energy use is $0.73 * 0.40=0.29$, and baseline commercial energy use is $0.73 * 0.375=0.27$.
} 


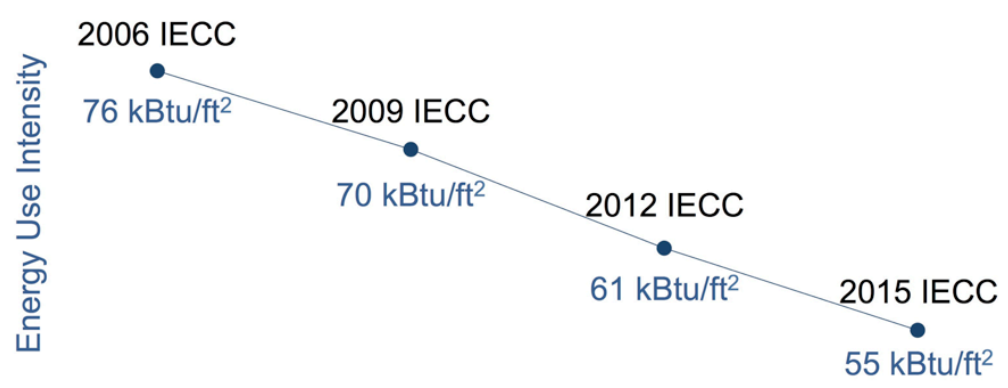

Figure 5. Reductions in site energy use intensity over building code vintages (commercial buildings)

Based on data from Zhang et al. 2015

Variable population growth rates across cities also affect the quantity of new construction and major renovations. Rapidly growing cities will see more new construction and major renovations and thus increased energy use in these new buildings. To capture some of this variation, the quantity of new construction and major renovations is adjusted in each city according to projections for future growth based on population growth rates between 2000 and $2010 .{ }^{14}$

\section{Building Code Energy Realization Rate Change}

Energy realization rate (ERR) refers to the percentage of potential energy savings that are actually achieved through a building code update. For the purposes of this section, energy realization rate is defined: ${ }^{15}$

$$
E R R=1+\frac{E U I_{\text {required }}-E U I_{\text {achieved }}}{E U I_{\text {required }}}
$$

Where $E R R$ is the energy realization rate, $E U I_{\text {required }}$ is the energy use intensity (EUI) required by the relevant building code, and EUI $I_{\text {achieved }}$ is the EUI actually achieved in the new building or renovation. If the new building or renovation uses more energy than required by the relevant building code, the energy realization rate is less than $100 \%$ because some energy savings have not been fully realized. If the new building or renovation uses less energy than required by the relevant building code, the energy realization rate is greater than $100 \%$.

Recent DOE field studies of new single-family home construction suggest that energy realization rates vary considerably across different building energy components (e.g., lighting, HVAC, windows) and geographically (DOE 2016a). Preliminary results suggest that aggregate home energy realization rates are close to full realization (i.e., $E R R=1$ ). However, aggregate measurements are biased by over-compliant $(E R R>1)$ building elements that effectively offset under-compliant $(E R R<1)$ building elements. For example, a building that realizes $50 \%$ of the energy savings of a given code's lighting standards and $150 \%$ of the savings of a given code's HVAC standards may, in aggregate, achieve a 100\% energy realization rate. However additional energy savings are still possible by bringing under-compliant elements up to code.

\footnotetext{
${ }^{14}$ The adjustment factor is the percentage change in population according to U.S. Census data from 2000 to 2010, bounded at $+/-20 \%$.

${ }^{15}$ Energy realization rate definitions may vary. The realization rate is defined this way for mathematical purposes in the methodology.
} 
There are two ways to increase the energy realization rate with respect to a given building code. First, policies designed to improve compliance with the existing code can increase energy realization rates up to full compliance $(E R R=1)$. Second, "beyond code" measures designed to improve building energy efficiency above and beyond existing codes can effectively increase energy realization rates above full compliance $(E R R>1)$.

In both abatement scenarios, baseline energy realization rates are assumed to be $90 \% .{ }^{16}$ In the moderate abatement scenario, it is assumed that city policies to improve compliance with existing codes increase energy realization rates to full compliance $(E R R=1)$. In the high abatement scenario, it is assumed that city "beyond code" measures increase energy realization rates $10 \%$ beyond full compliance, consistent with an average building code update energy use reduction $(E R R=1.1)$. Assuming the applicable building code reduces building EUI by $10 \%$, it can be shown that increasing the energy realization rate from $90 \%$ to $100 \%$ equates to a $9 \%$ reduction in building energy use, and increasing the energy realization rate from $90 \%$ to $110 \%$ equates to an $18 \%$ reduction in building energy use (see Appendix A. 2 for a proof of this proposition). Assumed building energy use reductions are therefore $9 \%$ from improved building code compliance in the moderate abatement scenario and $18 \%$ from beyond code measures in the high abatement scenario.

\section{Carbon Intensity of Displaced Building Energy Use}

Based on the Pacific Northwest National Laboratory data, about $86 \%$ of building energy use reductions between code vintages are derived from reduced electricity use, while about $14 \%$ of reductions are derived from reduced natural gas use (PNNL 2013). The potential carbon reductions of displaced electricity consumption are a function of the carbon intensity of the local grid. Local grid carbon intensity is based on regional marginal emissions rates from the U.S. Environmental Protection Agency (EPA) Emissions and Generation Resource Integrated Database (eGRID) adjusted for U.S. Energy Information Administration (EIA) projections of reduced grid carbon intensity (see reference case in Section A.1 of Appendix A). For the sake of simplicity, a single emissions factor of 53.06 kilograms $(\mathrm{kg}) \mathrm{CO}_{2} / \mathrm{mmBtu}$ is used for on-site natural gas consumption (EPA 2014).

\section{Summary of Assumptions}

The key assumptions for our analysis of the carbon abatement potential of building energy codes are:

- Baseline new construction and major renovation energy use is $28 \%$ of current energy use.

- New buildings are assumed to use $27 \%$ less energy than older buildings, the equivalent of about three building code updates, before any policy intervention.

- In the moderate abatement scenario, city actions to improve energy savings with existing building codes increase energy realization rates by 10 percentage points. In the high

\footnotetext{
${ }^{16}$ A baseline energy realization rate is assumed only for descriptive purposes. Ongoing DOE field studies suggest that realization rates vary significantly. Conceptually, the value of the baseline does not affect the outcome of the analysis. For example, if the true baseline realization rate is $80 \%$ and city actions in the moderate abatement scenario increase realization rates to $90 \%$, the change remains 10 percentage points.
} 
abatement scenario, city actions to improve energy savings through "beyond code" measures increase energy realization rates by 20 percentage points.

- The carbon intensity of displaced electricity is determined by regional emissions factors; the carbon intensity of on-site natural gas consumption is $53.06 \mathrm{~kg} \mathrm{CO}_{2} / \mathrm{mmBtu}$.

\subsection{Results: Carbon Abatement Potential of City Building Energy Codes}

Our analysis suggests that cities could abate 59-117 MMT $\mathrm{CO}_{2} /$ year by 2035 through code compliance improvement and beyond-code measures, or about $0.9 \%-1.9 \%$ of 2013 U.S. emissions. At the city level, the results suggest that an average city can reduce local emissions by $3.1 \%$ (moderate) to $6.3 \%$ (high) relative to current city emissions. Figure 6 illustrates the distributions of city-level carbon abatement potential from building energy codes in the moderate and high abatement scenarios.

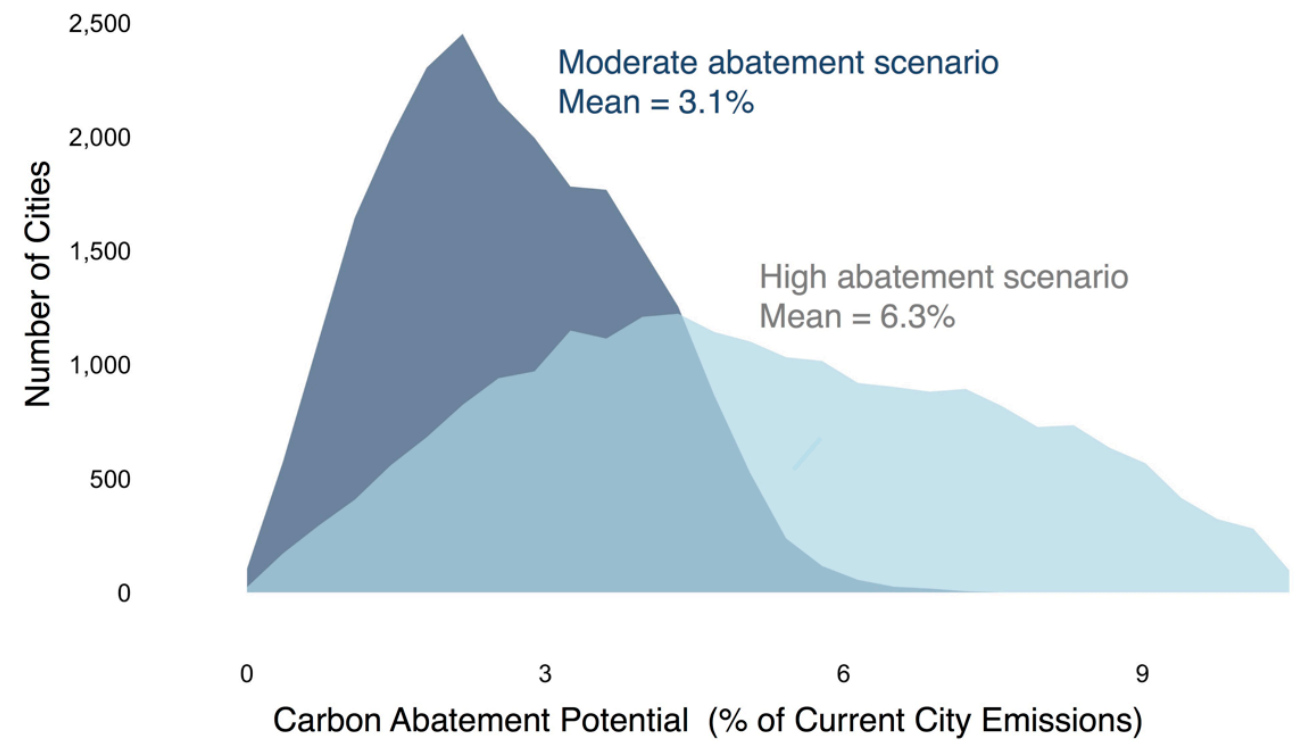

Figure 6. City-level carbon abatement potential distribution of building energy codes 


\section{Building Energy Incentives}

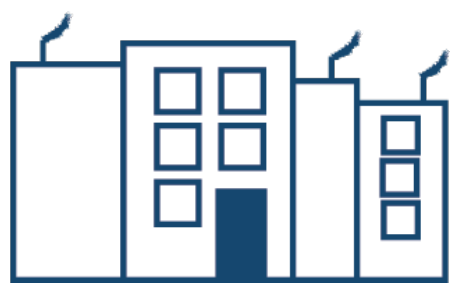

\section{Building energy incentives are policies that indirectly reduce building energy use by supporting investment in more energy efficient technology or building practices.}

A growing body of research suggests that city policies can incentivize private building owners and occupants to invest in energy efficient technologies that reduce building energy use. While the building energy codes analyzed in Section 2 apply only to new construction and major renovations, building energy incentives are more inclusive of existing buildings. Our analysis suggests that incentive policies regarding city building energy could abate about 40-110 MMT $\mathrm{CO}_{2}$ /year, or about $0.6 \%-1.7 \%$ of 2013 U.S. emissions. ${ }^{17}$ The building energy incentive policies analyzed in this section represent only a subset of possible city actions that cities could take to incentivize the private uptake of building energy efficiency measures (Schwartz et al. 2016).

\subsection{Summary of City Building Energy Incentive Policies Currently Enacted}

Cities have developed a variety of policies to encourage building owners and occupants to use energy more efficiently. Aznar et al. (2015) found that direct grants for home weatherization upgrades were the most common building energy incentive (11.1\% of city actions), followed by grants for home energy audits (6.4\%), grants for home HVAC upgrades $(5.5 \%)$, grants for energy efficient appliances (4.7\%), and grants for business energy audits $(4.2 \%) .{ }^{18}$ More recently, cities have used information and transparency policies such as building energy benchmarking that facilitate reductions in building energy use by making building energy use more evident. Building energy incentives in this analysis are organized into two categories: financial incentives (primarily residential) and building energy benchmarking (commercial).

\section{Financial Incentives}

Sixty-four percent (39/61) of ACEEE Scorecard cities offer some type of financial incentive for energy efficient building practices. Table 3 provides examples of direct financial incentives for building energy efficiency.

\footnotetext{
${ }^{17}$ Based on 2013 U.S. greenhouse gas emissions (EPA 2015).

${ }^{18}$ These findings are based on ICMA (2010). The term "grant" is used for consistency with the language used in ICMA (2010), but may include other forms of compensation such as rebates.
} 
Table 3. City Financial Incentives for Building Energy Efficiency

\begin{tabular}{lcl}
\hline $\begin{array}{l}\text { Financial } \\
\text { Incentive }\end{array}$ & $\begin{array}{l}\text { Percentage of ACEEE } \\
\text { Scorecard Cities }\end{array}$ & Example \\
\hline $\begin{array}{l}\text { Low-interest } \\
\text { finance }\end{array}$ & $48 \%$ & $\begin{array}{l}\text { The Denver Energy Challenge low-interest loan is available for } \\
\text { residential and commercial projects that achieve } 15 \% \text { energy } \\
\text { efficiency savings. }\end{array}$ \\
$\begin{array}{l}\text { Tax } \\
\text { incentive }\end{array}$ & $16 \%$ & $\begin{array}{l}\text { New York City provides a one-year tax abatement worth } \$ 4.50 \\
\text { per square foot of residential green roofs. }\end{array}$ \\
Rebate & $13 \%$ & $\begin{array}{l}\text { Cincinnati offers rebates of up to } \$ 750 \text { for residential home } \\
\text { energy improvements recommended by the Greater Cincinnati } \\
\text { Energy Alliance. }\end{array}$ \\
Grant & $10 \%$ & $\begin{array}{l}\text { The Pittsburgh Home Rehabilitation Program provides grants } \\
\text { of up to } \$ 2,500 \text { for energy efficiency home improvements for } \\
\text { income-qualified residents. }\end{array}$ \\
\hline
\end{tabular}

Source: ACEEE 2016

\section{Building Energy Benchmarking}

Building energy benchmarking refers to the tracking and reporting of building energy consumption data and the comparison of building energy use metrics across buildings. The ENERGY STAR ${ }^{\circledR}$ Portfolio Manager is an example of a benchmarking tool. The Portfolio Manager tool assigns buildings a score of 1-100 based on energy performance relative to other buildings, where the score corresponds to the building's percentile in the energy use distribution. For example, a score of 80 indicates that the building is more efficient than $80 \%$ of buildings. Twenty-six percent (16/61) of ACEEE Scorecard cities have implemented some form of building energy benchmarking requirement.

A benchmarked building will not necessarily reduce building energy use. However, a growing body of research suggests that the provision of information alone can affect energy use behavior. Prospective buyers and tenants may be more confident in paying premiums for energy efficient buildings with more transparent information about building energy use. In turn, building owners and developers may be more willing to invest in energy efficiency if they are more confident their investment could be recouped through a sale or lease premium (Ciochetti and McGowan 2010). Similarly, benchmarking allows building owners/occupants to make more certain estimates of future energy savings from investments in energy efficiency. Building owner/occupants tend to discount future energy savings at a relatively high rate to compensate for the risk that such savings will not materialize (Frederick, Loewenstein, and O'Donoghue 2002). High discount rates for future energy savings reduce investments in energy-efficient equipment (Cox, Brown, and Sun 2013). Theoretically, benchmarking can reduce discount rates of future energy savings by making future savings more certain; lower discount rates for future energy savings would effectively reduce the up-front cost of energy efficiency investments relative to future savings and increase investments in energy efficiency (Coller and Williams 1999; Cox, Brown, and Sun 2013). 
Benchmarking policies may be coupled with other building energy policies. For example, the Boston Building Energy Reporting and Disclosure Ordinance requires medium and large buildings to benchmark and report energy and water use to the City of Boston. Every five years, medium and large buildings must complete an energy assessment or take an energy action. However, buildings may obtain an exemption from the energy assessment/action requirement by demonstrating progress through their benchmarked energy use.

\subsection{Scenarios, Assumptions, and Methods for Estimating Carbon Abatement Potential of Building Energy Incentives}

Table 4 summarizes the moderate and high abatement scenarios used to model the carbon abatement potential of building energy incentive policies. This section describes the basis, assumptions, and methods for the two scenarios.

Table 4. City Building Energy Incentive Scenarios

\begin{tabular}{ll}
\hline Scenario & Description \\
\hline Moderate abatement scenario & $\begin{array}{l}\text { Four percent of residential customers reduce home energy use by } \\
10 \% \text { through home energy efficiency incentive programs; } 80 \% \text { of } \\
\text { commercial customers reduce building energy use by } 5 \% \text { by } \\
\text { participating in required building energy benchmarking programs. }\end{array}$ \\
High abatement scenario & $\begin{array}{l}\text { Sixteen percent of residential customers reduce home energy use } \\
\text { by } 17 \% \text { through home energy efficiency incentive programs; } 95 \% \\
\text { of commercial customers reduce building energy use by } 10 \% \text { by } \\
\text { participating in required building energy benchmarking programs }\end{array}$ \\
\hline
\end{tabular}

The carbon abatement potential of the city policy scenarios is estimated as a function of four factors: baseline building energy use, building energy use reductions, program participation rates, and the carbon intensity of displaced building energy use (Figure 7).

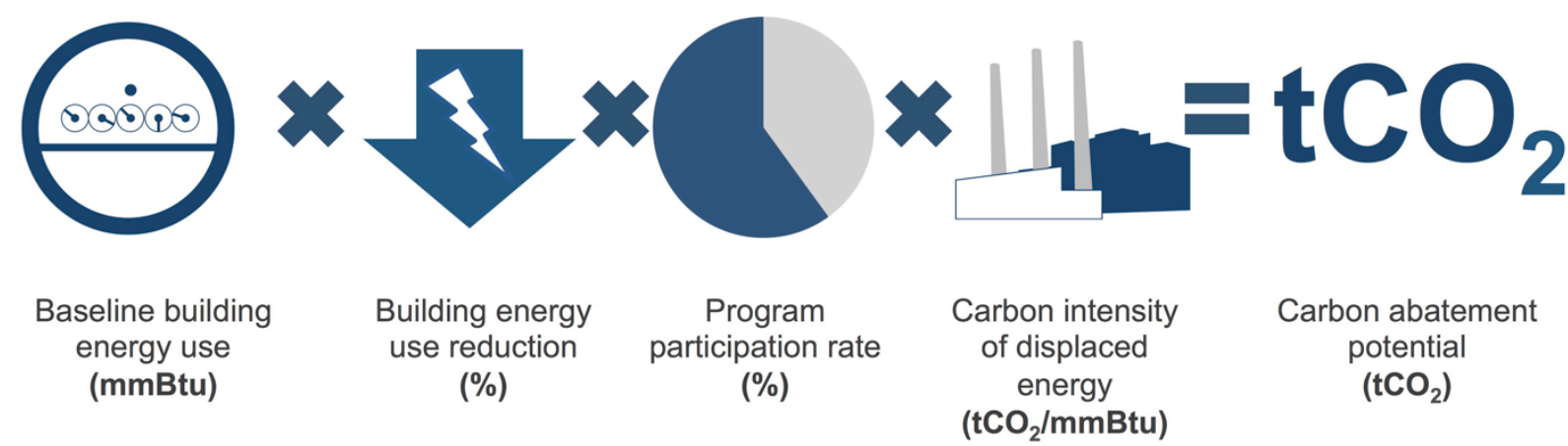

Figure 7. Method for carbon abatement potential estimation of building energy incentives

\section{Baseline Building Energy Use}

Baseline building energy use is based on the reference case (see Section A.1 of Appendix). The reference case assumes a 16\% increase in building energy use from 2015 to 2035 (DOE 2012). 


\section{Reduction of Building Energy Use}

The energy use impacts of building energy incentives at the national and utility levels have been well documented. Allaire and Brown (2012) found that the 12 most effective federal energy efficiency programs reduced U.S. annual carbon emissions by an average of about $30 \mathrm{MMT} \mathrm{CO}_{2}$ from 2005 to 2009 , or roughly $0.4 \%$ of annual U.S. carbon emissions. In a survey of six utilityled building energy loan programs, Hayes et al. (2011) found that program participants achieved energy use savings of $5 \%-17 \%$, with an average of $13 \%$ across the six programs.

Alberini and Towe (2015) provided a more localized study of the effects of energy efficiency incentives. The authors studied the energy use impacts of a home energy audit program and a rebate for efficient air-source heat pumps in Maryland. Under various model assumptions, the authors found that participants in the home energy audit program reduced energy use by $2.5 \%$ $5.4 \%$, and that recipients of the heat pump rebate reduced energy use by $2 \%-6 \%$.

Cox, Brown, and Sun (2013) used the National Energy Modeling System (NEMS) to model the energy use impact of a commercial building energy benchmarking policy. The study assumed that information provided by benchmarking would reduce energy savings discount rates by $5 \%-$ $10 \%$. The study found that the building energy benchmarking policy could result in a $2.2 \%$ reduction in building natural gas use and a 1.4\% reduction in building electricity use from 2015 to 2035 . In a sensitivity analysis, projected building energy use reductions reached as high as $10 \%$ by 2035 in a high electricity price scenario.

Anecdotal evidence supports the notion that building energy benchmarking can reduce energy use. Table 5 summarizes findings from a few early studies. However, it is important to note that benchmarking programs are generally too new to estimate a precise program effect; in other words, the estimates in Table 5 do not differentiate between energy use reductions achieved through benchmarking and energy use reductions that were achieved through other means. This is partly because cities that have instituted benchmarking have typically paired that policy with other efforts directly aimed at incenting energy efficiency in commercial buildings.

Table 5. Observed Energy Use Reductions in Benchmarking Programs

\begin{tabular}{lll}
\hline Program & Observed Energy Use Effect & Study \\
\hline $\begin{array}{l}\text { ENERGY STAR Use Portfolio } \\
\text { Manager (nationwide) }\end{array}$ & $7 \%$ energy use reduction (2008-2011) & EPA (2012) \\
\hline $\begin{array}{l}\text { New York City Benchmarking and } \\
\text { Transparency Policy }\end{array}$ & $5.7 \%$ energy use reduction (2010-2013) & DOE (2015) \\
\hline $\begin{array}{l}\text { San Francisco Existing Commercial } \\
\text { Buildings Performance Ordinance }\end{array}$ & $\begin{array}{l}11.8 \% \text { energy use reduction (2010-2014) } \\
\text { Seattle Energy and Reporting }\end{array}$ & $\begin{array}{l}\text { Hooper et al. } \\
(2015)\end{array}$ \\
$\begin{array}{l}\text { Flat energy use intensity from 2011 to } \\
\text { Program Benchmarking }\end{array}$ & $\begin{array}{l}\text { higher building occupancy rates } \\
\text { hige due to }\end{array}$ & OSE (2014) \\
\hline
\end{tabular}

Separate assumptions about energy use reduction were developed for residential and commercial buildings based on the literature. For residential buildings, Alberini and Towe (2015) found 
targeted programs could achieve energy reductions of $2 \%-6 \%$, while Hayes et al. (2011) found programs that are more expansive could achieve much higher energy use reductions of up to $17 \%$. It is assumed that home energy efficiency incentives targeting multiple energy efficiency upgrades could achieve home energy use reductions of 10\% (moderate abatement scenario) to $17 \%$ (high abatement scenario). Based on the modeled results in Cox, Brown, and Sun (2013) and documented energy use reductions in city benchmarking programs, we assume commercial building energy use reductions of 5\% (moderate abatement scenario) to $10 \%$ (high abatement scenario) through building energy benchmarking programs.

\section{Program Participation Rates}

Building energy efficiency incentives are generally underutilized. Vine et al. (1994) found that the participation rate in eight utility-led programs ranged from $0.6 \%$ to $16.1 \%$, with an average of $4 \%$. Similarly, Hayes et al. (2011) found participation rates in building energy loan programs were about $2.4 \%$ on average across 12 programs. However, improved program designs could theoretically increase participation rates to above 50\% (York et al. 2013). To capture both the range of observed participation rates and the possibility of higher participation through improved program design, total participation rates of $4 \%$ (moderate abatement scenario) to $16 \%$ (high abatement scenario) are assumed.

Participation rates in building energy benchmarking programs have been relatively high. Programs in New York City, Philadelphia, San Francisco, and Seattle have reported participation rates of $84 \%, 87 \%, 80 \%$, and $93 \%$, respectively (C40 Cities 2015). ${ }^{19}$ Commercial building participation rates in benchmarking programs of $85 \%$ (moderate abatement scenario) to $95 \%$ (high abatement scenario) are assumed in the analysis.

\section{Carbon Intensity of Displaced Energy Use}

The potential carbon reductions of displaced electricity consumption are a function of the carbon intensity of the local grid. Local grid carbon intensity is based on regional marginal emissions rates from EPA's eGRID-adjusted-for-EIA projections of reduced grid carbon intensity (see reference case in Section A.1 of Appendix A). For simplicity, a single emissions factor of 53.06 $\mathrm{kg} \mathrm{CO} / \mathrm{mmBtu}$ is used for on-site natural gas consumption (EPA 2014).

\section{Summary of Assumptions}

The key assumptions for our analysis of the carbon abatement potential of building energy incentives are:

- Baseline building energy use in 2035 is equal to $116 \%$ of 2015 building energy use.

- Residential participants in energy efficiency incentive programs reduce home energy use by $10 \%$ (moderate abatement scenario) to $17 \%$ (high abatement scenario). Commercial participants in building energy benchmarking programs reduce building energy use by $5 \%$ (moderate abatement scenario) to $10 \%$ (high abatement scenario).

- Participation rates for residential energy efficiency incentive programs are 4\% (moderate abatement scenario) to $16 \%$ (high abatement scenario). Commercial building energy

\footnotetext{
${ }^{19}$ These observed participation rates are generally for a subset of commercial buildings.
} 
benchmarking program participation rates are $85 \%$ (moderate abatement scenario) to 95\% (high abatement scenario).

- The carbon intensity of displaced electricity is determined by regional emissions factors; the carbon intensity of on-site natural gas consumption is $53.06 \mathrm{~kg} \mathrm{CO}_{2} / \mathrm{mmBtu}$.

\subsection{Results: Carbon Abatement Potential of City Building Energy Incentives}

The results suggest that city building energy incentives could reduce carbon emissions by 40 $110 \mathrm{MMT} \mathrm{CO}_{2} /$ year, or about $0.6-1.7 \%$ of 2013 U.S. emissions. At the city level, the results suggest that an average city can reduce local emissions by $1.6 \%$ (moderate) to $4.6 \%$ (high) relative to current city emissions. Figure 8 illustrates the distributions of city-level carbon abatement potential from building energy incentives in the moderate and high abatement scenarios.

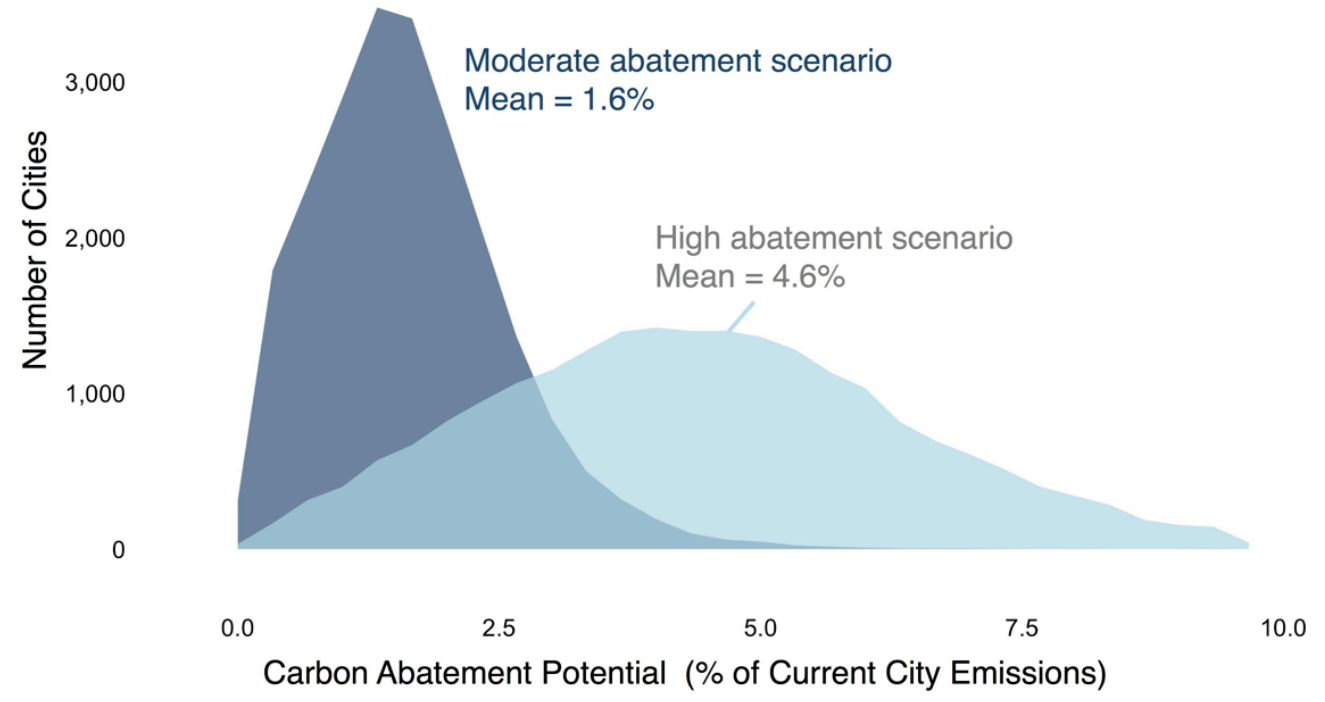

Figure 8. City-level carbon abatement potential distribution of building energy incentives 


\section{Smart Growth Policies}

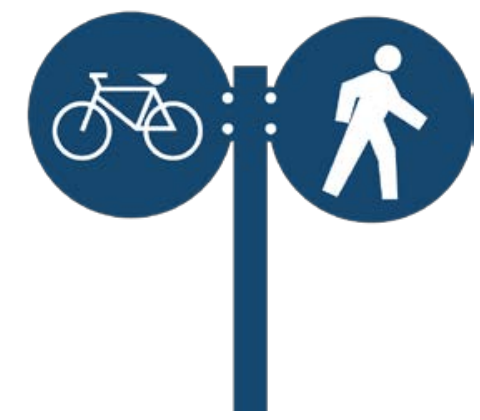

Smart growth policies refer to city actions that aim to reduce personal vehicular travel through urban planning practices that facilitate alternative modes of transit (e.g., walking and biking).

A body of literature has emerged on the relationship between urban form and travel. The general premise is that cities can reduce personal vehicular travel through urban planning practices that reduce trip lengths or incentivize alternative modes of transportation such as walking, biking, and public transit. The relationship between urban form and travel has motivated city planners to use development as a travel reduction strategy. For the purposes of this section, smart growth refers to the suite of policies aiming to reduce transportation-related carbon emissions through urban development strategies. The results suggest that city smart growth policies could reduce carbon emissions by about 30-80 $\mathrm{MMT} \mathrm{CO}_{2} /$ year nationwide, or about $0.4 \%-1.2 \%$ of 2013 U.S. emissions. ${ }^{20}$ It is worth noting that short-term emissions reduction potential is limited by the turnover of residential and commercial zones into new development. Thus, smart growth policies may have much more significant long-term emissions reduction potential.

\subsection{Summary of Smart Growth Policies Currently Enacted}

Smart growth is among the most common city-level transportation actions to reduce carbon emissions (Aznar et al. 2015), though smart growth policies may be implemented to achieve a variety of other objectives (e.g., improved walkability, connectivity, liveability). Cities have developed a variety of policies to promote smart growth that vary significantly in form and potential impact. Table 6 summarizes smart growth approaches identified in the literature.

Table 6. Sample of City Smart Growth Policies

\begin{tabular}{lll}
\hline Policy & Description & Example \\
\hline Affordable urban housing & $\begin{array}{l}\text { Affordable urban housing } \\
\text { policies can incentivize urban } \\
\text { rather than suburban } \\
\text { residence, as suburban } \\
\text { residents have higher carbon } \\
\text { footprints than urban residents. }\end{array}$ & $\begin{array}{l}\text { New York City's New Housing } \\
\text { M7 billion into the provision of } \\
\text { low- and moderate-income } \\
\text { urban housing. }\end{array}$ \\
& & \\
\end{tabular}

\footnotetext{
${ }^{20}$ Based on 2013 U.S. greenhouse gas emissions (EPA 2015).
} 


\begin{tabular}{|c|c|c|}
\hline Policy & Description & Example \\
\hline $\begin{array}{l}\text { Bike and pedestrian } \\
\text { infrastructure }\end{array}$ & $\begin{array}{l}\text { City policies that improve bike } \\
\text { and pedestrian infrastructure } \\
\text { can reduce carbon emissions } \\
\text { by making biking and walking } \\
\text { more attractive than driving. }\end{array}$ & $\begin{array}{l}\text { Developers in Pennsylvania are } \\
\text { required to describe how new } \\
\text { development accommodates } \\
\text { bike and pedestrian facilities. }\end{array}$ \\
\hline Location-based fees & $\begin{array}{l}\text { Cities can levy development } \\
\text { fees based on the costs of } \\
\text { public service provision (e.g., } \\
\text { refuse collection, public safety } \\
\text { services), accounting for the } \\
\text { distance from public } \\
\text { infrastructure. }\end{array}$ & $\begin{array}{l}\text { Lancaster, California, charges } \\
\text { development impact fees to any } \\
\text { proposed development outside } \\
\text { of the city core. }\end{array}$ \\
\hline $\begin{array}{l}\text { Location-efficient } \\
\text { development }\end{array}$ & $\begin{array}{l}\text { Cities can focus development in } \\
\text { areas with available public } \\
\text { infrastructure. }\end{array}$ & $\begin{array}{l}\text { Austin, Texas, uses a "Smart } \\
\text { Growth Matrix" to evaluate } \\
\text { development proposals. The } \\
\text { city may provide incentives to } \\
\text { proposals close to public } \\
\text { services. }\end{array}$ \\
\hline Open space preservation & $\begin{array}{l}\text { Cities can protect certain areas } \\
\text { within their jurisdiction from } \\
\text { development. }\end{array}$ & $\begin{array}{l}\text { The State of Oregon requires } \\
\text { cities to implement urban growth } \\
\text { boundaries. }\end{array}$ \\
\hline Targeted investments & $\begin{array}{l}\text { Cities can target investments in } \\
\text { city centers. }\end{array}$ & $\begin{array}{l}\text { Trenton New Jersey's } \\
\text { Transportation Master Plan } \\
\text { focuses investments in the } \\
\text { existing transportation network. }\end{array}$ \\
\hline $\begin{array}{l}\text { Transit-oriented } \\
\text { development }\end{array}$ & $\begin{array}{l}\text { Cities can concentrate } \\
\text { development in areas with } \\
\text { access to public transit. }\end{array}$ & $\begin{array}{l}\text { The Rosslyn-Ballston corridor in } \\
\text { Arlington County, Virginia, is a } \\
\text { three-mile long area developed } \\
\text { around five Metrorail stations } \\
\text { designed for walkability and } \\
\text { transit access. }\end{array}$ \\
\hline Zoning code reform & $\begin{array}{l}\text { Cities can reform local zoning } \\
\text { codes to explicitly allow mixed } \\
\text { land use. }\end{array}$ & $\begin{array}{l}\text { Santa Barbara, California, } \\
\text { amended its zoning code to } \\
\text { allow residential uses in } \\
\text { commercial zones. }\end{array}$ \\
\hline
\end{tabular}

Sources: Kingsley and Williams 2007; Jones and Kammen 2014; Litman 2015a 


\subsection{Scenarios, Assumptions, and Methods for Estimating Carbon Abatement Potential of Smart Growth Policies}

Table 7 summarizes the moderate and high abatement scenarios used to model the carbon abatement potential of smart growth policies. This section describes the basis, assumptions, and methods for the two scenarios.

Table 7. City Smart Growth Scenarios

\begin{tabular}{ll}
\hline Scenario & Description \\
\hline Moderate abatement scenario & $\begin{array}{l}\text { Smart growth policies affect } 50 \% \text { of new development and reduce } \\
\text { personal vehicular travel by } 30 \% .\end{array}$ \\
High abatement scenario & $\begin{array}{l}\text { Smart growth policies affect } 80 \% \text { of new development and reduce } \\
\text { personal vehicular travel by } 60 \% .\end{array}$ \\
\hline
\end{tabular}

The carbon abatement potential of the city smart growth policy scenarios is modeled as a function of four factors: new development baseline travel, the percentage of travel affected, travel reduction, and the carbon intensity of displaced travel (Figure 9). ${ }^{21}$

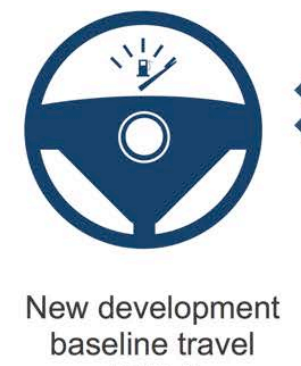

(VMT)

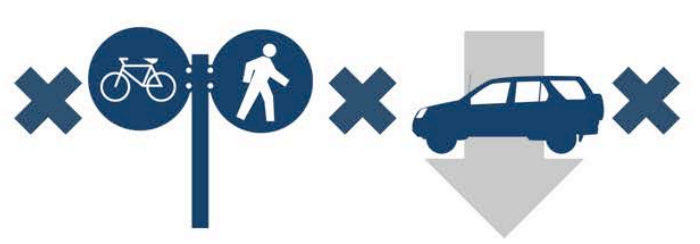

Percentage of travel affected

(\%)
Travel reduction $(\% \Delta)$

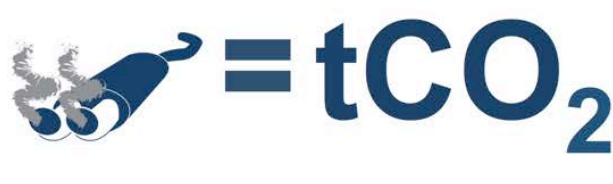
Carbon intensity of displaced travel (tCO $\left.{ }_{2} / \mathrm{VMT}\right)$

\section{Carbon abatement} potential $\left(\mathrm{tCO}_{2}\right)$

Figure 9. Method for carbon abatement potential estimation of smart growth policies

\section{New Development Baseline Travel}

Vehicle miles traveled (VMT), which is defined as the number of miles driven by all vehicles within a defined area over some period, is the most common metric to measure quantities of vehicular travel. Total baseline VMT is based on the reference case, which assumes VMT growth of 1.04\%/year from 2015 to 2035 (see Appendix A.1). We assume that smart growth policies will only affect travel in segments of the city undergoing development. It is assumed that annual residential development represents about $1.6 \%$ of the existing housing stock. ${ }^{22}$ Over a study period of 15 years, about $24 \%$ of the 2020 housing stock would classify as new development. Assuming that VMT in new development would be the same as VMT in existing

\footnotetext{
${ }^{21}$ A potentially significant omitted factor is the impact of smart growth on home energy consumption. Impacts on home energy use were omitted to avoid duplication with building energy use reductions covered in Sections 5 and 6 .

${ }^{22}$ Based on data from DOE (2012)
} 
development in the absence of smart growth policies, it is assumed that VMT in new development zones is $30 \%$ of baseline VMT in $2035 .^{23}$

\section{Percentage of Travel Affected}

Smart growth policies directly affect the travel of residents that live in or access employment and services in smart growth zones. Several previous studies have made assumptions about the potential percentage of new development that could follow smart growth principles; the range is from $25 \%$ to $90 \%$ (Table 8 ).

Table 8. Sample of Smart Growth Assumptions

\begin{tabular}{ll}
\hline Study & $\begin{array}{l}\text { Percentage of New Development that } \\
\text { Followed Smart Growth Principles }\end{array}$ \\
\hline Ewing et al. (2008) & $60 \%-90 \%$ \\
Cambridge Systematics (2009) & $64 \%-90 \%$ \\
TRB (2009) & $25 \%-75 \%$ \\
\hline
\end{tabular}

Although assumptions that as much as $90 \%$ of new development could adhere to smart growth principles may appear optimistic, several trends suggest that demand for smart growth is increasing and will continue to increase. First, an aging U.S. population may demand less vehicular travel as the baby-boom generation enters retirement age (older drivers drive about $40 \%$ less than younger drivers) (TRB 2009). Second, young adults entering the housing market have recently shown a preference for centralized urban areas (TRB 2009). Third, increased immigration could increase demand for smart growth, as immigrant populations generally reside in city centers and use alternative modes of transportation more than other groups do (TRB 2009).

EPA has collected data on development in existing urban or suburban lots, a practice known as "urban infill." Infill accounted for about $21 \%$ of new construction in 209 metropolitan regions between 2000 and 2009. Infill rates varied considerably across cities, ranging from $2 \%$ in Prescott, Arizona, to $80 \%$ in San Jose, California (EPA 2012).

Based on the literature, it is assumed that city smart growth policies could affect $50 \%$ (moderate abatement scenario) to $80 \%$ (high abatement scenario) of new development.

\section{Travel Reduction}

Several studies have measured travel as a function of various urban form factors. The VMT differential between cities with various urban forms can serve as an estimate of the VMT reduction potential of policies that promote certain urban forms. Salon et al. (2012) inventoried 37 studies that modeled travel as a function of 14 factors. Figure 10 illustrates travel reduction effect sizes, in terms of percentage change in VMT, for five categories of land use planning related to smart growth. The studies show a broad range of effect sizes ranging from slightly positive (i.e., travel increases) to greater than a 30\% reduction in VMT. The effects provide

\footnotetext{
${ }^{23}$ The product of the projected 2035 VMT as a percentage of current VMT $(123 \%)$ and the new development percentage of 2035 VMT (24\%).
} 
plausible ranges of travel reductions under city policies that increase density, jobs-housing balance, land use mix, network connectivity, and regional accessibility.

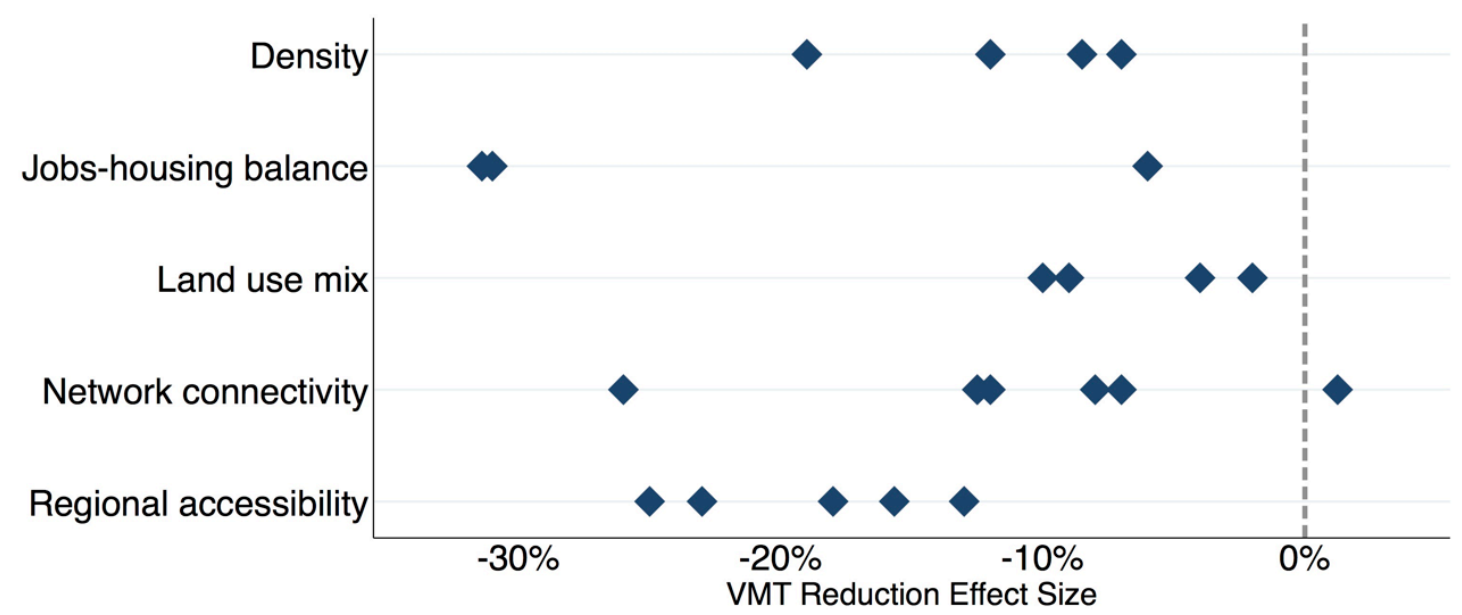

Figure 10. VMT reduction effect sizes from urban form studies

(Salon et al. 2012)

Each point represents a single study. Average effect sizes are plotted where studies reported multiple effects for several urban form factors.

Two recent studies suggest that the relationship between VMT and population density is more nuanced than the findings of Salon et al. (2012) generally support. Jones and Kammen (2014) found a nonlinear relationship between population density and per capita carbon emissions. They found that increasing population density reduces per capita carbon emissions when moving from suburban to urban areas, but that increasing population density increases per capita carbon emissions when moving from rural to suburban areas. Gately, Hutyra, and Wing (2015) found a similar nonlinear relationship between transportation-related emissions and population density. They found that transportation-related emissions were strongly positively associated with increasing population density up to about 1,650 persons per square kilometer. These results suggest that population density per se does not have an absolutely negative effect on carbon emissions.

The estimated influence of various land use factors on travel summarized in Salon et al. (2012) generally fall below a 20\% reduction in VMT (Figure 10). However, the possibility of achieving multiple VMT reduction effects through smart growth policies that increase several factors in Figure 10 suggests that greater VMT reductions are possible. Further, previous analysts have assumed smart growth VMT reduction effects of 25\%-60\% (Ewing et al. 2008; Cambridge Systematics 2009; TRB 2009). Based on the literature, it is assumed that smart growth policies reduce VMT by $30 \%$ (moderate abatement scenario) to $60 \%$ (high abatement scenario) in smart growth zones. 


\section{Carbon Intensity of Displaced Travel}

Based on EIA forecasts for vehicle distributions in $2040,{ }^{24}$ a weighted carbon intensity of 0.18 $\mathrm{kg} \mathrm{CO} /$ mile is used for travel in 2035 (see Section A.3 of Appendix A).

\section{Summary of Assumptions}

The key assumptions for the analysis of the carbon abatement potential of smart growth policies are:

- Baseline travel (VMT) in new development zones will be about $30 \%$ of current travel.

- Smart growth policies will affect 50\% (moderate abatement scenario) to $80 \%$ (high abatement scenario) of travel in new development zones.

- Smart growth policies reduce travel in smart growth zones by $30 \%$ (moderate abatement scenario) to $60 \%$ (high abatement scenario).

- The carbon intensity of displaced travel is $0.18 \mathrm{~kg} \mathrm{CO}_{2} / \mathrm{mile}$.

\subsection{Results: Carbon Abatement Potential of Smart Growth Policies}

The results suggest that city smart growth policies could reduce carbon emissions by $30-80$ MMT $\mathrm{CO}_{2} /$ year, or about $0.4 \%-1.2 \%$ of 2013 U.S. emissions. Short-term emissions reduction potential is limited by the turnover of residential and commercial zones into new development. At the city level, the results suggest that an average city can reduce local emissions by $0.8 \%$ (moderate) to $2.5 \%$ (high) relative to current city emissions. Figure 11 illustrates the distributions of city-level carbon abatement potential from smart growth in the moderate and high abatement scenarios.

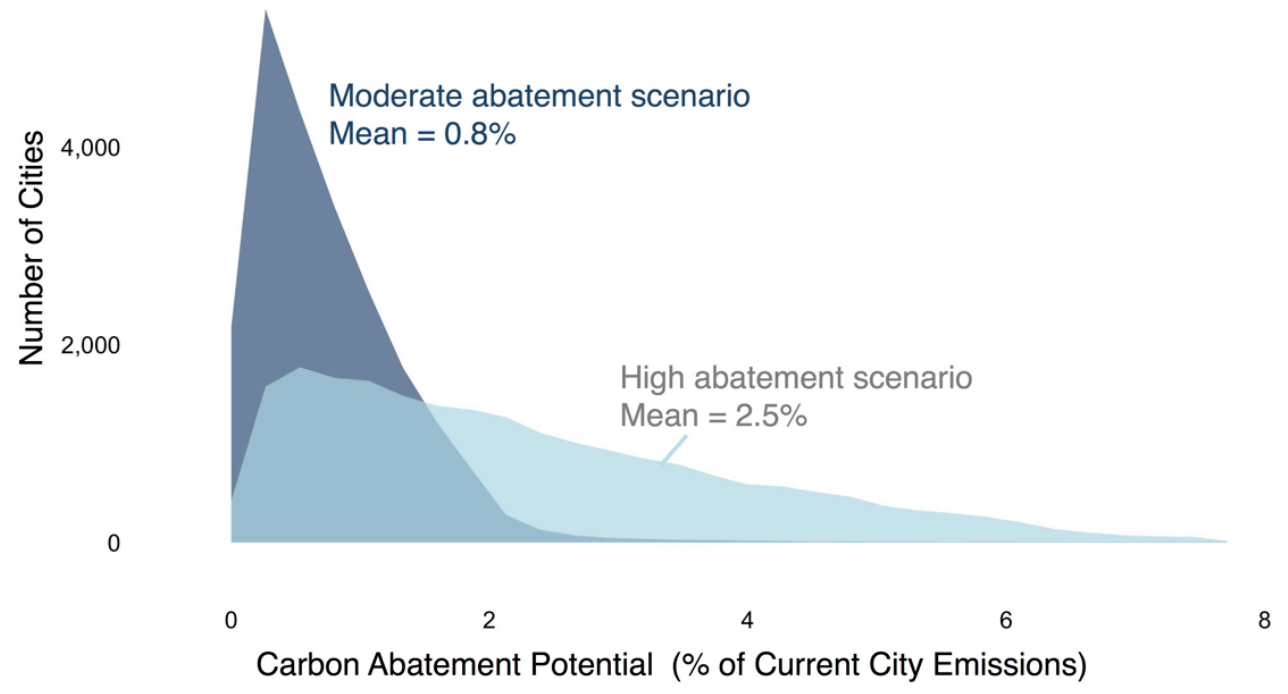

Figure 11. City-level carbon abatement potential distribution of smart growth policies

\footnotetext{
${ }^{24}$ A 2035 estimate was not available, the 2040 estimate is used as a close proxy.
} 


\section{Public Transit Expansion}

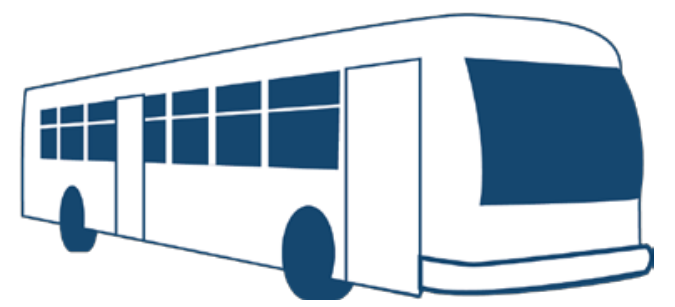

Public transit expansion policies are actions that increase the use of existing services or develop new public transit infrastructure.

For the purposes of this analysis, public transit refers to any publicly funded form of transportation, including van and carpooling services. The results suggest that city actions to expand the use of public transit could reduce carbon emissions by about 60-110 MMT $\mathrm{CO}_{2} /$ year, or about $0.9 \%-1.7 \%$ of 2013 U.S. emissions. ${ }^{25}$ It is important to note that the analysis assumes no interaction between public transit and smart growth policies (Section 4) in order to produce two independent results. However, significant interactions exist between these two policy areas, such that strong smart growth policies could significantly increase the carbon abatement potential of public transit policies and vice-versa.

\subsection{Summary of Public Transit Expansion Policies Currently Enacted}

Policies regarding expansion of public transit services were the fourth most common city action taken to reduce carbon emissions (Aznar et al. 2015). In 2013, U.S. passengers took 10.7 billion trips in public transit, amounting to 58.9 billion passenger miles (APTA 2015). About $45 \%$ of public transit vehicle miles occurred in buses, about $21 \%$ occurred by rail, and the remainder occurred in other transit services. Bus services were by far the most common public transit service offered by cities, followed by commuter bus and transit vanpool programs (Figure 12).

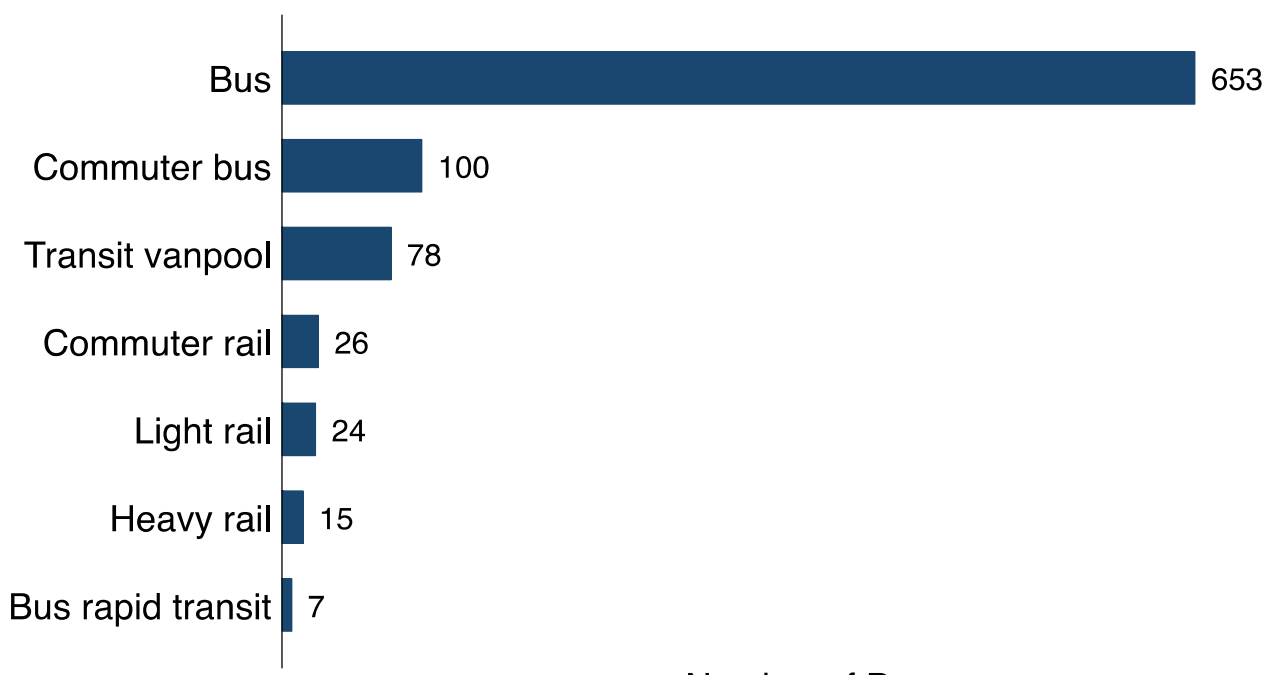

Number of Programs

Figure 12. Number of public transit programs, by transit services (APTA 2015)

\footnotetext{
${ }^{25}$ Based on 2013 U.S. greenhouse gas emissions (EPA 2015).
} 
Cities have developed a variety of policies to increase the use of existing services or provide new public transit services. Table 9 summarizes commonly enacted public transit policies.

Table 9. Public Transit Expansion Policy Descriptions

\begin{tabular}{|c|c|}
\hline Policy & Description \\
\hline Service development & $\begin{array}{l}\text { Service development is the implementation of new modes of public } \\
\text { transit. Cities have developed a variety of public service transit } \\
\text { services (see Figure 12), primarily bus and vanpooling programs. } \\
\text { Some "commuter transit" programs are designed specifically } \\
\text { around commuting patterns. More recently, some cities have } \\
\text { developed bus-based mass transit systems or bus rapid transit } \\
\text { (BRT) with established routes that maximize system efficiency. The } \\
\text { type of service development is a function of city size; small or rural } \\
\text { cities mostly offer bus programs, while some large cities can } \\
\text { support rail programs. }\end{array}$ \\
\hline $\begin{array}{l}\text { High-occupancy vehicle (HOV) } \\
\text { facilities }\end{array}$ & $\begin{array}{l}\text { HOV facilities include lanes and roadways reserved for the use of } \\
\text { transit, HOV travel (e.g., carpooling), or both. For example, an } \\
\text { HOV lane in Seattle increased average vehicle occupancy on one } \\
\text { freeway by } 36 \% \text {. }\end{array}$ \\
\hline Information and promotion & $\begin{array}{l}\text { These are policies that aim to increase ridership or retain existing } \\
\text { riders through customer information services and active promotion. }\end{array}$ \\
\hline Routing and coverage changes & $\begin{array}{l}\text { These changes include the adjustment, extension, or creation of } \\
\text { transit routes. }\end{array}$ \\
\hline $\begin{array}{l}\text { Scheduling and frequency } \\
\text { changes }\end{array}$ & $\begin{array}{l}\text { These changes include modifications to transit schedules and } \\
\text { service frequencies to increase ridership. For example, } \\
\text { enhancements of frequency and service hours in Santa Clarita } \\
\text { Transit (Los Angeles) service resulted in a } 120 \% \text { increase in } \\
\text { ridership. }\end{array}$ \\
\hline
\end{tabular}

Sources: TRB 2013; APTA 2015; Aznar et al. 2015

\subsection{Scenarios, Assumptions, and Methods for Estimating Carbon Abatement Potential of Public Transit Expansion Policies}

Table 10 summarizes the moderate and high abatement scenarios used to model the carbon abatement potential of public transit expansion policies. This section describes the basis, assumptions, and methods for the two scenarios. 
Table 10. Public Transit Expansion Scenarios

\begin{tabular}{ll}
\hline Scenario & Description \\
\hline Moderate abatement scenario & $\begin{array}{l}\text { Public transit expansion measures reduce private vehicle } \\
\text { passenger miles by } 15 \% .\end{array}$ \\
High abatement scenario & $\begin{array}{l}\text { Public transit expansion measures reduce private vehicle } \\
\text { passenger miles by } 30 \% .\end{array}$ \\
\hline
\end{tabular}

The carbon abatement potential of the two city policy scenarios is modeled as a function of three factors: baseline private vehicle travel, private vehicle travel reduction, and the carbon intensity differential of private and public transit (Figure 13).

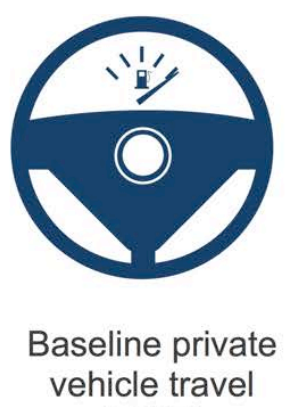

(PMT)

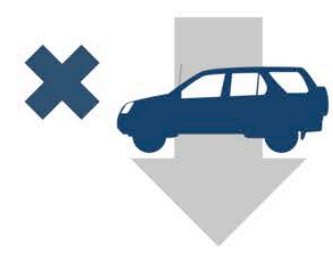

Private vehicle travel reduction

$(\% \Delta)$
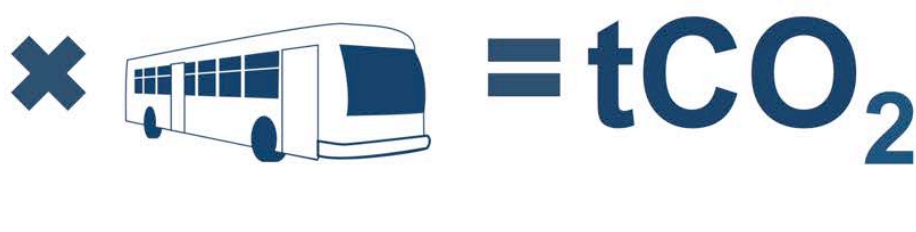
Change in
carbon intensity
from mode
change
( $\left.\mathrm{tCO}_{2} / \mathrm{PMT}\right)$

Carbon abatement

potential

$\left(\mathrm{tCO}_{2}\right)$

Figure 13. Method for carbon abatement potential estimation of public transit expansion policies

\section{Baseline Private Vehicle Travel}

Passenger miles, rather than more typical VMT, are generally used in comparisons of energy use and travel for different transportation modes. Passenger miles are the product of the number of passengers and the distance travelled in a given trip. For example, four passengers traveling 10 miles equal 40 passenger miles. Baseline private vehicle travel is based on the reference case, which assumes VMT growth of 1.04\%/year from 2015 to 2035 (see Section A.1 of Appendix A). To convert to passenger miles, an average private vehicle occupancy of 1.67 passengers per vehicle is assumed (Santos et al. 2009).

\section{Reduction of Private Vehicle Travel}

The significant recent growth of public transit use-about a $25 \%$ increase in passenger miles from 2000 to 2013 (BTS 2016a) — may be evidence of unmet demand for public transit services. To the extent that unmet demand exists, public transit expansion policies can reduce private vehicle travel by facilitating a mode switch to public transit.

Estimates of the percentage of drivers that would mode switch because of public service expansion vary significantly. Litman (2015) suggested modest changes such as providing maps and schedules could cause a $10 \%$ reduction in private vehicle travel, while more complex public transit policies such as providing commuter financial incentives could cause a private travel reduction of up to $40 \%$ (Table 11). In a literature review, Arrington and Cervero (2008) found 
that commuters in areas with improved access to public transit use public transit two to five times more than other commuters in their region do.

Table 11. Private Vehicle Travel Reductions Associated with Transit Expansion (Litman 2015)

\begin{tabular}{lc}
\hline Policy & Private Vehicle Travel Reduction \\
\hline $\begin{array}{l}\text { Special lanes for buses and high-occupancy vehicles, traffic } \\
\text { signal preemption, faster loading systems }\end{array}$ & $4 \%-30 \%$ \\
$\begin{array}{l}\text { Parking management (e.g., parking pricing and incentives for } \\
\text { reduce parking space requirements) }\end{array}$ & $10 \%-30 \%$ \\
$\begin{array}{l}\text { Commute trip reduction programs (e.g., commuter financial } \\
\text { incentives, rideshare matching, and guaranteed rides home) }\end{array}$ & $20 \%-40 \%$ \\
$\begin{array}{l}\text { Improved user information (e.g., schedules, maps, and } \\
\text { wayfinding) }\end{array}$ & $5 \%-15 \%$ \\
\hline
\end{tabular}

Several studies have suggested public service expansion can result in significant reductions in private vehicle travel. A 2003 Transportation Research Board study found that several BRT programs achieved sustained ridership increases and mode switching from private vehicle travel (Levinson et al. 2003). For example, the Hartford BRT program reported that more than half of its passengers had mode switched, the Houston BRT program reported that more than $70 \%$ of its passengers had mode switched, and the Los Angeles BRT program reported that about one third of its passengers had mode switched. Similarly, Peak et al. (2005) found that between $24 \%$ and $67 \%$ of passengers in BRT programs represented mode switches.

A Transportation Research Board study (TRB 2013) examined passenger responses to different transit policies. Relevant findings from the study include the following:

- The elasticity of ridership to route expansions is generally between 0.6 and 1 (i.e., a doubling of the number of available routes is generally associated with a $60 \%-100 \%$ increase in ridership), although a large portion of new ridership typically represents passengers that previously used other forms of transit.

- The elasticity of ridership to frequency changes is about 0.5 .

- HOV facilities typically increase average vehicle occupancy by $5 \%-20 \%$.

- About half of vanpool passengers formerly commuted in a private vehicle.

- Information and promotion programs can result in significant short-term increases in ridership; however, the long-term effects of transit information programs are generally unknown.

Several counterarguments suggest that conservative assumptions may be merited. First, cities have already exploited some of the most viable public transit opportunities, and it is unclear whether future service expansion will have levels of success that are comparable to past expansion (DOT 2010). Further, research suggests that cities must achieve certain thresholds of 
population density in order to implement cost-effective public transit programs. For example, Cervero and Guerra (2011) suggested that a population density of about 30 people per acre is necessary for a successful light rail program, although Godavarthy et al. (2014) suggested that different forms of public transit may be cost effective in small urban and even rural areas.

Based on the literature, it is assumed that public transit expansion measures could reduce personal vehicular travel by $15 \%$ (moderate abatement scenario) to $30 \%$ (high abatement scenario).

\section{Change in Carbon Intensity from Mode Change}

The carbon abatement of mode changing from private vehicle travel to public transit is a function of the difference between the carbon intensity of the two modes. A common metric for comparing the carbon intensity of various transport modes is carbon per passenger mile traveled (PMT), measured in terms of $\mathrm{kg} \mathrm{CO}_{2} / \mathrm{PMT}$; it is calculated using Equation 1:

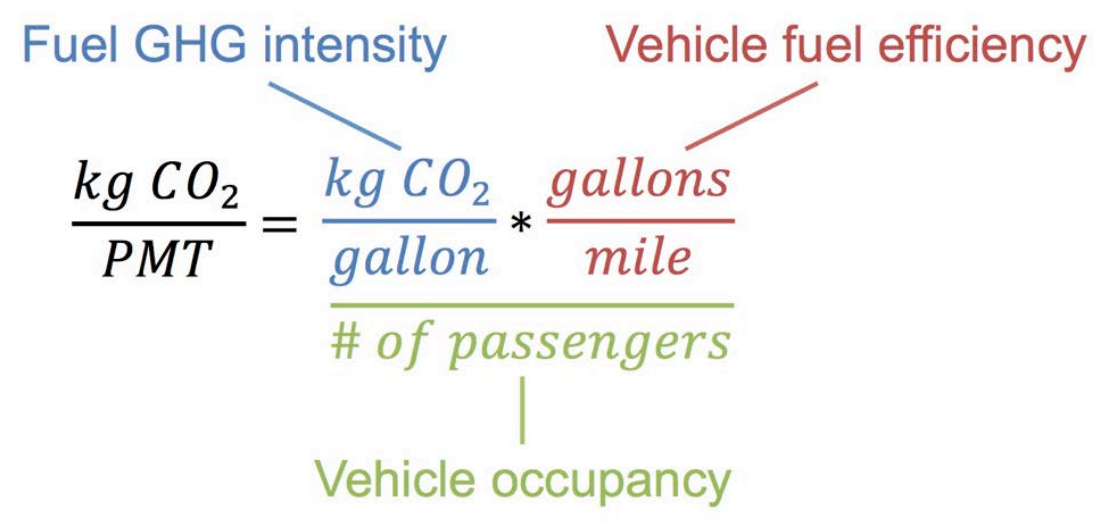

\section{Equation 1. Carbon intensity of passenger miles traveled (PMT)}

The metric of passenger mile carbon intensity normalizes the carbon intensity of travel with different numbers of passengers. For example, the passenger mile carbon intensity of a given vehicle is lower when that vehicle carriers more passengers. Based on Equation 1, the carbon abatement potential of public transit can be increased by increasing vehicle fuel efficiency or increasing vehicle occupancy.

Improvements in fuel efficiency and the electrification of public transit vehicles are two approaches for lowering the passenger mile carbon intensity of public transit. However, an analysis of abatement potential must account for the increasing fuel efficiency and electrification of private vehicles, such that constant increases in the fuel efficiency and electrification of private vehicles could offset any potential gains from the increased fuel efficiency and electrification of public transit vehicles. Any carbon abatement from transit vehicle fuel efficiency improvements and electrification are assumed to be fully offset by concomitant carbon abatement from fuel efficiency improvements and the electrification of private vehicles.

Increasing public transit vehicle occupancy is a second approach for lowering the passenger mile carbon intensity of public transit. The number of passengers in a public transit vehicle as a percentage of total possible occupancy is known as the vehicle's load factor. High quality transit 
designed to compete with automobile travel, which is offered in a few large urban areas, with high load factors generally reduce PMT carbon intensity (Litman 2015).

Figure 14 summarizes the PMT carbon intensity of various transportation modes. In general, public transit lowers PMT carbon intensity relative to private vehicle travel due to high load factors. Off-peak buses are one notable exception. Most U.S. public transit provides basic mobility services to passengers who could not otherwise drive. Such basic mobility services are associated with relatively low load factors and thus high PMT carbon intensity (Litman 2015).

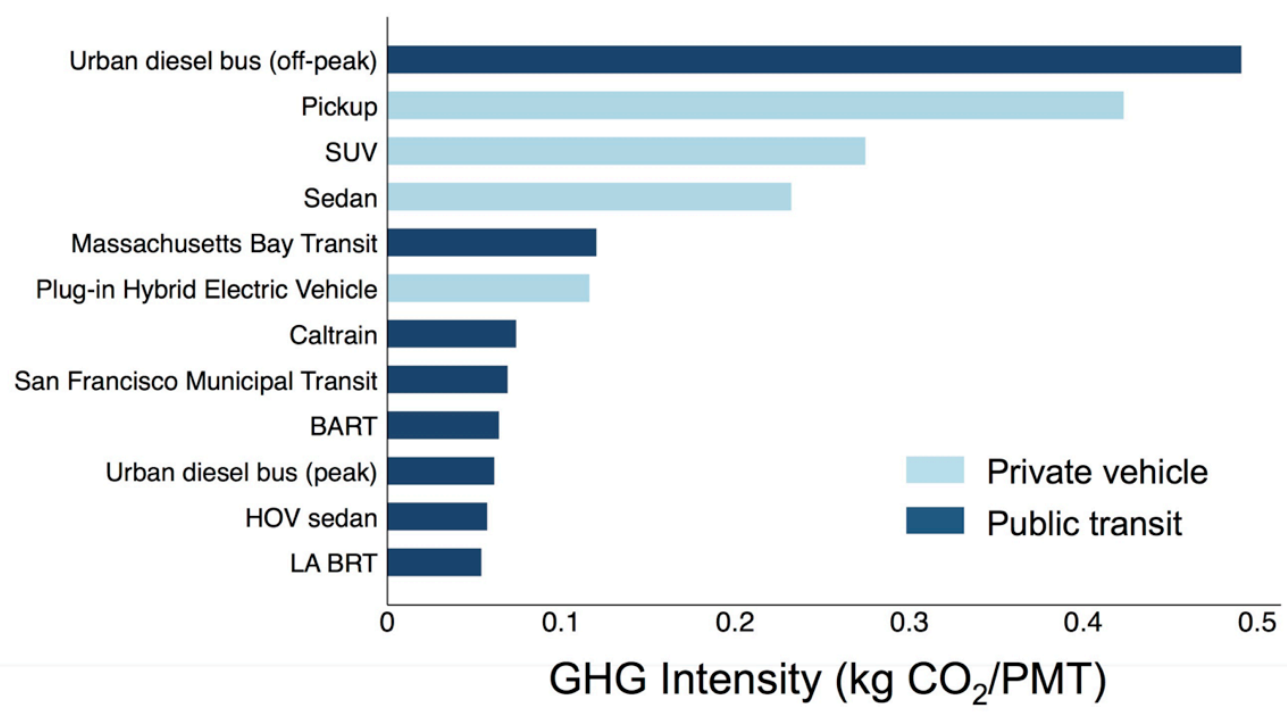

Figure 14. Carbon intensity (kg CO $2 / P M T)$ of various transportation modes

Assuming the private vehicle fleet is a mix of sedans and SUVs, the results in Figure 14 suggest that the potential PMT carbon intensity reduction from mode switching is on the order of $0.25 \mathrm{~kg}$ $\mathrm{CO}_{2} / \mathrm{PMT}$, compared to an average of $0.12 \mathrm{~kg} \mathrm{CO}_{2} / \mathrm{PMT}$ for the public transit options, or a difference of $0.13 \mathrm{~kg} \mathrm{CO}_{2} / \mathrm{PMT}$. For the purposes of this analysis, it is assumed that the carbon intensity of public transit is $0.13 \mathrm{~kg} \mathrm{CO}_{2} / \mathrm{PMT}$ lower than it is for personal vehicular travel. ${ }^{26}$

\section{Summary of Assumptions}

The key assumptions for the analysis of the carbon abatement potential of public transit expansion policies are:

- Baseline 2035 private vehicle travel (PMT) is $123 \%$ of current travel, and average vehicle occupancy is 1.67 passengers per vehicle.

- Public transit expansion policies reduce private vehicle travel by $15 \%$ (moderate abatement scenario) to $30 \%$ (high abatement scenario).

- The carbon intensity of public transit is $0.13 \mathrm{~kg} \mathrm{CO}_{2} / \mathrm{PMT}$ lower than it is for private vehicle travel.

\footnotetext{
${ }^{26}$ We did not attempt to quantify the carbon abatement potential of improved public transit fuel efficiency. Rather, we assume the fuel efficiency of public transit fleets will improve proportionally to fuel efficiency improvements in private vehicles. This assumption allows us to base the change in PMT carbon intensity on historical figures without projecting new private or public transit fleet compositions.
} 


\subsection{Results: Carbon Abatement Potential of Public Transit Policies}

The results suggest that public transit expansion measures could reduce carbon emissions by about $60-110 \mathrm{MMT} \mathrm{CO}_{2} /$ year, or about $0.8 \%-1.7 \%$ of 2013 U.S. emissions. At the city level, the results suggest that an average city can reduce local emissions by $1.8 \%$ (moderate) to $3.6 \%$ (high) relative to current city emissions. Figure 15 illustrates the distributions of city-level carbon abatement potential from public transit expansion in the moderate and high abatement scenarios.

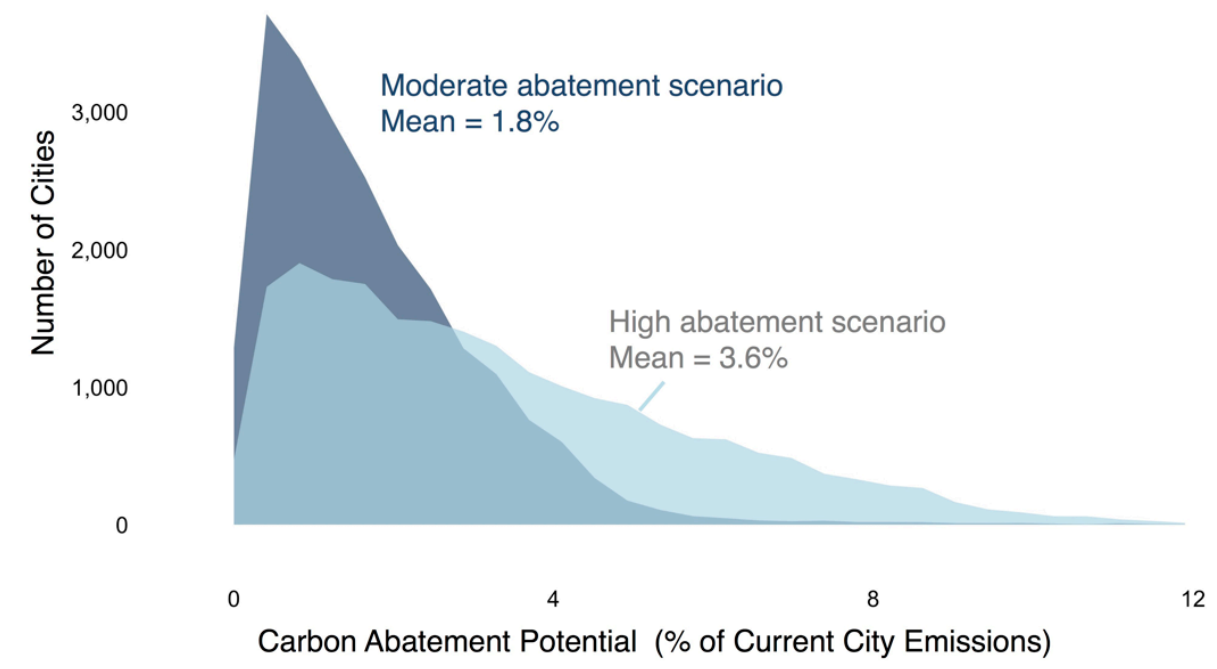

Figure 15. City-level carbon abatement potential distribution of public transit expansion 


\section{Solar PV Policies}

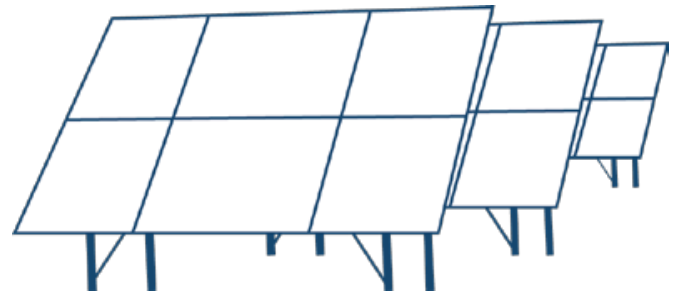

\section{Solar photovoltaic (PV) policies are city actions aimed at increasing the private deployment of rooftop or ground- mounted utility-scale solar PV.}

Urban solar resources are largely untapped; cities have installed less than $1 \%$ of the technical potential of rooftop solar PV, and they have hardly begun to exploit urban solar resources at a utility scale. ${ }^{27}$ Cities already have much of the infrastructure required to host solar PV systems. Solar PV systems can be co-located with city loads, thereby reducing transmission and distribution losses and other inefficiencies resulting from transferring electricity over long distances. Further, urban solar PV systems entail lower environmental impacts and land use changes than solar PV systems sited outside of cities in undisturbed environments (Hernandez et al. 2015). The results suggest that city solar PV policies could reduce carbon emissions by about $10-30 \mathrm{MMT} \mathrm{CO}_{2} /$ year, or about $0.2 \%-0.4 \%$ of 2013 U.S. emissions. ${ }^{28}$

\subsection{Summary of Solar PV Policies Currently Enacted}

Solar energy policy is the most frequently codified type of municipal alternative energy policy. Cities use a variety of policies to increase urban solar PV deployment. City solar PV policies include financial incentives, local permitting, zoning codes, education and outreach, resource access, and direct investment.

\section{Financial Incentives}

About $8.8 \%$ and $7.6 \%$ of cities offer financial incentives for residential and commercial solar PV, respectively (ICMA 2016). Financial incentives include system rebates, low-interest loans, grants, and production-based incentives. Financial incentives are particularly effective city solar $\mathrm{PV}$ policies because they directly reduce the high costs of solar systems, one of the primary barriers to solar deployment ( $\mathrm{Li}$ and Yi 2014).

\section{Local Permitting}

Cities can reduce the regulatory burden of solar PV project development by expediting or otherwise improving local permitting processes. Thirteen percent of respondents to a survey by the International City/County Management Association (ICMA) had implemented expedited permitting processes that simplify or shorten the permitting phase of project development (ICMA 2012). Li and Yi (2014) found that five of the top ten solar deployment cities in their sample had expedited solar permitting (compared to $25 \%$ of programs in the research sample). Burkhardt et al. (2015) found that local permitting variation can cause price differences of up to $\$ 0.18 / \mathrm{W}$

\footnotetext{
${ }^{27}$ According to a sample of 47 cities from Gagnon et al. (2016), the average installed capacity of systems smaller than 1 megawatt (MW) was $0.4 \%$ of estimated technical rooftop solar PV capacity on average. More than half of the cities had no utility-scale (>1 MW) solar capacity, according to data from NREL's OpenPV Project (https://openpv.nrel.gov/).

${ }^{28}$ Based on 2013 U.S. greenhouse gas emissions (EPA 2015).
} 
across jurisdictions. Streamlined permitting processes can shorten process times by as much as 24 days (Wiser and Dong 2013).

\section{Zoning Codes}

About $43 \%$ of cities have incorporated solar PV into city-level zoning codes (ICMA 2012). Cities can amend zoning laws to improve the process of solar PV project approval through a special permit, or they can allow solar PV projects to be more comprehensive as an "as-of-right" use within zoning districts. Some cities have amended codes to require that all new construction be "solar ready" with adequate infrastructure to host a system (e.g., Lancaster, California, and Tucson, Arizona). Some cities have amended zoning codes to facilitate solar installations on historic buildings (e.g., Ann Arbor, Michigan, and Madison, Wisconsin).

\section{Education and Outreach}

Twelve percent of ICMA survey respondents offered solar community outreach programs. Thirty-one percent of ICMA respondents had invested in a solar demonstration project for community education purposes (ICMA 2012). Some cities have developed consumer guides, permitting guides, solar maps, workshops, and other tools to assist potential solar customers (e.g., Ann Arbor, Michigan; Berkeley, California; Boston, Massachusetts; Knoxville, Tennessee; Madison, Wisconsin; San Diego, California; and San Francisco, California). Other cities provide guides or training for solar installers (e.g., Knoxville, Tennessee; Minneapolis, Minnesota; New Orleans, Louisiana; Orlando, Florida; Philadelphia, Pennsylvania; and Pittsburgh, Pennsylvania).

\section{Solar Access Policies}

Solar access policies protect solar customers' use of the sunlight incident upon their systems. Solar access laws restrict the obstructions that may be built around a system that could affect solar production. Twelve percent of ICMA respondents had adopted a solar access ordinance (ICMA 2012). Conventional solar access zoning restricts the height of buildings surrounding a structure and specifies a setback. A solar "envelope" sets imaginary boundaries around a building based on the sun's relative motion to ensure solar access during peak generation periods.

\subsection{Scenarios, Assumptions, and Methods for Estimating Carbon Abatement Potential of Solar PV Policies}

Table 12 summarizes the moderate and high abatement scenarios used to model the carbon abatement potential of city solar PV policies. This section describes the basis, assumptions, and methods for the two scenarios.

Table 12. Solar PV Policy Scenarios

\begin{tabular}{ll}
\hline Scenario & Description \\
\hline Moderate abatement scenario & $\begin{array}{l}\text { City policies (e.g., permitting, codes, rebates) reduce solar PV } \\
\text { system costs by } \$ 0.50 / \mathrm{W}\end{array}$
\end{tabular}

High abatement scenario City policies reduce solar PV system costs by $\$ 1.00 / \mathrm{W}$ 
The carbon abatement potential of the three city policy scenarios is estimated as a function of three factors: technical potential, the change in willingness to adopt solar, and the carbon intensity of displaced electricity use (Figure 16).

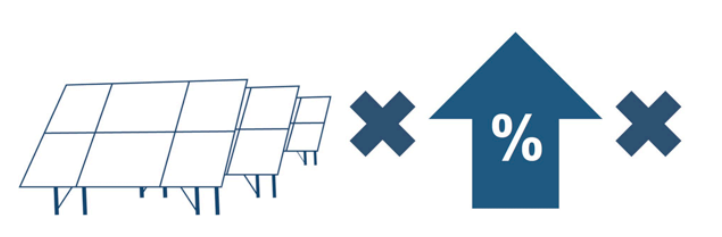

Technical potential

(MWh)

\begin{abstract}
Change in willingness to adopt solar
\end{abstract}

(\%)

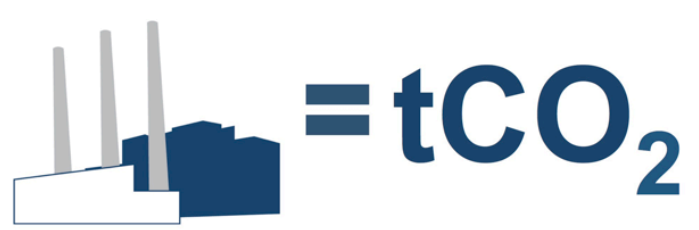

GHG abatement potential $\left(\mathrm{tCO}_{2}\right)$

Figure 16. Method for carbon abatement potential estimation of city solar PV policies

\section{Technical Potential of Solar PV}

The technical potential of solar PV is an estimate of the amount of energy that could be generated if PV were installed in all of the technically suitable area within a city. ${ }^{29}$ Estimates of the technical potential of urban rooftop solar PV range from $16 \%$ to $88 \%$ of the annual electricity consumption of a city, depending on rooftop characteristics, quality of the local solar resource, and quantity of consumption of both the residential and industrial sectors of a city (Gagnon et al. 2016). The United States has approximately $25,000 \mathrm{~km}^{2}$ of urban space that is suitable for deployment of ground-mounted solar PV, which results in a potential of 1,218 gigawatts (GW) of capacity (Lopez et al. 2012).

For the purposes of this report, technical potential for rooftop solar PV is based on city-level estimates developed for the City Energy Profile tool. ${ }^{30}$ Technical potential is limited to rooftop potential due to the predominance of rooftop PV in historical urban installations. Cities could increase their carbon abatement from solar PV beyond these estimates by encouraging the development of ground-mounted solar PV where appropriate. Module productivity (output in kilowatt-hours $[\mathrm{kWh}]$ per kilowatt $[\mathrm{kW}]$ of installed capacity) is influenced by the quality of the local solar resource as well as both the slope and direction of roof planes. We use NREL's System Advisor Model $^{31}$ — with data from the Typical Meteorological Year data set (Wilcox and Marion 2008) and rooftop orientation trends from GIS and lidar-based analysis performed by NREL (Gagnon et. al. 2016) — to estimate the total potential energy generation from all suitable roof area in each of the cities in the analysis.

\section{Change in Willingness to Adopt Solar}

The impact of a city solar PV policy on solar PV deployment is modeled as a function of the policy's effect on the willingness to adopt solar. Survey data (Sigrin and Drury 2014) are used to

\footnotetext{
${ }^{29}$ Following the criteria laid out in Gagnon et. al. (2016), roof area was defined as suitable if it had a slope of less than 60 degrees, was not facing north, did not lose more than $30 \%$ of energy from shading, and was part of at least 10 contiguous square meters of area. See Lopez et al. (2012) for urban PV suitability criteria. Technical potential does not account for economic viability.

${ }^{30}$ Based on suitable rooftop area in buildings with smaller than 5,000-square-foot footprint.

${ }^{31}$ The System Advisor Model (SAM) is a free publically available performance and economic model designed to facilitate decision making and analysis for renewable energy projects (Gilman and Dobos 2012).
} 
build a willingness-to-pay curve, which represents the fraction of potential customers that would be willing to adopt solar PV for any given payback period (Figure 17). The willingness-to-pay curve illustrates that the fraction of customers willing to adopt is negatively correlated with the payback period (i.e., policies that effectively lower payback periods result in higher adoption rates).

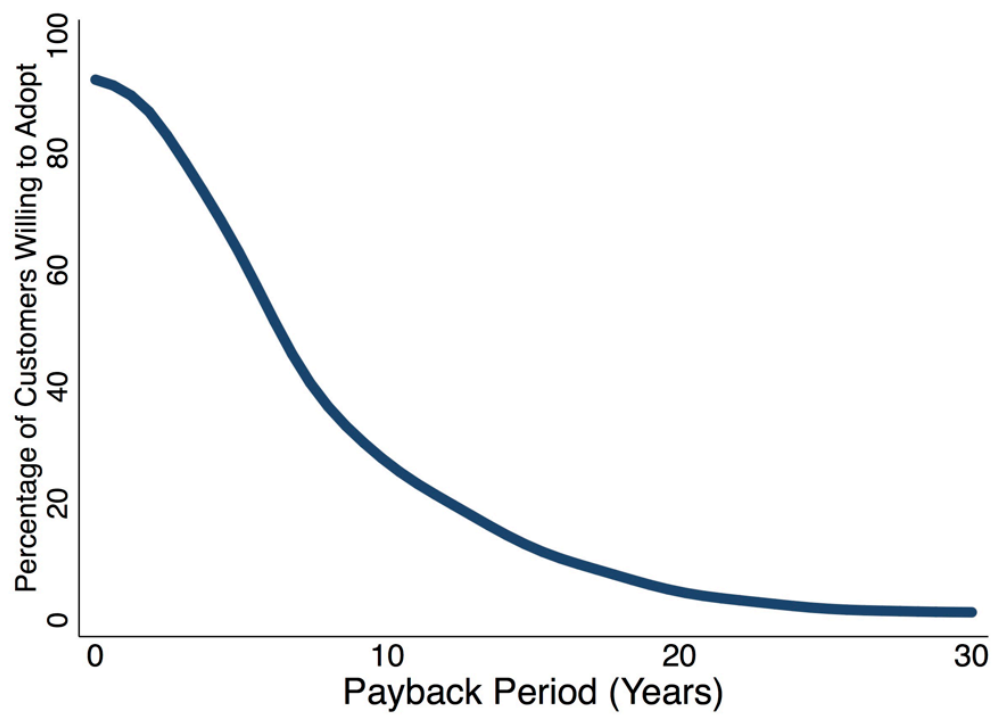

Figure 17. Residential solar PV willingness-to-pay curve

(Based on data from Sigrin and Drury 2014)

A set of residential rate tariffs from the Utility Rate Database ${ }^{32}$ is used to determine current solar PV payback periods for cities in the City Energy Profile data set. ${ }^{33}$ The payback period is then calculated for a representative residential PV system in every city served by one of these rates. ${ }^{34}$ A solar PV system price of $\$ 3.12$ per watt, direct current $\left(\mathrm{W}_{\mathrm{dc}}\right)$ is used, which was the bottom-up modeled price for a 5-kW residential system quoted in 2015 (Feldman et. al. 2015). The resulting payback period for this representative investment produced an estimate of the fraction of customers willing to adopt solar PV under current economic conditions.

The impact of a city solar PV policy on PV deployment is modeled as the change in willingness to adopt resulting from the modeled effects of rebates on payback periods. ${ }^{35} \mathrm{On}$ average, the model results suggest that a $\$ 0.50 / \mathrm{W}$ rebate would reduce payback periods by 1.8 years and

\footnotetext{
${ }^{32}$ See http://en.openei.org/wiki/Utility Rate Database.

${ }^{33}$ This simplified illustrative national analysis only analyzed residential rates and extends those results to all sectors. This assumes the responsiveness of the commercial sector would be approximately similar to that of the residential sector. Due to significant variation in the structure of commercial rates, which heavily influences the economics of solar PV, an analysis of the commercial rates available to businesses within a particular city is strongly encouraged in order to more thoroughly characterize local conditions.

34 The model is based on a south-facing solar PV module tilted at 20 degrees, $14.08 \%$ system losses, $0.5 \% / y e a r$ degradation, 95\% inverter efficiency, and a DC to AC ratio of 1.4. Financing was through a 15-year, 5\% APR loan with $80 \%$ debt fraction (modeled after a PACE loan), with $10 \%$ real discount rate.

${ }^{35}$ Solar PV rebates have the most direct effect on solar PV payback periods; however, city policies such as permitting and zoning can also have indirect impacts on system costs and thus payback periods.
} 
increase solar PV adoption by $3.5 \%$, while a $\$ 1.00 / \mathrm{W}$ rebate would reduce payback periods by 3.7 years and increase PV adoption by $8.2 \%$ (Figure 18$).^{36}$

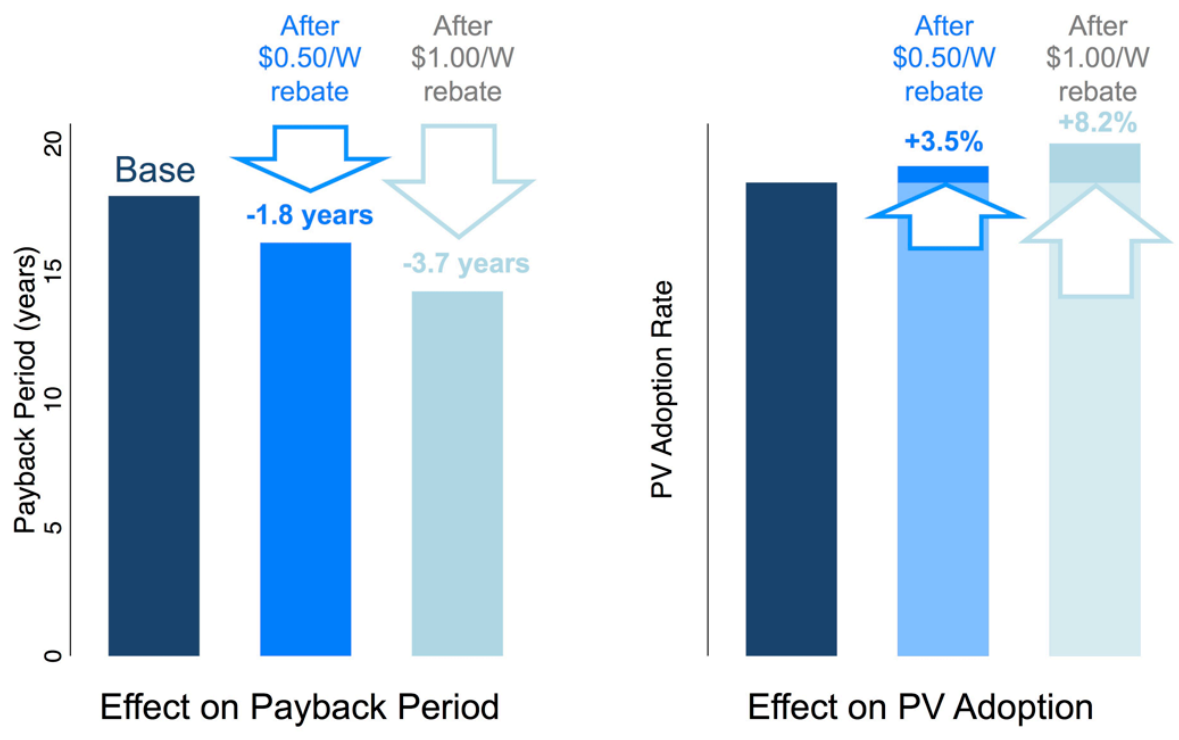

Figure 18. Modeled effects of city PV rebates on PV adoption

Changes in solar PV adoption are then translated to changes in solar PV capacity according to city technical potential. Solar PV adopters do not necessarily procure the full technical potential of their rooftops. Technical potential is derated by $44 \%$ to account for the fact that customers typically utilize about $56 \%$ of their rooftop's potential (see Section A.4 of Appendix A).

Technology diffusion through customer adoption often occurs through an S-curve, with slow uptake by early movers followed by a period of mass diffusion and a final period of lagging diffusion (Bass 1969; Rogers 2003). An S-curve diffusion model fitted to the current rate of PV adoption projects that more than $99 \%$ of the customers who would be willing to adopt solar PV will have done so by 2035 . Therefore, the results of this analysis are presented under the simplifying assumption that all customers who would be willing to adopt solar PV at a given payback period will have done so by 2035 .

\section{Carbon Intensity of Displaced Electricity Use}

The final carbon reduction potentials are estimated by multiplying the energy generation from the increased deployment of distributed solar PV (in megawatt-hours per year) described in the previous section by the carbon intensity of the local grid (in megatons of $\mathrm{CO}_{2}$ per megawatt-hour of electricity produced). Local grid carbon intensity is based on regional marginal emissions rates from EPA's eGRID adjusted for EIA projections of reduced grid carbon intensity (see reference case in Section A.1 of Appendix A).

\section{Summary of Assumptions}

The key analytical assumptions for the carbon abatement potential of city solar policies are:

\footnotetext{
${ }^{36}$ These effects are assumed to apply equally to customers that lease systems or buy power from third-party owned systems installed on their roof.
} 
- City PV technical potential is based on City Energy Profile data.

- Customer PV adoption is a function of solar PV payback periods; therefore, city policies that effectively reduce PV payback periods induce customer solar PV adoption.

- All potential customers who would be willing to adopt solar PV in the current economic conditions will have done so by 2035.

- Local grid carbon intensity is based on regional grid marginal emissions rates.

\subsection{Results: Carbon Abatement Potential of City PV Policies}

The results suggest that city solar PV policies could reduce carbon emissions by about 10-30 MMT $\mathrm{CO}_{2} /$ year, or about $0.2 \%-0.4 \%$ of 2013 U.S. emissions. At the city level, the results suggest that an average city can reduce local emissions by $0.7 \%$ (moderate) to $1.6 \%$ (high) relative to current city emissions. Figure 19 illustrates the distributions of city-level carbon abatement potential from solar PV policies in the moderate and high abatement scenarios.

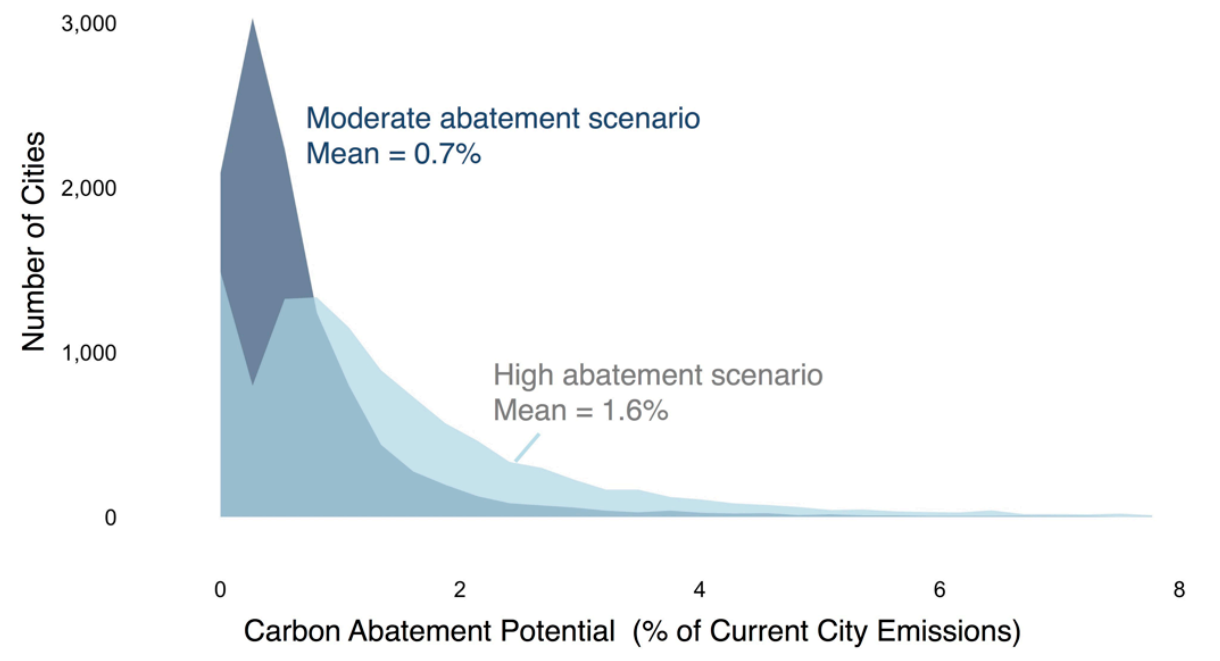

Figure 19. City-level carbon abatement potential distribution of solar PV policies 


\section{Municipal Action Policies}

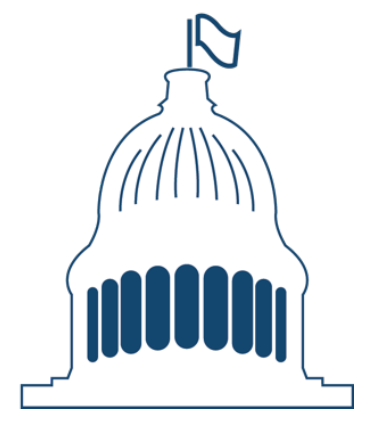

\section{Municipal action policies are measures taken by cities to reduce the carbon emissions of their own operations.}

Municipal action policies allow cities to lead by example and often result in more directly quantifiable reductions in carbon emissions, as cities have more direct control over their own energy use than the energy use of the community at large (Aznar et al. 2015). The results suggest that municipal action policies could reduce carbon emissions by about 10-20 $\mathrm{MMT} \mathrm{CO}_{2} /$ year, or about $0.2 \%-0.3 \%$ of 2013 U.S. emissions. ${ }^{37}$

\subsection{Summary of City Municipal Action Policies Currently Enacted}

Figure 20 illustrates the top 10 planned municipal actions to reduce energy use in a sample of 20 cities with climate or energy plans (Aznar et al. 2015). The three most common municipal actions all focus on reductions in building energy use.

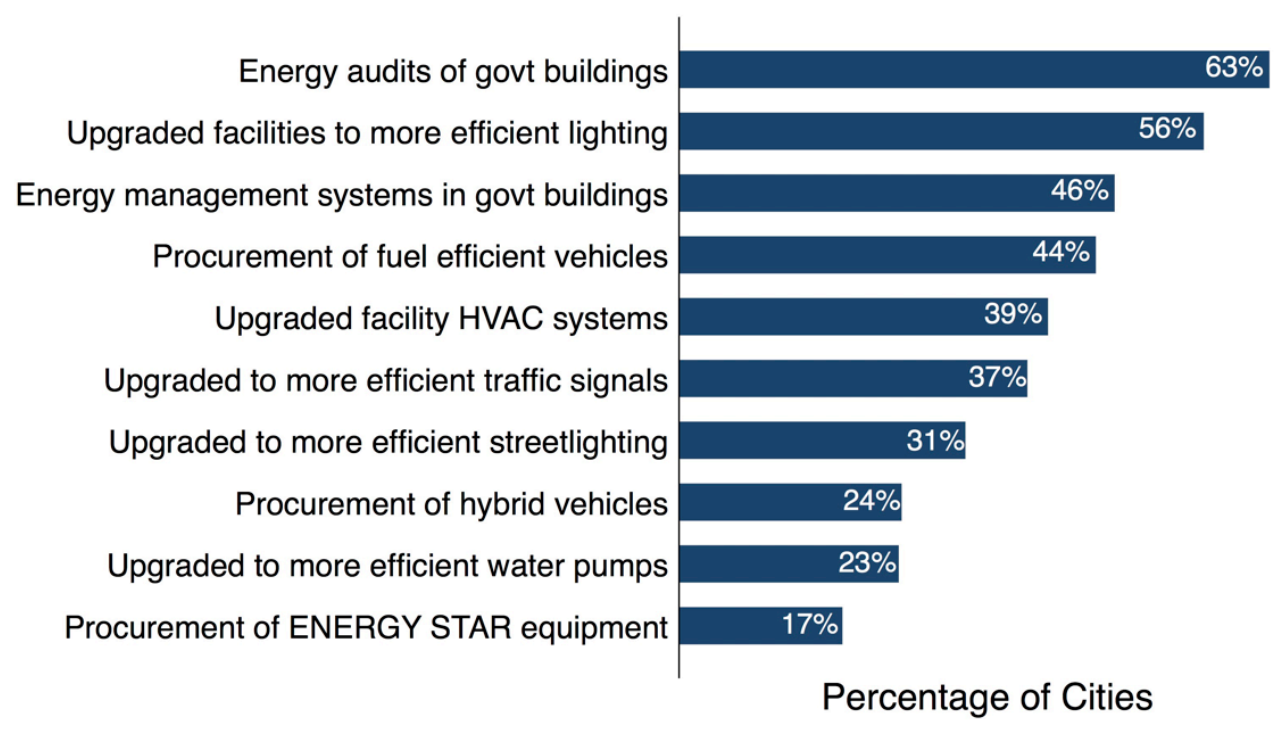

Figure 20. Common municipal actions

Based on data from Aznar et al. 2015

${ }^{37}$ Based on 2013 U.S. greenhouse gas emissions (EPA 2015). 


\section{Municipal Facility Energy Use Actions}

Cities can reduce energy use through energy efficiency measures in municipal buildings, waste/wastewater treatment facilities, and street lighting (DOE 2016), collectively referred to as "facilities." Specifically for municipal buildings, building energy audits and energy efficiency measures are the most common municipal carbon reduction actions (Aznar et al. 2015).

Some cities have taken further steps to reduce city building energy consumption through green building standards for city buildings. Green building standards refer to systems that certify that buildings meet certain energy efficiency standards (and in some cases, several non-energy metrics). Twenty-seven (27) of 61 ACEEE Scorecard cities have implemented a green building standard requirement for city-owned buildings. Twenty-three (23) of these cities use the U.S. Green Building Council's Leadership in Energy and Environmental Design (LEED) certification system.

\section{Municipal Fleet Actions}

Cities can reduce city fleet emissions by lowering vehicle use (i.e., VMT), reducing the carbon intensity of fleet fuels (i.e., $\mathrm{kg} \mathrm{CO}_{2} /$ gallon), or increasing the efficiency of fleet vehicles (i.e., miles per gallon). Cities have predominantly pursued improvements in fleet fuel efficiency through the procurement of more fuel-efficient and hybrid vehicles (Aznar et al. 2015). City investments in electric vehicle charging infrastructure could drive carbon reductions in both municipal and private fleets.

\section{Municipal Solar Energy Actions}

Several barriers, including ineligibility to use federal tax incentives directly and unsupportive state policies, have prevented most cities from using the direct procurement of solar energy as a means to reduce carbon emissions (Farrell and Grimley 2015). Nonetheless, about $18 \%$ of ICMA survey respondents had installed solar panels on a government facility (ICMA 2016).

\subsection{Scenarios, Assumptions, and Methods for Estimating Carbon Abatement Potential of Municipal Action Policies}

The carbon abatement potential of municipal actions is estimated for three categories: facilities, fleet, and solar power procurement. This list of actions is not comprehensive but covers the bulk of commonly implemented municipal actions (see Figure 20). Table 13 summarizes the scenarios for municipal actions. 
Table 13. Municipal Action Policy Scenarios

\begin{tabular}{ll}
\hline Scenario & Description \\
\hline Moderate abatement scenario & $\begin{array}{l}\text { Facilities: Cities make multiple energy efficiency upgrades to city } \\
\text { facilities (e.g., building, wastewater treatment, street lighting), } \\
\text { employ building energy management systems that collectively } \\
\text { reduce city building energy use by } 20 \%\end{array}$ \\
& Fleet: Cities hybridize $50 \%$ of city fleets \\
Solar: Cities deploy $50 \%$ of technical potential solar PV on city- \\
owned buildings \\
$\begin{array}{l}\text { Facilities: Cities make multiple energy efficiency upgrades to city } \\
\text { facilities, employ building energy management systems, and } \\
\text { implement green building code standards for new construction } \\
\text { and major renovation that collectively reduce city building energy } \\
\text { use by } 40 \%\end{array}$ \\
$\begin{array}{l}\text { Fleet: Cities hybridize } 75 \% \text { of city fleets } \\
\text { Solar: Cities deploy } 90 \% \text { of technical potential solar PV on city- } \\
\text { owned buildings }\end{array}$
\end{tabular}

According to data provided by ICLEI, municipal electricity use is about $1.5 \%$ of total city electricity use, on average (ICLEI 2016). This heuristic is applied to estimate municipal energy use as a proportion of total city energy use for the purposes of this analysis.

\section{Facilities}

Scenarios of carbon abatement potential from municipal facilities actions are developed as a function of three factors: baseline facility energy use, reduction of facility energy use, and the carbon intensity of facility energy use (Figure 21).

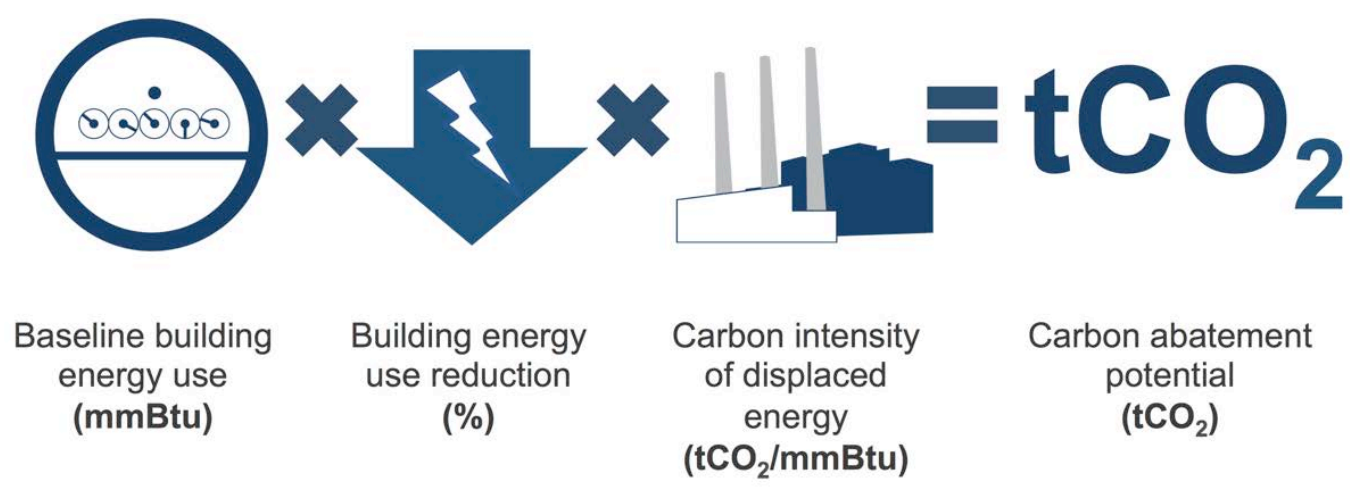

Figure 21. Method for carbon abatement potential estimation of municipal building actions Baseline Facility Energy Use

Baseline facility energy use is $1.5 \%$ of total current city building energy use, based on City Energy Profile tool data. 


\section{Reduction of Facility Energy Use}

Estimation of facility energy use reductions from energy efficiency measures in municipal facilities is not fundamentally different from estimation in other buildings. Section 2 provides an in-depth review of the estimation of building energy use reductions from building upgrades due to the application of new building codes. Reductions in building energy use on the order of about $10 \%$ are possible when upgrading building codes, reflecting upgrades in building functions such as lighting and HVAC. However, cities are also applying two building energy use reduction approaches not analyzed in Section 2: building energy management systems and green building standards.

Building energy management systems are programs to verify improvements in building energy management and performance. Therkelsen et al. (2013) studied the energy use impacts in nine industrial facilities of the Superior Energy Performance (SEP) program, a common building energy management system. The study found that the SEP program resulted in a $10.1 \%$ reduction in energy use in the first half of the second year of the program. The energy use effect of the study is consistent with observed energy use reductions achieved between building code vintages.

Several studies have examined the building energy use impacts of green building standards. A U.S. Green Building Council survey found that the energy use intensity of 195 LEED-certified buildings was $57 \%$ below the national average. ${ }^{38}$ In a study of 22 sustainably designed federal buildings, 13 of which were LEED-certified, Fowler et al. (2011) found that the buildings performed $18 \%$ better than regional averages for energy use intensity. Newsham et al. (2013) found that LEED-certified buildings achieved an energy use reduction of $18 \%-39 \%$ over noncertified buildings for medium energy use buildings. However, it should be noted that the superior performance of green buildings is not universal. Newsham et al. (2013) found that between $28 \%-35 \%$ of LEED-certified buildings were less energy efficient than comparable noncertified buildings. Further, Scofield (2013) found that LEED-certified buildings in New York collectively showed no difference in energy efficiency unless the building had achieved LEED gold (the second highest certification level).

Collectively, the literature suggests that reductions in facility energy use on the order of $10 \%$ to above $30 \%$ are possible through energy efficiency upgrades, building energy management systems, and green building standards. It is assumed that municipal facility energy actions could reduce city facility energy use by $20 \%$ (moderate abatement scenario) to $40 \%$ (high abatement scenario).

\section{Carbon Intensity of Displaced Facility Energy Use}

The potential carbon reductions of displaced electricity consumption are a function of the carbon intensity of the local grid. Local grid carbon intensity is based on regional marginal emissions rates from EPA's eGRID adjusted for EIA projections of reduce grid carbon intensity. ${ }^{39}$ For simplicity, a single emissions factor of $53.06 \mathrm{~kg} \mathrm{CO}_{2} / \mathrm{mmBtu}$ is used for on-site natural gas consumption (EPA 2014). In some cases facility energy use reductions will reduce self-

\footnotetext{
${ }^{38} \mathrm{http}: / /$ www.usgbc.org/articles/green-building-facts .

39 The EIA estimates that the carbon intensity of the U.S. energy supply will decline by about $0.2 \%$ per year through 2040 , in part due to the substitution of natural gas for coal-fired power plants.
} 
consumption of solar power (see Section 7.2.3), in which case the displaced energy would have no carbon emissions. However, it is assumed that all excess solar power is exported to the grid, so that all reductions in building energy use ultimately displace grid electricity use.

\section{Fleet}

Fleet carbon abatement potential is estimated as a function of two factors: baseline carbon emissions and an emissions adjustment factor (Figure 22):

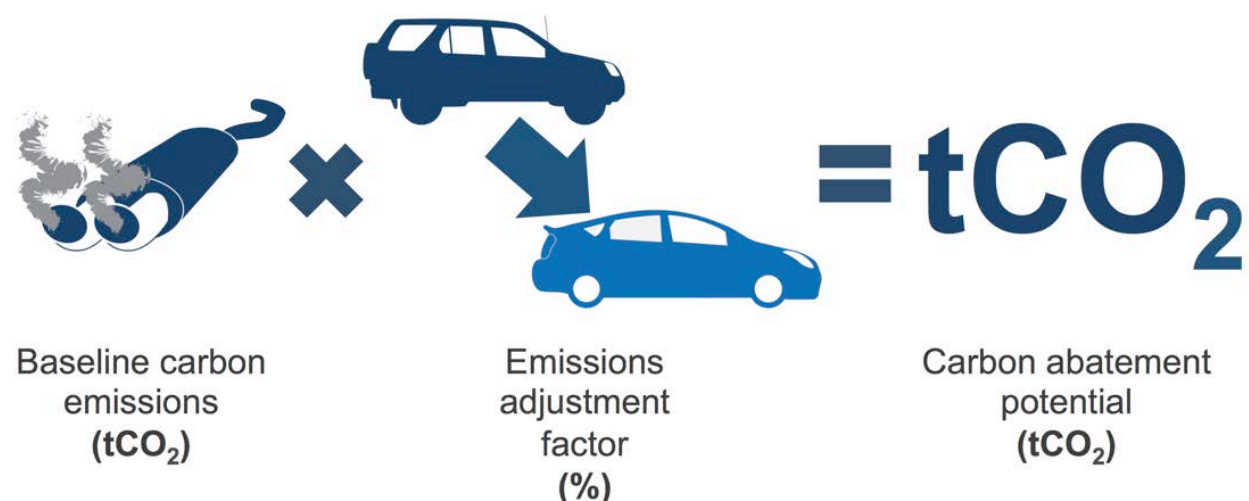

Figure 22. Method for carbon abatement potential estimation of municipal fleet actions

\section{Baseline Carbon Emissions}

Baseline municipal travel is $1.5 \%$ of total city travel, based on City Energy Profile tool data. City Energy Profile transportation fuel use data (gasoline and diesel) is used with emissions factors of $8.78 \mathrm{~kg} \mathrm{CO}_{2} /$ gallon and $10.21 \mathrm{~kg} \mathrm{CO}_{2} /$ gallon for gasoline and diesel, respectively, to establish an estimate of current fleet emissions. It is assumed that city fleet fuel use will increase proportionally to overall VMT (1.04\% per year, see reference case in Section A.1 of Appendix A). It is also assumed that fuel efficiency will improve by about $12 \%$ by 2035 , resulting in a $12 \%$ reduction in city fleet carbon emissions in the baseline (assuming no change in city fleet usage). ${ }^{40}$

\section{Emissions Adjustment Factor}

Based on a method developed in Stone et al. (2009) (see Section A.5 of Appendix A), we assume a hybridization emissions adjustment factor of 0.18 , i.e., a fully hybridized fleet emits about $18 \%$ fewer carbon emissions than a non-hybridized fleet.

Two scenarios of city fleet emissions reductions were modeled based on different levels of city fleet hybridization. Based on current city initiatives (e.g., Atlanta, GA; Boulder, CO; New York, NY), fleet hybridization above 50\% appears practical, and hybridization of up to $100 \%$ is an achievable target. Given that many cities have already partially hybridized their fleets, the analysis is capped at additional fleet hybridization of $75 \%$ of city fleets. It is assumed that cities hybridize $50 \%$ of fleets in the moderate abatement scenario, with the $18 \%$ hybrid adjustment factor this equates to a $9 \%$ reduction in fleet-related carbon emissions. The analysis assumes that

\footnotetext{
${ }^{40}$ Stone et al. (2009) estimated a $31 \%$ increase in stock fleet fuel economy from 2000 to 2050 . It is assumed that $20 \%$ of this increase, or $12 \%$, occurs from 2015 to 2035 .
} 
cities hybridize $75 \%$ of fleets in the high abatement scenario, this equates to a $13.5 \%$ reduction in fleet-related carbon emissions.

\section{Solar Power Procurement}

Similar to methods summarized in Section 6, the carbon abatement potential of city solar power procurement is estimated as a function of the technical potential of solar on city-owned buildings (see Section 6 for a full discussion of the methodology for estimating city-level solar PV technical potential), city solar PV deployment, and the carbon intensity of displaced electricity use:

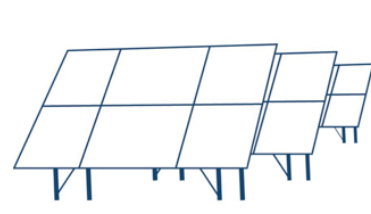

Technical potential (MWh)

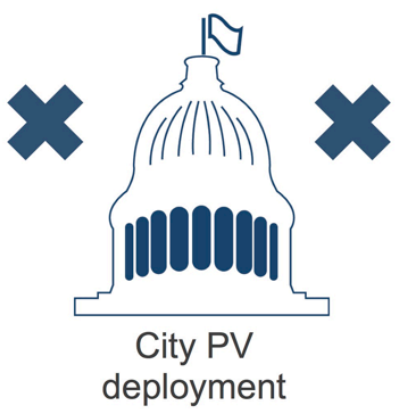

(\%)

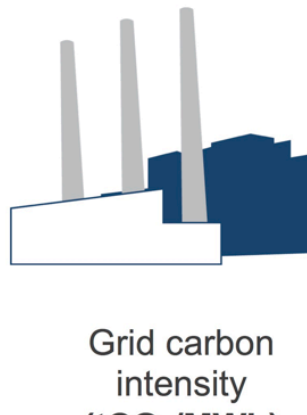

$\left(\mathrm{tCO}_{2} / \mathrm{MWh}\right)$

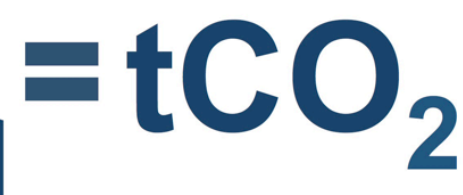

Carbon abatement potential $\left(\mathrm{tCO}_{2}\right)$

Figure 23. Method for carbon abatement potential estimation of municipal solar PV actions

\section{Technical Potential of City Solar PV}

The analysis assumes that solar PV technical potential on city-owned buildings is $1.5 \%$ of citywide technical potential, based on technical potential data from the City Energy Profile tool (see Section A.1 of Appendix A).

\section{City PV Deployment}

Few cities have exploited city-owned solar PV-suitable rooftop space for large-scale solar PV deployment (Farrell and Grimley 2015). Therefore, it is difficult to determine scenarios of potential solar PV deployment on city buildings. Based on City Energy Profile tool data, the small building rooftop technical potential of more than $90 \%$ of cities is below one megawatt (MW). The analysis assumes that city solar procurement policies could result in the deployment of $50 \%$ of city solar PV technical potential (moderate abatement scenario) to $90 \%$ of city solar PV technical potential (high abatement scenario). The analysis does not distinguish between municipal ownership and other procurement forms (e.g., power purchase agreements, where a building owner buys power from solar panels owned by a third party).

\section{Carbon Intensity of Displaced Electricity Use}

The potential carbon reductions of displaced electricity consumption are a function of the carbon intensity of the local grid. Local grid carbon intensity is based on regional marginal emissions rates from EPA's eGRID adjusted for EIA projections of reduced grid carbon intensity (see reference case in Section A.1 of Appendix A). 


\section{Summary of Assumptions}

The key assumptions for the analysis of the carbon abatement potential of municipal action policies are:

- Cities reduce building energy use by $20 \%$ (moderate abatement scenario) to $40 \%$ (high abatement scenario) through energy efficiency upgrades, building energy management systems, and green building standards. The carbon intensity of displaced energy use is based on the carbon intensity of the local grid and an emissions factor of $53.06 \mathrm{~kg}$ $\mathrm{CO}_{2} / \mathrm{mmBtu}$ for on-site natural gas consumption.

- A fully hybridized city fleet emits about $18 \%$ fewer carbon emissions than a nonhybridized fleet. Assuming that 50\% (moderate abatement scenario) to $75 \%$ (high abatement scenario) of the city fleet is hybridized, this equates to carbon emissions reductions of $9 \%$ to $13.5 \%$.

- Cities deploy 50\% (moderate abatement scenario) to $90 \%$ (high abatement scenario) of their technically potential solar PV on city-owned buildings.

\subsection{Results: Carbon Abatement Potential of Municipal Action Policies}

Our analysis suggests city municipal action policies could reduce nationwide carbon emissions by about $10-20 \mathrm{MMT} \mathrm{CO}_{2}$ /year, or about $0.2 \%-0.3 \%$ of 2013 U.S. emissions. ${ }^{41}$ At the city level, the results suggest that an average city can reduce local emissions by $0.5 \%$ (moderate) to $1.0 \%$ (high) relative to current city emissions. Figure 24 illustrates the distributions of city-level carbon abatement potential from municipal actions in the moderate and high abatement scenarios.

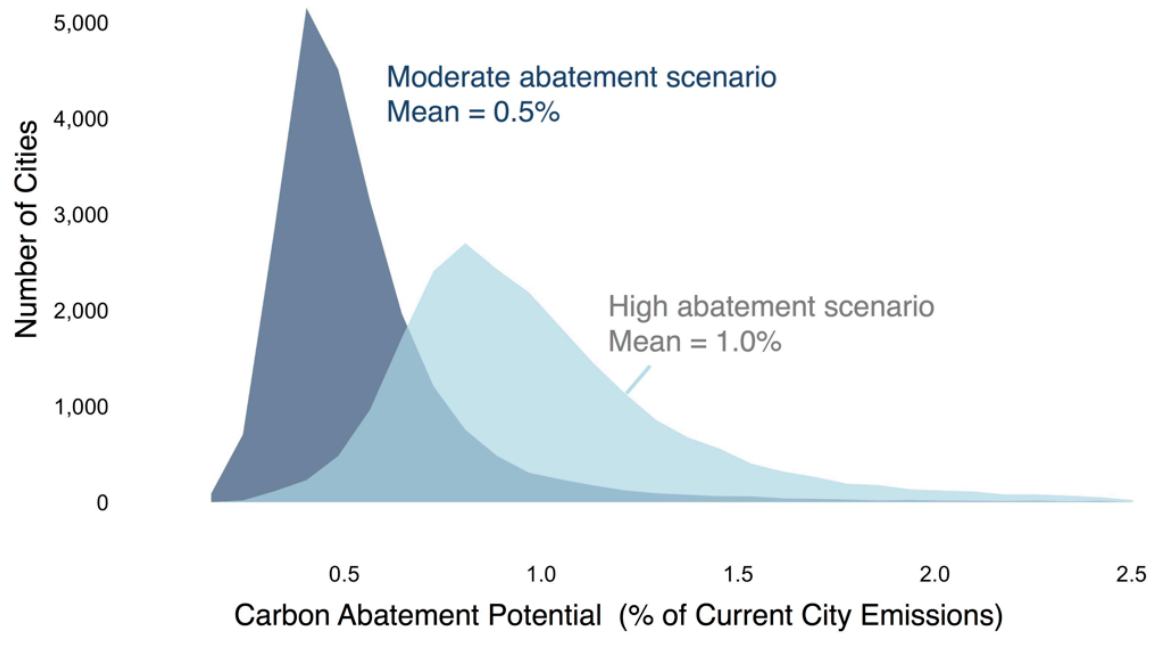

Figure 24. City-level carbon abatement potential distribution of municipal action policies

\footnotetext{
${ }^{41}$ Based on 2013 U.S. greenhouse gas emissions (EPA 2015)
} 


\section{Economic Impact Analysis}

Estimated net economic impacts from city carbon abatement actions in three policy areas are small, indicating associated carbon reductions may be achieved without significant local economic losses or gains.

City actions to reduce carbon emissions have economic impacts, including impacts on city budgets, job impacts, and impacts on energy consumer expenditures. Estimating these impacts relative to implementation costs could help cities prioritize city actions that cost-effectively reduce carbon emissions. Using an input-output approach, we analyze the economic impacts of three policy areas and find that all three have net economic costs and benefits in terms of jobs, earnings, and value added.

The economic analysis suggests that city actions across three of the policy areas considered in this analysis could support between 52,000 net jobs nationally (moderate abatement scenario) and 269,000 net jobs (high abatement scenario) while being implemented and an average of 6,000 jobs (moderate) to 96,000 jobs (high) annually thereafter. After implementation, however, the policy areas show slight reductions in tax payments and property-type income (such as business profits or returns on investments), resulting in national GDP reductions of up to $-\$ 880,000$ in the moderate abatement scenario and $-\$ 3.4$ million under the high abatement scenario.

These employment and GDP figures are not large in the context of current employment and GDP. Employment impacts range from less than $0.03 \%$ of 2015 U.S. employment during implementation to a maximum of $0.1 \%$ thereafter. Associated GDP reductions are less than $0.1 \%$ of 2015 GDP during construction and less than $0.1 \%$ thereafter. Overall, the analysis suggests that the net economic impacts of city carbon abatement actions are minimal and generally slightly positive.

We present the economic analysis in four parts and include additional material in Appendix B. The general method and basic assumptions are outlined in Section 8.1. Economic impacts during implementation are summarized in Section 8.2. Ongoing economic impacts are summarized in Section 8.3. Last, in order to place the results in context, economic impacts are compared with national economic data in Section 8.4.

\subsection{Method}

Economic impact estimates were generated using the IMPLAN input-output (I-O) model (see Section B.2 of Appendix B for a broader discussion of I-O models and their limitations). I-O models require certain key inputs to form a basis of assumptions for the costs and benefits of various actions. Three policy areas were selected for a national-level economic impact analysis based on the availability of valid data inputs: building energy codes, building energy incentives, and municipal actions. ${ }^{42}$ Table 13 shows this subset as well as the assumptions used to estimate impacts for these policy areas in the moderate and high abatement scenarios (see Section B.1 of

\footnotetext{
42 The national level of analysis shows generalized results. State- or local-level analysis would produce different results that stem from a number of factors such as on how large and diverse the local economy is, where funding comes from, and how a policy is implemented.
} 
Appendix B for methodologies for implementation cost assumptions). Construction and other implementation costs are total costs, while savings values are annual.

Table 14. Economic Impact National Assumptions (\$ billions, 2015)

\begin{tabular}{lll}
\hline Assumption & Moderate & High \\
\hline Building Energy Codes & & \\
\hline Implementation cost & $\$ 6$ & $\$ 6$ \\
Construction cost & $\$ 25$ & $\$ 25$ \\
Electricity savings & $\$ 3.9 / \mathrm{yr}$ & $\$ 13 / \mathrm{yr}$ \\
$\quad$ Gas savings & $\$ 0.2 / \mathrm{yr}$ & $\$ 0.6 / \mathrm{yr}$ \\
Building Incentives & & \\
\hline Implementation cost & $\$ 31$ & $\$ 84$ \\
$\quad$ Electricity savings & $\$ 6 / \mathrm{yr}$ & $\$ 16 / \mathrm{yr}$ \\
$\quad$ Gas savings & $\$ 1 / \mathrm{yr}$ & $\$ 4 / \mathrm{yr}$ \\
Municipal Actions & & \\
\hline Implementation cost & $\$ 21$ & $\$ 38$ \\
$\quad$ Electricity savings & $\$ 1 / \mathrm{yr}$ & $\$ 2 / \mathrm{yr}$ \\
$\quad$ Gas savings & $\$ 0.3 / \mathrm{yr}$ & $\$ 0.6 / \mathrm{yr}$ \\
\hline
\end{tabular}

Three impact metrics are reported for each policy area: jobs, earnings, and value added:

- Jobs are total employment, including proprietors and employees of companies and nonprofits. All job numbers reported are for the equivalent of one year.

- Earnings are total earned income, which includes benefits paid to workers.

- Value added is the value of production. It is the same as an industry's contribution to gross domestic product (GDP). Value added consists of earnings, taxes less subsidies, and property-type income (such as profits and returns on capital investments).

City actions may have three types of impacts: direct, indirect, and induced. Impacts are reported both during construction and implementation and annually thereafter.

- Direct impacts are those impacts most closely associated with the policy. Initially, direct impacts include expenditures spent on planning and implementation. For example, direct impacts could include payments to engineers and construction workers. After policy implementation, direct impacts could reflect decreases in demand for services provided by utilities.

- Indirect impacts are secondary or spinoff effects. Indirect impacts reflect economic activity required to support direct effects such as business-to-business services, raw material providers, or service providers. 
- Induced impacts arise from changes in household expenditures. Induced impacts include changes in disposable income caused by paying to implement policies or saving money on electricity or gas.

\subsection{Results: Impacts During Action Implementation}

Implementation costs and resulting economic impacts refer to those incurred during policy implementation. Implementation costs and impacts are calculated for the equivalent of one year. For example, if the impact is 400 jobs created but policy implementation takes two years, the analysis assumes that 200 jobs are created in year one and 200 jobs are created in year two. Implementation costs are associated with two impacts: (1) jobs and other economic activity supported by construction and planning and (2) reduced disposable household income during implementation (assuming policy implementation is financed through incremental tax revenue). All implementation costs and impacts are assumed to be additional. In other words, it is not assumed that cities offset costs through reductions in other parts of local budgets.

Figure 25 shows single-year equivalent up-front job impacts from policy implementation. The chart shows direct combined with indirect employment impacts and induced impacts. Total net impacts are listed. Direct and indirect impacts are driven by increases in demand for specific goods and services. During implementation, direct and indirect impacts are positive due to increases in demand for construction and design as well as subsequent economic activity such as provision of raw materials used in construction and other goods and services provided to construction and design. Induced impacts are driven by changes in disposable household income. Reductions in disposable income reduce the amount that households have available to pay for goods and services provided by industries such as restaurants and entertainment venues. Induced impacts are negative for all policies, as households are assumed to fund these projects through taxes or other mechanisms. Building energy code cost assumptions are the same under the medium and high assumptions, and so impacts are the same. Building incentives and municipal actions, however, have increased expenditure levels in the high abatement scenario. 


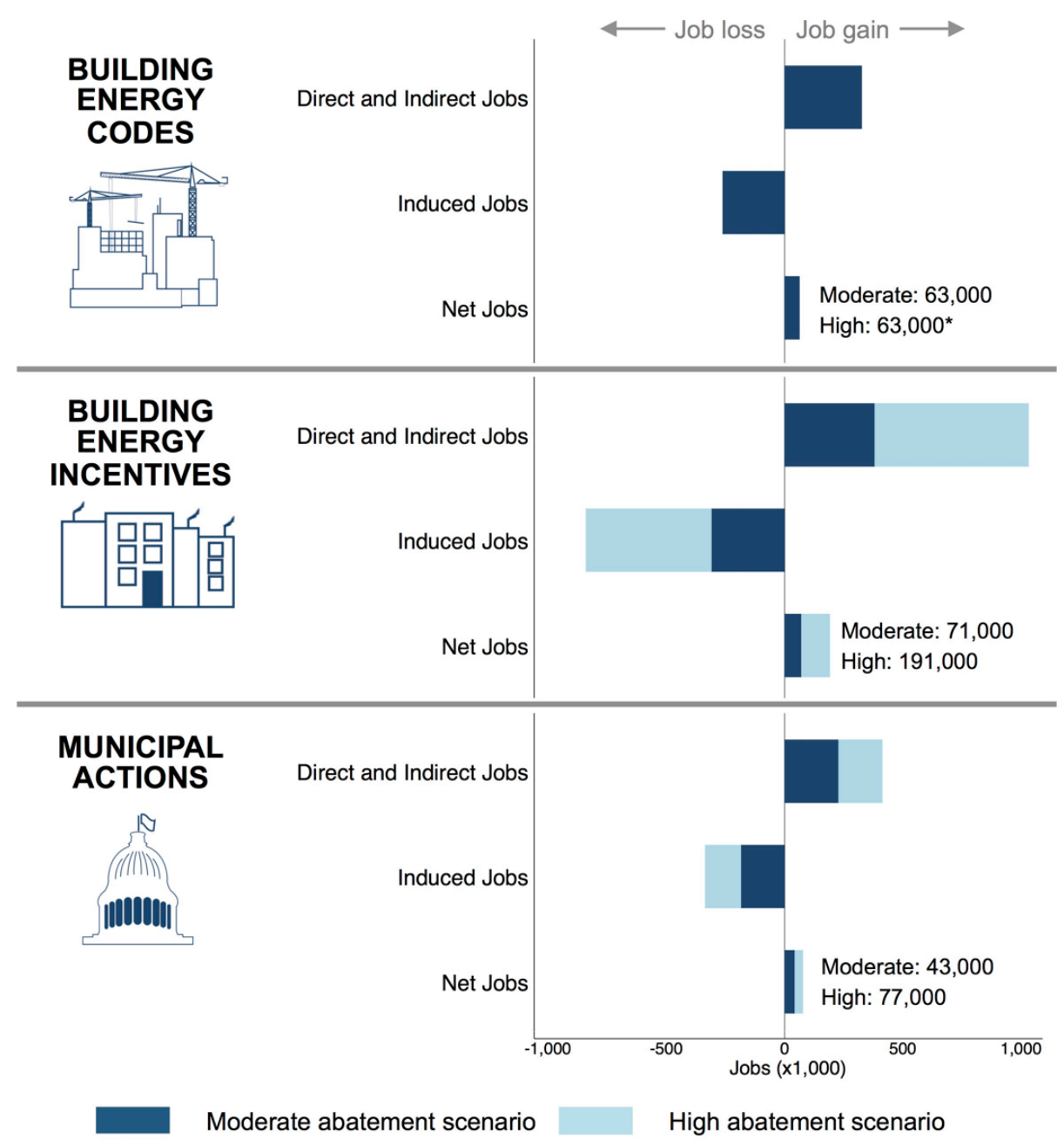
Figure 25. Estimated national employment impacts during implementation of actions in three
policy areas

Employment and other net economic impacts are positive in all three policy areas under the moderate abatement scenario (Table 15), with building incentives supporting the highest net impacts. Building incentives also require the most significant up-front investment during implementation and drive the most significant direct and indirect economic activity — nearly 400,000 direct and indirect jobs as well as $\$ 33$ billion in value added (GDP). Building incentives also have the most significant induced impacts, reducing employment and GDP by a single-year equivalent of nearly 300,000 jobs and $\$ 28$ billion in GDP for a positive net total of 71,000 jobs and $\$ 5$ billion in GDP.

The cost of implementing the building energy codes scenario is $\$ 31$ billion, trailing building incentives by $\$ 4$ billion. These similar costs drive similar impacts: During implementation it supports 63,000 jobs under both the medium and high scenarios as well as $\$ 3$ billion in GDP. 
Despite being the least expensive scenario, the $\$ 22$ billion municipal actions scenario supports more jobs and GDP in the high scenario than building codes: 77,000 and $\$ 5$ billion. This is not the case under the moderate scenario, in which municipal actions drive 43,000 jobs and $\$ 3$ billion in GDP.

Table 15. Impacts During Implementation (Moderate Abatement Scenario) ${ }^{a}$

\begin{tabular}{llrrr}
\hline & & Employment & Earnings & $\begin{array}{l}\text { Value Added } \\
\text { (GDP) }\end{array}$ \\
\hline \multirow{3}{*}{ Building Codes } & Direct & 196,000 & $\$ 12$ & $\$ 15$ \\
& Indirect & 130,000 & $\$ 7$ & $\$ 12$ \\
& Induced & $-262,000$ & $-\$ 14$ & $-\$ 24$ \\
& Total & 63,000 & $\$ 7$ & $\$ 3$ \\
\hline \multirow{3}{*}{ Building } & Direct & 219,000 & $\$ 20$ & $\$ 19$ \\
Incentives & Indirect & 162,000 & $\$ 10$ & $\$ 14$ \\
& Induced & $-309,000$ & $-\$ 16$ & $-\$ 28$ \\
& Total & 71,000 & $\$ 14$ & $\$ 5$ \\
Municipal & Direct & 131,000 & $\$ 12$ & $\$ 12$ \\
Actions & Indirect & 97,000 & $\$ 6$ & $\$ 8$ \\
& Induced & $-185,000$ & $-\$ 10$ & $-\$ 17$ \\
\hline Dotar & Total & 43,000 & $\$ 8$ & $\$ 3$ \\
\hline
\end{tabular}

${ }^{a}$ Dollar figures are \$ billions, 2015.

Table 16 shows impacts during implementation under the high abatement scenario. As with the moderate scenario, building incentives support the highest net value added impact with a net estimate of $\$ 13$ billion, while municipal actions support $\$ 5$ billion in value added. Building incentives support an additional $\$ 38$ billion in worker earnings and municipal actions support $\$ 15$ billion. Earnings are one component of value added. 
Table 16. Impacts During Implementation (High Abatement Scenario) ${ }^{a}$

\begin{tabular}{llrrr}
\hline & & Employment & Earnings & \multicolumn{2}{c}{$\begin{array}{c}\text { Value Added } \\
\text { (GDP) }\end{array}$} \\
\hline \multirow{3}{*}{ Building Codes } & Direct & 196,000 & $\$ 12$ & $\$ 15$ \\
& Indirect & 130,000 & $\$ 8$ & $\$ 12$ \\
& Induced & $-262,000$ & $-\$ 14$ & $-\$ 24$ \\
& Total & 63,000 & $\$ 7$ & $\$ 3$ \\
\hline \multirow{3}{*}{ Building } & Direct & 593,000 & $\$ 55$ & $\$ 53$ \\
Incentives & Indirect & 438,000 & $\$ 26$ & $\$ 37$ \\
& Induced & $-840,000$ & $-\$ 44$ & $-\$ 77$ \\
& Total & 191,000 & $\$ 38$ & $\$ 13$ \\
Municipal & Direct & 237,000 & $\$ 22$ & $\$ 21$ \\
Actions & Indirect & 176,000 & $\$ 10$ & $\$ 15$ \\
& Induced & $-336,000$ & $-\$ 17$ & $-\$ 31$ \\
& Total & 77,000 & $\$ 15$ & $\$ 5$ \\
\hline
\end{tabular}

${ }^{a}$ Dollar figures are \$ billions, 2015.

\subsection{Results: Ongoing Impacts}

Ongoing impacts refer to the ongoing economic impacts that occur after a policy has been implemented. After policy implementation, impacts are annual and assumed to be ongoing. For example, if the impact is 400 jobs created, the analysis assumes an annual and ongoing impact of 400 jobs sustained in year one and each subsequent year.

Two policy impacts are associated with ongoing costs: increased disposable household income from reduced energy expenditures and reduced demand for gas and electricity. Post policyimplementation, consumers spend less on gas and electricity and increase their disposable income. Direct and indirect impacts, then, reflect reductions in demand for electricity while induced impacts reflect increases in disposable household income. As with implementation, cost increases and decreases are assumed to accrue to the population rather than directly decrease or increase government funds or programs.

Annual estimated net employment impacts from all three policy areas are positive, as they are driven by positive induced impacts (Figure 26). In this case, reductions in demand for electricity and gas result in negative direct and indirect employment impacts: $-12,000$ jobs annually under building energy codes, $-25,000$ jobs under building incentives, and $-3,000$ jobs under municipal actions, all in the moderate abatement scenario. The net impacts, however, are 19,000; 33,000; and 6,000 jobs under building energy codes, building incentives, and municipal actions, respectively, in the moderate abatement scenario, driven by increases in induced jobs reflecting an increase in consumer disposable income. Estimated impacts in the high abatement scenario are amplified versions of moderate abatement scenario impacts; net employment impacts are greater and are driven by positive gains in induced rather than losses in direct and indirect 
employment. Building energy codes support 61,000 net annual jobs, building incentives support 86,000 jobs, and municipal actions support 10,000 jobs in the high abatement scenario.

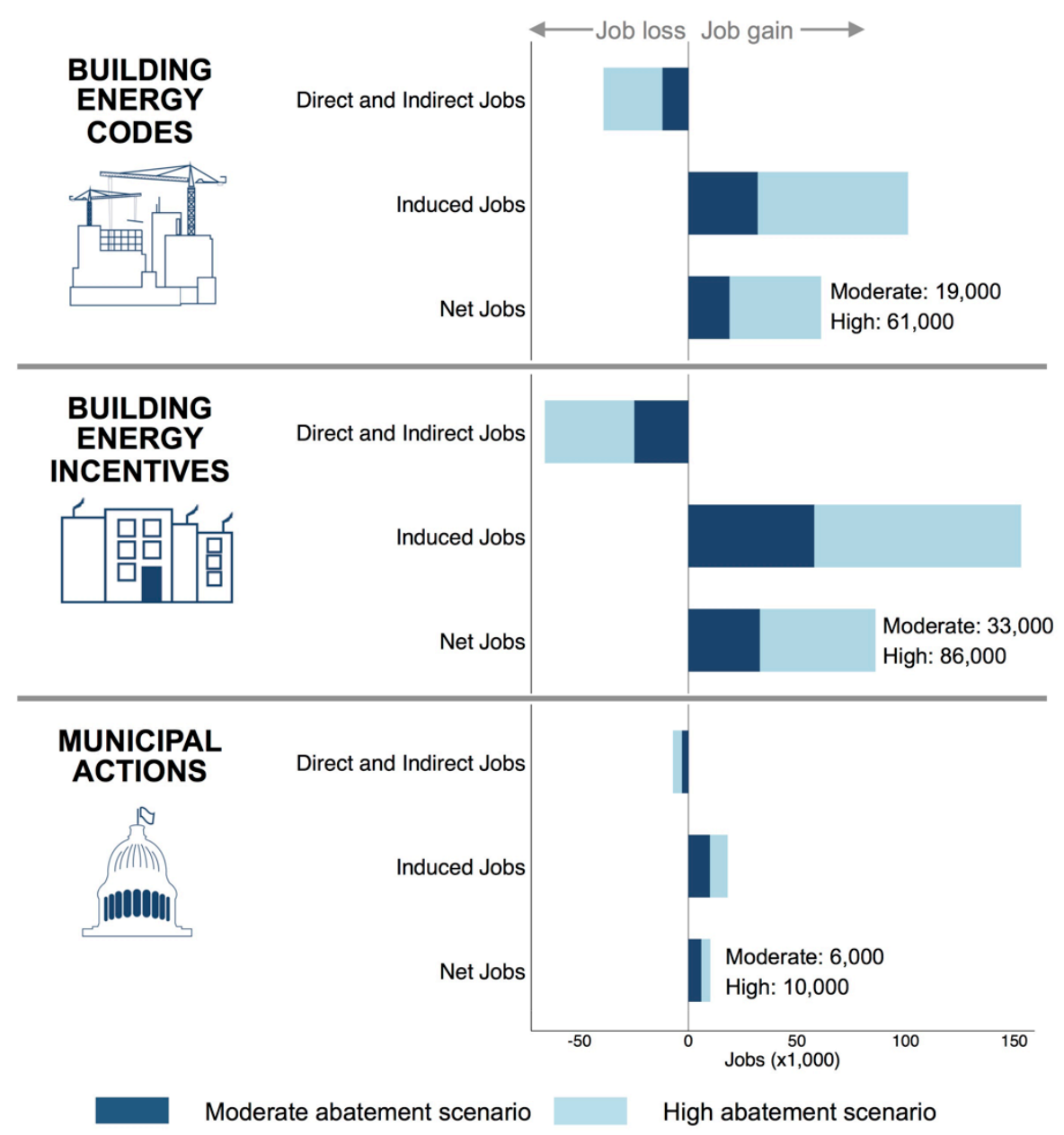

Figure 26. Estimated ongoing national employment impacts for actions in three policy areas

Annual changes in earnings under municipal actions are unchanged despite employment gains (Table 17). Reductions in payments for gas and electricity decrease demand for these products while increasing the amount of money that households have to spend elsewhere. This reflects a transition from relatively high-paying jobs in the gas and electricity sectors, including those that support these industries, to lower-paying jobs in other industries that are supported by increases in household disposable income. The change under building codes and building incentives is $\$ 1$ billion, which is slightly higher than for municipal actions.

Value added typically changes less than income. This is the case under the building energy codes and building incentives policy areas, where estimated changes in value added are $-\$ 1$ billion annually. This decrease is driven by reductions in tax revenue and property-type income. 
Table 17. Ongoing Impacts (Moderate Abatement Scenario) ${ }^{a}$

\begin{tabular}{llrrr}
\hline & & Employment & Earnings & Value Added \\
\hline \multirow{3}{*}{ Building Codes } & Direct & $-3,000$ & $\$ 0$ & $-\$ 2$ \\
& Indirect & $-9,000$ & $-\$ 1$ & $-\$ 2$ \\
& Induced & 32,000 & $\$ 2$ & $\$ 3$ \\
& Total & 19,000 & $\$ 0$ & $-\$ 1$ \\
\hline \multirow{3}{*}{ Building } & Direct & $-8,000$ & $-\$ 1$ & $-\$ 3$ \\
Incentives & Indirect & $-17,000$ & $-\$ 1$ & $-\$ 3$ \\
& Induced & 58,000 & $\$ 3$ & $\$ 5$ \\
& Total & 33,000 & $\$ 0$ & $-\$ 1$ \\
\hline \multirow{3}{*}{ Municipal } & Direct & $-1,000$ & $\$ 0$ & $-\$ 1$ \\
Actions & Indirect & $-2,000$ & $\$ 0$ & $-\$ 1$ \\
& Induced & 10,000 & $\$ 0$ & $\$ 1$ \\
& Total & 6,000 & $\$ 0$ & $\$ 0$ \\
\hline
\end{tabular}

${ }^{a}$ Dollar figures are \$ billions, 2015.

Earnings gains are also positive across the building codes and building incentives policy areas in the high abatement scenario, and value added is less than or equal to these gains (Table 18). Under buildings energy codes value added decreases by $\$ 3$ billion, under building incentives value added decreases $\$ 4$ billion, and under municipal actions, there is no change in either earnings or value added. 
Table 18. Ongoing Impacts (High Abatement Scenario) ${ }^{a}$

\begin{tabular}{llccc}
\hline & & Employment & Earnings & Value Added \\
\hline \multirow{3}{*}{ Building Codes } & Direct & $-10,000$ & $-\$ 1$ & $-\$ 5$ \\
& Indirect & $-29,000$ & $-\$ 3$ & $-\$ 6$ \\
& Induced & 101,000 & $\$ 5$ & $\$ 9$ \\
& Total & 61,000 & $\$ 1$ & $-\$ 3$ \\
\hline \multirow{3}{*}{ Building } & Direct & $-21,000$ & $-\$ 3$ & $-\$ 9$ \\
Incentives & Indirect & $-45,000$ & $-\$ 4$ & $-\$ 9$ \\
& Induced & 153,000 & $\$ 8$ & $\$ 14$ \\
& Total & 86,000 & $\$ 1$ & $-\$ 4$ \\
\hline \multirow{3}{*}{ Municipal } & Direct & $-2,000$ & $\$ 0$ & $-\$ 1$ \\
Actions & Indirect & $-5,000$ & $\$ 0$ & $-\$ 1$ \\
& Induced & 18,000 & $\$ 1$ & $\$ 2$ \\
& Total & 10,000 & $\$ 0$ & $\$ 0$ \\
\hline
\end{tabular}

${ }^{a}$ Dollar figures are \$ billions, 2015.

\subsection{Economic Impacts in Context}

The economic impacts identified in this analysis are small when compared to the U.S. economy as a whole. Table 19 shows value added changes both during implementation and annually thereafter. In 2015, U.S. GDP was $\$ 18$ trillion (BEA 2016). Estimated implementation impacts range from $0.02 \%$ to $0.07 \%$ of this level for the single-year equivalent. Implementation that occurs over multiple years would be an even smaller percentage on an annual basis. Ongoing GDP impacts are even smaller, with an estimated reduction of less than $0.1 \%$. 
Table 19. Estimated Value Added Impacts Compared to 2015 GDP (\$ billions, 2015)

\begin{tabular}{llcccc}
\hline & \multicolumn{2}{c}{$\begin{array}{c}\text { During Implementation } \\
\text { Value Added } \\
\text { Estimate }\end{array}$} & $\begin{array}{c}\text { Value Added as } \% \\
\text { of 2015 GDP }\end{array}$ & $\begin{array}{c}\text { Value Added } \\
\text { Estimate }\end{array}$ & $\begin{array}{c}\text { Value Added as \% } \\
\text { of 2015 GDP }\end{array}$ \\
\hline \multirow{2}{*}{ Moderate } & $\begin{array}{l}\text { Building } \\
\text { Codes } \\
\text { Building } \\
\text { Incentives }\end{array}$ & $\$ 3$ & $0.02 \%$ & $-\$ 0.8$ & $0.00 \%$ \\
& $\begin{array}{l}\text { Municipal } \\
\text { Actions }\end{array}$ & $\$ 3$ & $0.03 \%$ & $-\$ 1.5$ & $-0.01 \%$ \\
\hline $\begin{array}{l}\text { Building } \\
\text { Codes }\end{array}$ & $\$ 3$ & $0.02 \%$ & $-\$ 0.2$ & $0.00 \%$ \\
\hline $\begin{array}{l}\text { Building } \\
\text { Incentives }\end{array}$ & $\$ 13$ & $0.02 \%$ & $-\$ 2.7$ & $-0.01 \%$ \\
$\begin{array}{l}\text { Municipal } \\
\text { Actions }\end{array}$ & $\$ 5$ & $0.07 \%$ & $-\$ 3.9$ & $-0.02 \%$ \\
\hline
\end{tabular}

Employment estimates are similarly small as a percentage of U.S. employment (although they are larger than value added percentages of GDP), which was 146.6 million in 2015 (BEA 2016). ${ }^{43}$ As shown in Table 20, single-year equivalent implementation percentages are less than $0.1 \%$, and annual percentages are $0.1 \%$ or less.

\footnotetext{
${ }^{43}$ Employment estimates from the U.S. Bureau of Economic Analysis were used rather than employment estimates from the U.S. Bureau of Labor Statistics here because the latter do not include workers not covered by state unemployment insurance programs whereas the Bureau of Economic Analysis does include these workers. Workers not covered by the Bureau of Labor Statistics include sole proprietors, most railroad workers, some membership organizations, and some nonprofits. The IMPLAN model does include these workers in employment impact estimates so Bureau of Economic Analysis data are more appropriate for comparison.
} 
Table 20. Estimated Employment Impacts Compared to 2015 National Employment

\begin{tabular}{|c|c|c|c|c|c|}
\hline & & \multicolumn{2}{|c|}{ During Construction } & \multicolumn{2}{|c|}{ Ongoing } \\
\hline & & $\begin{array}{c}\text { Employment } \\
\text { Estimate }\end{array}$ & $\begin{array}{l}\text { Employment } \\
\text { Impact as \% } \\
\text { of } 2015 \\
\text { Employment }\end{array}$ & $\begin{array}{c}\text { Employment } \\
\text { Estimate }\end{array}$ & $\begin{array}{c}\text { Employment } \\
\text { Estimate }\end{array}$ \\
\hline \multirow{3}{*}{ Moderate } & Building Codes & 63,000 & $0.04 \%$ & 19,000 & $0.01 \%$ \\
\hline & $\begin{array}{l}\text { Building } \\
\text { Incentives }\end{array}$ & 71,000 & $0.05 \%$ & 33,000 & $0.02 \%$ \\
\hline & $\begin{array}{l}\text { Municipal } \\
\text { Actions }\end{array}$ & 43,000 & $0.03 \%$ & 6,000 & $0.00 \%$ \\
\hline \multirow{3}{*}{ High } & Building Codes & 63,000 & $0.04 \%$ & 61,000 & $0.04 \%$ \\
\hline & $\begin{array}{l}\text { Building } \\
\text { Incentives }\end{array}$ & 191,000 & $0.13 \%$ & 153,000 & $0.10 \%$ \\
\hline & $\begin{array}{l}\text { Municipal } \\
\text { Actions }\end{array}$ & 77,000 & $0.05 \%$ & 10,000 & $0.01 \%$ \\
\hline
\end{tabular}

While impacts may be small compared to the national economy, this does not mean that they may be insignificant to affected business and individuals. The net employment totals in all scenarios do not necessarily mean that workers will not be displaced. A retail worker supported by household expenditures, for example, cannot necessarily transition easily to being a civil engineer or an electrician. Some regional workforce programs attempt to assist previously employed workers in the transition between occupations. ${ }^{44}$ Others may work with educational institutions such as community colleges to offer curricula that are in line with local demand for certain occupations. Businesses affected by workforce shortages may also set up their own workforce training centers. ${ }^{45}$ Yet these are not necessarily effective for all individuals due to several factors, including geographic mobility, expense, the time involved to obtain training, certifications or degrees, or simply a lack of interest in newer in-demand occupations.

Impacts can also be different at the municipal level. Every region has different mixes of industries and businesses as well as different ways of implementing policies. Construction activity in one city that reduces purchases from another may grow the economy in one region while dampening growth in another. Economic impacts to municipal areas can also vary considerably based on who pays for the implementation and who benefits.

\footnotetext{
${ }^{44}$ An example of this is the Larimer County Workforce Center's Career Transition Services program (http://larimerworkforce.org).

${ }^{45}$ As part of its workforce planning, the New York Power Authority (http://www.nypa.gov/), for example, has its own training program that is free to students and helps fill its workforce needs.
} 


\section{Summary, Conclusions, and Next Steps}

The nationwide implementation of a suite of six commonly implemented city policy areas could reduce U.S. carbon emissions by 210-480 $\mathrm{MMT} \mathrm{CO}_{2} /$ year in 2035 (Figure 27), or about 3\%-7\% of 2013 U.S. emissions. ${ }^{46}$ At the city level, the results suggest the average city could reduce carbon emissions by $7 \%$ (moderate) to $19 \%$ (high) relative to current city-level emissions.

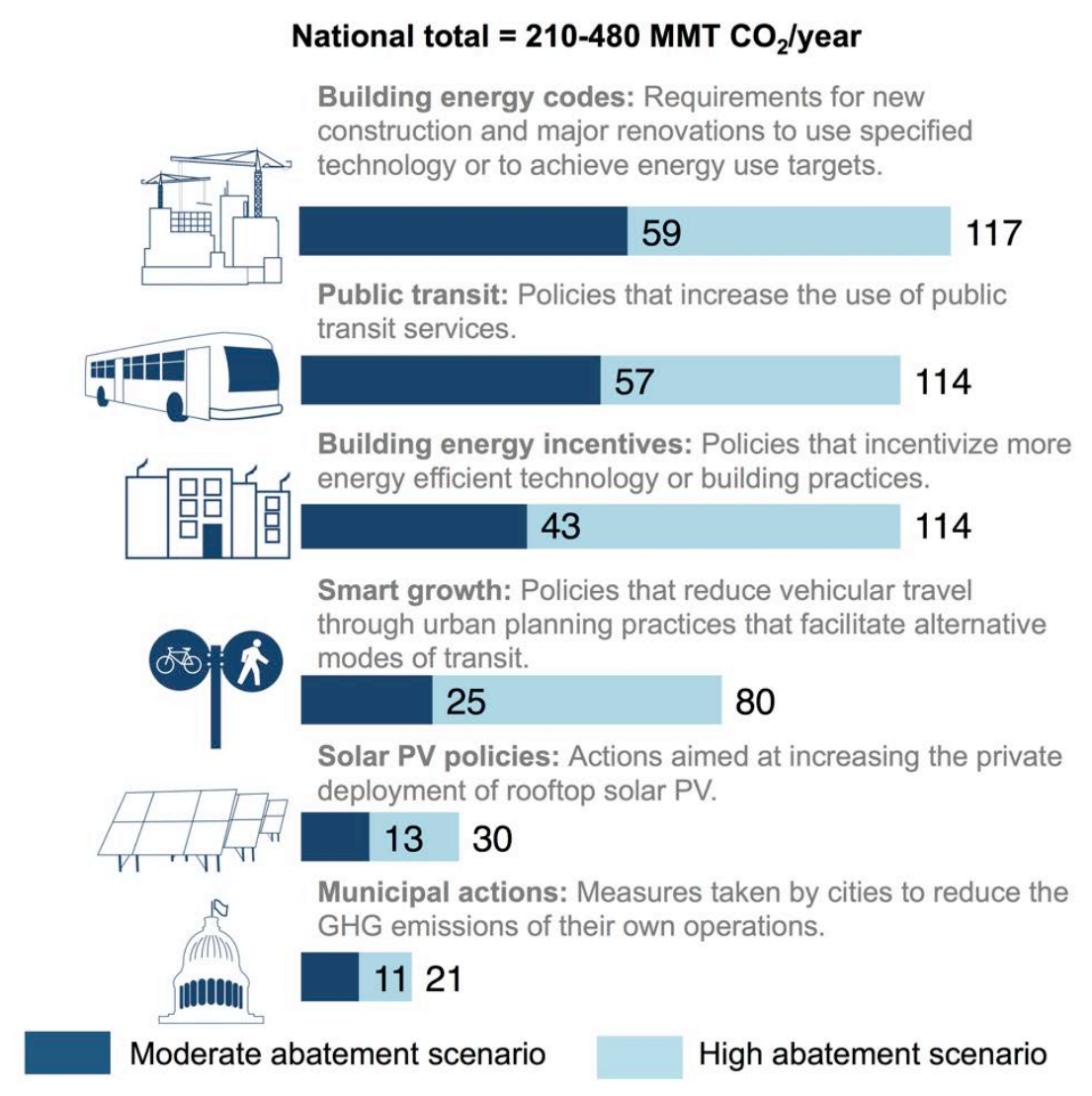

Figure 27. Summary of results

The carbon abatement potential of multiple city policies is not necessarily additive. For example, actions to reduce the carbon intensity of electricity (e.g., solar PV policies) could effectively reduce the carbon abatement potential of actions to reduce building electricity use. The reverse is also possible: multiple policies, when implemented together, could result in greater carbon abatement potential than the sum of their individual potentials. For example, smart growth policies have been shown to increase the use of public transit. Taking account of these policy interactions would be an important step in any city-level analysis.

\subsection{Findings and Conclusions}

Common city-level actions could contribute to national carbon abatement targets. The results suggest that commonly implemented city actions in six policy areas could reduce national carbon emissions by about 210-480 MMT $\mathrm{CO}_{2}$ /year. In the context of U.S. climate commitments under COP21, estimated national abatement potential equates to about $15 \%$ to $35 \%$ of the remaining

\footnotetext{
${ }^{46}$ Based on 2013 U.S. greenhouse gas emissions (EPA 2015).
} 
carbon abatement necessary to achieve the U.S. COP21 target (Figure 28). ${ }^{47}$ Additional city actions such as community choice aggregation, zero energy districts, and multi-level governance strategies could significantly augment the carbon abatement contributions of city actions toward national climate targets. The results suggest that cities may play a pivotal role in progress toward national climate targets.

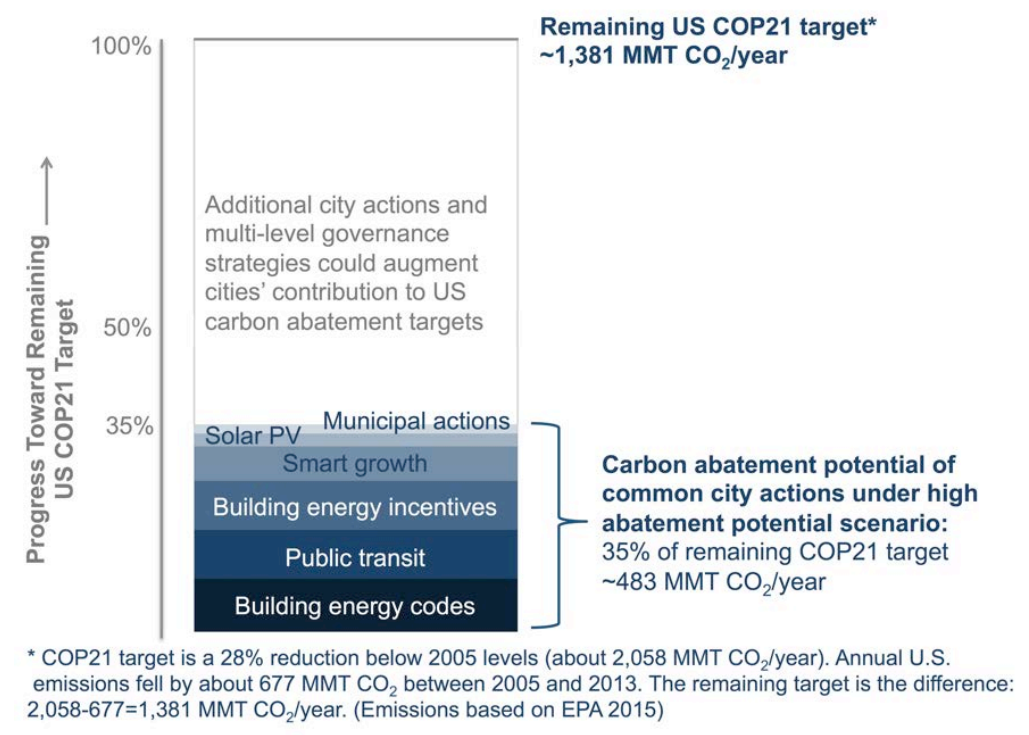

Figure 28. Carbon abatement potential of common city actions in the context of U.S. COP21 targets (high abatement potential scenario)

Commonly implemented city actions are only a first step toward cities achieving their full carbon abatement potential. Our analysis is limited to policies that are crafted and implemented primarily at the city level. However, a city policy role framework developed by Broekhoff, Erickson, and Lee (2015) suggests that city carbon abatement potential can be optimized through a combination of city-level and multi-level governance strategies. The authors found that city carbon abatement could be achieved most efficiently when cities achieve about $20 \%$ of their carbon abatement potential as policy leaders and architects, about $40 \%$ of their carbon abatement potential as critical implementers of supra-city level policies (e.g., state and national), and about $40 \%$ of their carbon abatement potential as strategic partners with other authorities (e.g., utilities and state officials). These findings indicate that multi-level governance strategies could optimize carbon abatement potential from city actions. For example, cities could act as critical implementers to develop local electric vehicle charging infrastructure to help reach national-level vehicle efficiency goals and act as strategic partners by working with local utilities to lower the carbon intensity of the electricity grid. Our analysis does not include such multi-level governance strategies. The total carbon abatement potential of city actions when considering multi-level governance strategies would likely be significantly greater.

\footnotetext{
${ }^{47}$ U.S. COP21 targets and emissions in the U.S. EPA greenhouse gas inventory are measured in terms of carbon dioxide equivalent, which includes other greenhouse gases such as methane and nitrous oxide not measured in this report.
} 
Building energy code measures and public transit expansion have the greatest carbon abatement potential. This finding is consistent with the findings of Erickson and Tempest (2014), who likewise found that residential energy efficiency improvements and public transit policies could achieve the greatest carbon reductions among city actions. Expansions of public transit can have immediate impacts on travel throughout a city, whereas smart growth policies have accumulating impacts as new development zones are converted to smart growth. Further, the impacts of public transit on travel patterns are relatively well documented, which allows us to assume public transit expansion could result in significant mode switching.

Cities may want to consider least-cost polices in their decisions about how to reduce carbon emissions. While some polices may have greater carbon abatement potential, cities may find it more feasible to start with no- or low-cost-to-government policies, such as building energy disclosures. A coordinated approach to city actions could also prioritize city actions based on policies with the greatest positive economic impacts (see Section 8).

City carbon abatement policies have environmental and social co-benefits. Although our emphasis is carbon reduction, city actions to reduce carbon emissions will have environmental and social co-benefits. City policies that reduce demand for electricity also reduce emissions associated with fossil fuel-fired power plants, such as particulate matter, sulfuric acid (the basis of acid rain), and mercury. Further, the incomplete combustion of transportation fuels in automobiles can result in the local formation of ozone or "smog" in cities. Thus, city actions to reduce vehicle use can reduce ozone formation and its related health impacts. These and other environmental and social co-benefits may be factored into the cost-benefit analysis of city actions designed to reduce carbon emissions. Further, carbon reduction policies may directly improve the quality of life of city residents. For example, city actions to reduce transportationrelated emissions through increased use of non-vehicular modes of transit (e.g., walking and biking) can have tangible positive health impacts (Maizlish et al. 2013).

Carbon abatement actions can be implemented with a minimal, and in some cases slightly positive, impact on the national economy. The economic analysis in Section 8 demonstrates that city carbon abatement actions can be achieved without significantly benefiting or hurting the U.S. economy. Employment impacts range from $0.04 \%$ to $0.13 \%$ of 2015 U.S. employment during implementation and zero to $0.1 \%$ thereafter. GDP estimates show net impacts of $0.02 \%$ to $0.07 \%$ of GDP during implementation and impacts from $-0.02 \%$ to zero thereafter (BEA 2016). ${ }^{48}$

City carbon abatement potential is sensitive to national and state policies that affect the carbon intensity of electricity and transportation. Specifically, the U.S. Clean Power Plan and further renewable energy cost reductions could reduce city carbon emissions overall, helping cities achieve their carbon reduction goals.

Additional work is needed to make abatement potential estimates more precise. All of the abatement potential estimates we found span relatively broad ranges, with more than a factor of three in the case of smart growth. These broad ranges represent both ranges in the assumptions but also the range of possible city actions. The moderate abatement scenario is a lower-bound estimate of the minimum achievable abatement possible through the full implementation of the

\footnotetext{
${ }^{48}$ BEA employment and GDP estimates are 2015 levels.
} 
six policy areas. The high abatement scenario is an estimate of the carbon abatement potential of ambitious city actions in the six policy areas using the upper bound of literature-based policy impact estimates. Future work can apply the methodologies we developed with more cityspecific inputs to develop localized estimates of city carbon abatement potential that are more accurate.

\subsection{Next Steps: Using City Energy Data to Prioritize City Actions}

The primary purpose of this analysis is to estimate the national carbon abatement potential of commonly implemented city actions. However, the methodologies developed in Sections 2-7 also provide a foundation for city-level analyses that would allow cities to prioritize actions based on the carbon abatement potential of various options. Figure 29 illustrates the geographic distribution of carbon abatement potential (moderate abatement scenario) in the six policy areas as a percentage of local emissions. Each map shows clear geographic variability with some observable trends. For example, cities in inland northern states show higher carbon abatement potential from building-oriented policies because building energy use (especially natural gas for heating) is a larger contributor to local carbon emissions in these states. The estimated carbon abatement potential of building energy codes is $50 \%$ greater, on average, in Midwestern cities than in other cities. In contrast, transportation is a larger source of carbon emissions in more temperate, coastal states. Further, a variety of factors including local solar resources and electricity rates drive geographic variability in the carbon abatement potential of solar PV policies.

The geographic variability in the estimates further illustrates the need for more precise local analyses. Though some of the geographic variability reflects intuitive spatial patterns, some of the variability may also be due to some of the limitations discussed in Section 1. 

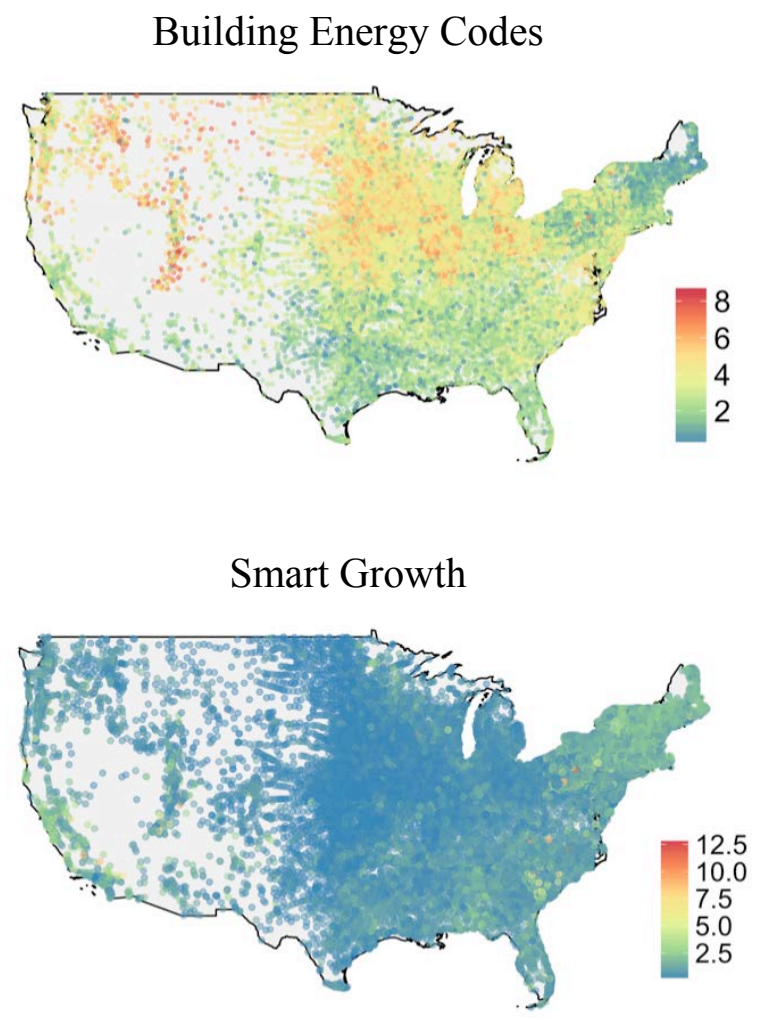

Solar PV Policies

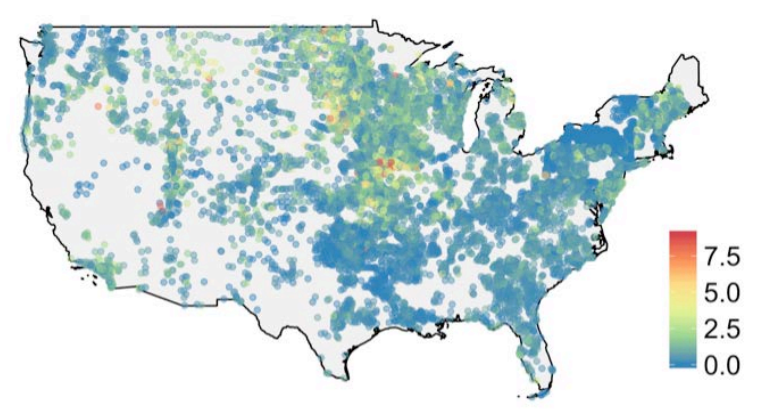

Building Energy Incentives

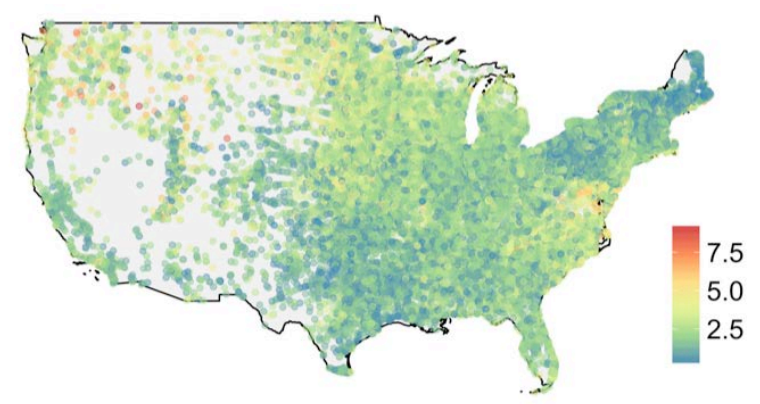

Public Transit

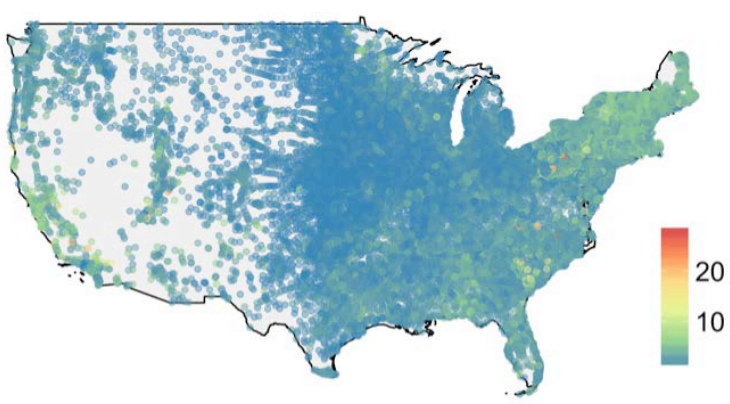

Municipal Actions

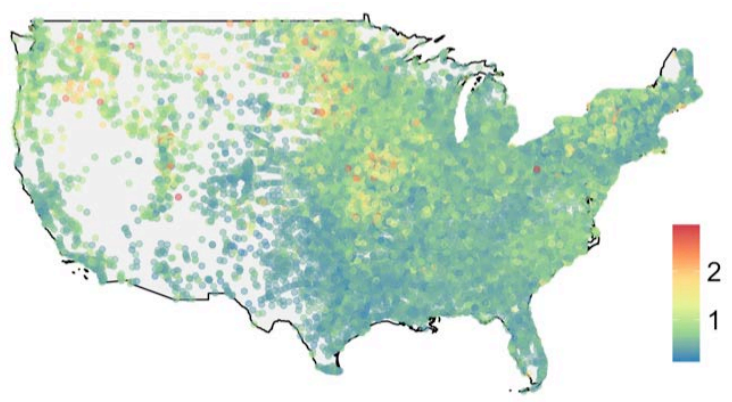

Figure 29. Carbon abatement potential as percentage of city emissions

The carbon abatement potential is not on the same scale for each map.

The geographic variability of carbon abatement potential illustrates the importance of city carbon policy prioritization based on unique city-level factors. Local climatic factors and existing infrastructure may influence city-level decisions about the optimal carbon abatement pathway. Cities may prioritize possible actions based on the largest existing sources of carbon emissions (e.g., natural gas use in northern states), the quality of local renewable resources (e.g., solar resources in the Southwest), or existing infrastructure (e.g., public transit systems in coastal cities). The methodologies developed in this analysis provide a template from which cities can develop more precise local carbon abatement potential estimates with city-level inputs. 


\section{References}

ACEEE (American Council for an Energy Efficient Economy). 2016. The City Energy Efficiency Scorecard.

AFDC (Alternative Fuel Data Center). 2016. "Average Annual Fuel Use of Major Vehicle Categories." http://www.afdc.energy.gov/data/10308.

Alberini, A., C. Towe. 2015. "Information v. Energy Efficiency Incentives: Evidence from Residential Electricity Consumption in Maryland.” Energy Economics 52:530-540. doi: http://dx.doi.org/10.1016/j.eneco.2015.08.013.

Allaire, M., and S.P.A. Brown. 2012. U.S. Energy Subsidies: Effects on Energy Markets and Carbon Dioxide Emissions. Pew Charitable Trusts.

Anderson, D., D. Belzer, O. Livingston, M. Scott. 2014. Assessing National Employment Impacts of Investment in Residential and Commercial Sector Energy Efficiency: Review and Example Analysis. PNNL/23402. Pacific Northwest National Laboratory. Richland, WA.

APTA (American Public Transportation Association). 2015. 2015 Public Transportation Factbook. $66^{\text {th }}$ Edition. APTA.

Arrington, G.B., R. Cervero. 2008. "Effects of TOD on Housing, Parking, and Travel.” Transit Cooperative Research Program. Report 128.

Aznar, A., M. Day, E. Doris, S. Mathur, P. Donohoo-Vallett. 2015. City-Level Energy Decision Making: Data Use in Energy Planning, Implementation, and Evaluation in U.S. Cities. Golden, CO: National Renewable Energy Laboratory. NREL/TP-7A40-

64128. http://www.nrel.gov/docs/fy15osti/64128.pdf.

Bass, F. 1969. "A New Product Growth for Model Consumer Durables.” Management Science 15 (5):215-227.

BCAP (Building Codes Assistance Project). 2008. Commercial Building Energy Codes:

Usability and Compliance Methods. Pacific Northwest National Laboratory.

BEA (U.S. Bureau of Economic Analysis). 2016. National Income and Product Accounts. Retrieved from http://www.bea.gov/iTable/index nipa.cfm.

Bess, R., Z. Ambargis. (2011). Input-Output Models for Impact Analysis: Suggestions for Practitioners Using RIMS II Multipliers. Southern Regional Science Association Conference. Retrieved from http://www.bea.gov/papers/pdf/wp iomia rimsii 020612.pdf.

Broekhoff, D., P. Erickson, C.M. Lee. 2015. What Cities Do Best: Piecing Together an Efficient Global Climate Governance. Seattle, WA: Stockholm Environmental Institute.

BTS (U.S. Bureau of Transportation Statistics). 2016a. "U.S. Passenger Miles." —. 2016b. "U.S. Vehicle Miles." 
Burkhardt, J., R. Wiser, N. Darghouth, C.G. Dong, J. Honeycutt. 2015. "Exploring the impact of permitting and local regulatory processes on residential solar prices in the United States." Energy Policy 78:102-112.

C40 Cities. 2015. Urban Efficiency: A Global Survey of Building Energy Efficiency Policies in Cities. C40 Cities. November 19. http://www.c40.org/blog_posts/c40-and-tokyo-highlight-cityactions-on-building-energy-efficiency-in-new-report.

Cambridge Systematics Inc. 2009. Moving Cooler: An Analysis of Transportation Strategies for Reducing Greenhouse Gas Emissions. Washington, D.C.: The Urban Land Institute.

CEP (City Energy Project). 2014. The City Energy Project Assessment Methodology for Energy Code Compliance in Medium to Large Cities. CEP.

Cervero, R., E. Guerra. 2011. Urban Densities and Transit: A Multi-Dimensional Perspective. Berkeley, CA: UC Berkeley Center for Future Urban Transport. Working Paper UCB ITS-VWP2011-6.

Choi Granade, H., J. Creyts, A. Derkach, P. Farese, S. Nyquist, K. Ostrowski. 2009. Unlocking Energy Efficiency in the U.S. Economy. McKinsey \& Company.

Ciochetti, B.A., M.D. McGowan. 2010. "Energy Efficiency Improvements: Do They Pay?" Journal of Sustainable Real Estate 2 (1):305-333.

Coller, M., M. Williams. 1999. "Eliciting Individual Discount Rates.” Experimental Economics 2:107-127.

Cox, M., M.A. Brown, X. Sun. 2013. "Energy Benchmarking of Commercial Buildings: A LowCost Pathway Toward Urban Sustainability.” Environmental Research Letters 8. doi:10.1088/1748-9326/8/3/035018.

CPUC (California Public Utilities Commission). 2006. California Energy Efficiency Evaluation Protocols: Technical, Methodological, and Reporting Requirements for Evaluation Professionals. San Francisco, CA: State of California Public Utilities Commission.

DOE (U.S. Department of Energy). 2010. Measuring State Energy Code Compliance. DOE.

- 2012. 2011 Buildings Energy Data Book. DOE.

- 2013. 90\% Compliance Pilot Studies: Final Report. DOE. DOE/EE-0929

. 2015. New York City Benchmarking and Transparency Policy Impact Evaluation Report. DOE. DOE/EE-1221.

- 2015a. Building Energy Codes Program: Single Family Residential Energy Code Field Study. DOE. Webinar, 12/7/15. 
-2016. How City-Led Efficiency Efforts Can Support State Climate and Energy Planning. DOE.

_. 2016a. "Residential Energy Code Field Study." DOE.

DOT (U.S. Department of Transportation). 2010. Transportation's Role in Reducing U.S.

Greenhouse Gas Emissions. DOT. Volume 1.

—.2016. Average Fuel Efficiency of U.S. Light Duty Vehicles.

EIA (U.S. Energy Information Administration). 2012. Commercial Buildings Energy

Consumption Survey.

—. 2015. Annual Energy Outlook.

Elder, E., W. Butcher. 1989. "Including the Economic Impact of Cost Paying in Regional InputOutput Analysis.” Western Journal of Agricultural Economics. 14(1): 78-84.

EPA (U.S. Environmental Protection Agency). 2012. Residential Construction Trends in America's Metropolitan Regions. EPA.

EPA. 2014. Emission Factors for Greenhouse Gas Inventories. EPA.

—. 2015. Inventory of U.S. Greenhouse Gas Emissions and Sinks. Washington, D.C.: EPA.

Erickson, P., K. Tempest. 2014. Advancing Climate Ambition: How City-Scale Actions Can Contribute to Global Climate Goals. Seattle, WA: Stockholm Environmental Institute.

Ewing, R., K. Bartholomew, S. Winkelman, J. Walters, D. Chen. 2008. Growing Cooler: The Evidence on Urban Development and Climate Change. Washington, D.C.: The Urban Land Institute.

Farrell, J., M. Grimley. 2015. Public Rooftop Revolution. Institute for Local Self-Reliance.

Feldman, D.; G. Barbose; R. Margolis; M. Bolinger; D. Chung; R. Fu; J. Seel; C. Davidson; N. Darghouth; R. Wiser. 2015. Photovoltaic System Pricing Trends. Golden, CO: NREL. NREL/PR-6A20-64898.

Frederick, S., G. Loewenstein, T. O'Donoghue. 2002. "Time Discounting and Time Preference: A Critical Review.” Journal of Economic Literature 40:351-401.

Gagnon, P., R. Margolis, J. Melius, C. Phillips, R. Elmore. 2016. Rooftop Solar Photovoltaic Technical Potential in the United States: A Detailed Assessment. Golden, CO: NREL. NREL/TP-6A20-65298.

Gately, C., L. Hutyra, I. Wing. 2015. "Cities, Traffic, and CO2: A Multidecadal Assessment of Trends, Drivers, and Scaling Relationships." PNAS 112 (16):4999-5004. doi: www.pnas.org/cgi/doi/10.1073/pnas.1421723112. 
George, K. 2015. Economic Interrelationships and Impacts of the Aviation/Aerospace Industry in the State of Florida using Input-Output Analysis. Embry-Riddle Aeronautical University Dissertations and Theses. Paper 51.

German, J. 2015. Hybrid Vehicles: Technology Development and Cost Reduction. The International Council on Clean Transportation. Technical Brief No. 1, July 2015.

Gilbraith, N., I.L. Azevedo, P. Jaramillo. 2014. "Evaluating the Benefits of Commercial Building Energy Codes and Improving Federal Incentives for Code Adoption." Environmental Science \& Technology 48:14121-14130. doi: dx.doi.org/10.1021/es502894m.

Gillingham, K., R. Newell, K. Palmer. 2006. "Energy Efficiency Policies: A Retrospective Examination." Annual Review of Environment and Resources 31:161-192.

Gilman, P., A. Dobos. 2012. System Advisor Model, SAM 2011.12.2: General Description. Golden, CO: National Renewable Energy Laboratory. NREL/TP-6A20-

53437. http://www.nrel.gov/docs/fy12osti/53437.pdf.

Hayes, S., S. Nadel, C. Grande, K. Hottel. 2011. What Have We Learned from Energy Efficiency Financing Programs? Washington, D.C.: ACEEE.

Hernandez, R., M. Hoffacker, C. Field. 2015. "Efficient use of land to meet sustainable energy needs.” Nature Climate Change. 5:353-358.

Hooper, B., F. Apaliski, L. Hirsch, H. Gurfel, M. Brill, C. Liu, M. Henn. 2015. San Francisco Existing Commercial Buildings Performance Report. SF Environment.

ICMA (International City/County Management Association). 2012. ICMA Solar Survey of Local Governments 2011. ICMA.

—. 2016. Local Government Sustainability Practices, 2015 Summary Report. ICMA.

IMT (Institute for Market Transformation). 2011. Third-Party Performance Testing: A Case Study of Residential Energy Code Enforcement in Austin, Texas. Washington, D.C.: IMT. http://www.imt.org/uploads/resources/files/CaseStudy1.pdf.

Jacobsen, G., M. Kotchen. 2013. "Are Building Codes Effective at Saving Energy? Evidence from Residential Billing Data in Florida." The Review of Economics and Statistics 95(1):34-49.

Jones, C., D. Kammen. 2014. "Spatial Distribution of U.S. Household Carbon Footprints Reveals Suburbanization Undermines Greenhouse Gas Benefits of Urban Population Density." Environmental Science \& Technology 48:895-902. doi: dx.doi.org/10.1021/es4034364.

Hoffman, I., S. Schiller, A. Todd, M. Billingsley, C. Goldman, L. Schwartz. 2015. Energy Savings Lifetimes and Persistence: Practices, Issues and Data. Lawrence Berkeley National Lab.

Kingsley, G.T., B.X. Williams. 2007. Policies for Affordable Housing in the District of Columbia: Lessons from Other Cities. The Urban Institute. 
Kneifel, J. 2011. "Beyond the code: Energy, carbon, and cost savings using conventional technologies." Energy and Buildings 43:951-959.

Kneifel, J. 2014. "Life-Cycle Cost Implications of More Stringent State Energy Codes.” ASTM Ideas to Impacts Symposium, New Orleans, LA.

Levinson, H., S. Zimmerman, J. Clinger, S. Rutherford, R. Smith, J. Cracknell, R. Soberman. 2003. Bus Rapid Transit Volume 1: Case Studies in Bus Rapid Transit. Transit Cooperative Research Program. Report 90

Li, H., H. Yi. 2014. "Multilevel governance and deployment of solar PV panels in U.S. cities." Energy Policy 69:19-27.

Litman, T. 2015. Evaluating Public Transit as an Energy Conservation and Emission Reduction Strategy. Victoria Transport Policy Institute.

- 2015a. Smart Growth Reforms. Victoria Transport Policy Institute.

Lopez, A., B. Roberts, D. Heimiller, N. Blair, G. Porro. 2012. U.S. Renewable Energy Technical Potentials: A GIS-Based Analysis. Golden, CO: National Renewable Energy Laboratory. NREL/TP-6A20-51946. http://www.nrel.gov/docs/fy12osti/51946.pdf.

Maizlish, N., J. Woodcock, S. Co, B. Ostro, A. Fanai, C. Imeche, D. Fairley. 2013. "Health Cobenefits and Transportation-Related Reductions in Greenhouse Gas Emissions in the San Francisco Bay Area.” American Journal of Public Health 103 (4):703-709.

McGraw Hill Construction. 2011. Business Case for Energy Efficient Building Retrofit and Renovation. DOE.

Mendon, V., R. Lucas, S. Goel. 2013. Cost-Effectiveness Analysis of the 2009 and 2012 IECC Residential Provisions: Technical Support Document. Richland, WA: PNNL.

Mendon, V., A. Selvacanabady, M. Zhao, Z.T. Taylor. 2015. National Cost-Effectiveness of the Residential Provisions of the 2015 IECC. Richland, WA: Pacific Northwest National Laboratory. PNNL-22068.

Misuriello, Ha., S. Penney, M. Eldridge, B. Foster. 2010. "Lessons Learned from Building Energy Code Compliance and Enforcement Evaluation Studies.” ACEEE Summer Study on Energy Efficiency in Buildings.

Nealer, R., D. Reichmuth, D. Anair. 2015. Cleaner Cars from Cradle to Grave: How Electric Cars Beat Gasoline Cars on Lifetime Global Warming Emissions. Cambridge, MA: The Union of Concerned Scientists.

OFM (State of Washington Office of Financial Management). 2002. The Input-Output Table for Impact Analysis. 
OSE (Seattle Office of Sustainability and Environment). 2014. 2011/2012 Seattle Building Energy Benchmarking Analysis Report. Seattle Office of Sustainability and Environment.

Peak, M., C. Henke, L. Wnuk. Bus Rapid Transit Ridership Analysis. DOT. FTA-CA-70682004.1.

PNNL (Pacific Northwest National Laboratory). 2013. End Use Table Data.

Ramaswami, A., M. Bernard, A. Chavez, T. Hillman, M. Whitaker, G. Thomas, M. Marshall. 2012. "Quantifying Carbon Mitigation Wedges in U.S. Cities: Near-Term Strategy Analysis and Critical Review.” Environmental Science \& Technology (46):3629-3642.

Rogers, E.M. 2003. Diffusion of Innovations, 5th ed. New York, NY: Free Press

Salon, D., M. Boarnet, S. Handy, S. Spears, G. Tal. 2012. "How do Local Actions Affect VMT? A Critical Review of the Empirical Evidence." Transportation Research Part D 17:495-508. doi: http://dx.doi.org/10.1016/j.trd.2012.05.006.

Santos, A., N. McGuckin, H.Y. Nakamoto, D. Gray, S. Liss. 2009. Summary of Travel Trends: 2009 National Household Travel Survey. DOT. FHWA-PL-11-022.

Schwartz, L., G. Leventis, S.R. Schiller, E.M. Fadrhonc. 2016. SEE Action Guide for States: Energy Efficiency as a Least-Cost Strategy to Reduce Greenhouse Gases and Air Pollution and Meet Energy Needs in the Power Sector. State and Local Energy Efficiency Action Network.

Sigrin, B., E. Drury. 2014. "Diffusing into New Markets: Economic Returns Required by Households to Adopt Rooftop Photovoltaics.” AAAI Fall Symposium Series.

Stellberg, S. 2013. Assessment of Energy Efficiency Achievable from Improved Compliance with U.S. Building Energy Codes: 2013-2030. Washington, D.C.: Institute for Market Transformation.

Stone, B., A. Mednick, T. Holloway, S. Spak. 2009. "Mobile Source CO2 Mitigation through Smart Growth Development and Vehicle Fleet Hybridization." Environmental Science and Technology 43:1704-1710.

Therkelsen, P., A. McKane, R. Sabouni, T. Evans, P. Scheihing. 2013. Assessing the Costs and Benefits of the Superior Energy Performance Program. Berkeley, CA: LBNL. LBNL-6349E.

TRB (Transportation Research Board). 2009. Driving and the Built Environment: The Effects of Compact Development on Motorized Travel, Energy Use, and CO2 Emissions. Washington, D.C.: TRB.

TRB. . 2013. Traveler Response to Transportation System Changes Handbook. Third Edition. 
Vine, E., J. Eto, L. Shown, R. Sonnenblick, C. Payne. 1994. "Evaluation of Commercial Lighting Programs: A DEEP Assessment.” 1994 Summer Study on Energy Efficiency in Buildings. Asilomar, CA: American Council for an Energy Efficient Economy.

Wilcox, S., W. Marion. 2008. Users Manual for TMY3 Data Sets. Golden, CO: National Renewable Energy Laboratory. NREL/TP-581-43156.Wiser, R., C. Dong. 2013. The Impact of City-Level Permitting Processes on Residential Photovoltaic Installation Prices and Development Times. Berkeley, CA: LBNL. LBNL-6140E.

York, D., M. Molina, M. Beubauer, S. Nowak, S. Nadel, A. Chittum, N. Elliott, K. Farley, B. Foster, H. Sachs, P. Witte. 2013. Frontiers of Energy Efficiency: Next Generation Programs Reach for High Energy Savings. Washington, D.C.: ACEEE.

Zhang, J., R. Athalye, R. Hart, M. Rosenberg, Y. Xie, S. Goel, V. Mendon, and B. Liu. 2013. Energy and Energy Cost Savings Analysis of the IECC for Commercial Buildings. Richland, WA: Pacific Northwest National Laboratory. PNNL-22760.

Zhang, J., Y. Xie, R. Athalye, J. Zhuge, M. Rosenberg, R. Hart, and B. Liu. 2015. Energy and Energy Cost Savings Analysis of the 2015 IECC for Commercial Buildings. Richland, WA: Pacific Northwest National Laboratory. PNNL-24269 


\section{Appendix A. Supplementary Materials: Data, Methods, and Results}

This appendix provides supplementary materials for data and methods used in this analysis.

\section{A.1 Reference Case Assumptions}

All estimates are in terms of $\mathrm{tCO}_{2}$ abatement and are relative to a 2035 reference case that is representative of what emissions would be in 2035 absent a city policy. Current year (2015) estimates for building energy use and vehicular travel were established using the City Energy Profile data. A 2035 reference case was then projected assuming residential and commercial building energy use increases by 16\% (DOE 2012) and VMT increase by 1.04\%/year from 2015 to 2035 (FHWA 2015). Private vehicles were assumed to comprise 99\% of VMT (BTS 2016b). Current city-level emissions are estimated based on City Energy Profile data.

For grid carbon intensity, a 2015 estimate was established using emissions factors for nonbaseload electricity from EPA's eGRID. A grid carbon intensity factor was assigned to each city based on the relevant eGRID subregion. A 2035 reference case was then projected, assuming grid carbon intensity will drop by $0.2 \%$ year or about $4 \%$ by 2035 , based on the reference case from the 2015 EIA Annual Energy Outlook (EIA 2015). For example, the 2015 non-baseload carbon intensity in the Midwest Reliability Organization West region is $891 \mathrm{~kg} \mathrm{CO}_{2} / \mathrm{MWh}$, and the projected 2035 non-baseload carbon intensity for the same region is $891 \times 0.96=855 \mathrm{~kg}$ $\mathrm{CO}_{2} / \mathrm{MWh}$.

\section{A.2 Building Energy Code Supplementary Materials: Energy Use Reductions between Building Code Vintages}

Estimates of the incremental change in building energy use from a building code update can be based on empirical studies of energy use or building energy use modeling. Empirical studies have measured energy use before and after a building code change to evaluate the energy use impacts of different building codes (e.g., Jacobsen and Kotchen 2013). Such studies are limited to specific research areas and are not easily applicable to different code updates in different climatic conditions. We therefore focus on modeling approaches.

The Pacific Northwest National Laboratory used the DOE EnergyPlus building energy simulation tool to model the energy use reductions of incremental changes between "vintages" (the year in which the code was released) of the International Energy Conservation Code (IECC) (Mendon, Lucas, and Goel 2013; Zhang et al. 2013; Mendon et al. 2015; Zhang et al. 2015). Tables A-1 and A-2 summarize the findings of these and other studies of the building energy reduction effects of updated building code vintages.

Table A-1 summarizes the main findings from the literature for reductions in commercial building energy use between building code vintages. Although significant variation exists, the literature suggests incremental building code updates generally result in an average commercial building energy use reduction of about $10 \%$. 
Table A-1. Estimated Energy Use Reductions from Commercial Building Code Update Studies

\begin{tabular}{|c|c|c|c|}
\hline Existing Code & Replacement Code & Energy Use Reduction & Source \\
\hline ASHRAE 90.1-2004 & ASHRAE 90.1-2007 & $3.2 \%$ & Kneifel (2011) \\
\hline ASHRAE 90.1-2004 & $\begin{array}{l}\text { LEC (beyond } \\
\text { ASHRAE 90.1-2007) }\end{array}$ & $10.5 \%-34 \%$ & Kneifel (2014) \\
\hline IECC 2006 & IECC 2009 & $8.7 \%$ & Zhang et al. (2013) \\
\hline IECC 2009 & IECC 2012 & $11.9 \%$ & Zhang et al. $(2013,2015)$ \\
\hline IECC 2012 & IECC 2015 & $11.2 \%$ & Zhang et al. (2015) \\
\hline
\end{tabular}

Tale A-2 summarizes literature findings for energy use reductions for residential buildings between building code vintages. Energy use reductions for residential buildings exhibit far more variability than commercial buildings. DOE (2012) reported that the 2012 IECC made a significant (24\%) reduction in energy use relative to the 2009 IECC, while Mendon et al. (2015) found that the 2015 IECC made little impact relative to the 2012 IECC.

Table A-2. Estimated Energy Use Reductions from Residential Building Code Update Studies

\begin{tabular}{llll}
\hline Existing code & Replacement code & Energy use reduction & Source \\
\hline IECC 2006 & IECC 2009 & $10.8 \%$ & DOE (2012) \\
IECC 2009 & IECC 2012 & $23.9 \%$ & DOE (2012) \\
IECC 2012 & IECC 2015 & $0.98 \%$ & Mendon et al. (2015) \\
\hline
\end{tabular}

In Section 2, the following equation is used to model the energy realization rate:

$$
E R R=1+\frac{E U I_{R}-E U I_{A}}{E U I_{R}}
$$

Where $E R R$ is the energy realization rate, $E U I_{R}$ is the energy use intensity required by the relevant building code, and $E U I_{A}$ is the EUI achieved in the new building or renovation. Written this way, the EUI achieved may be written as a function of required energy use:

$$
E U I_{A}=(2-E R R) E U I_{R}
$$

So, for example, if EUI achieved is $110 \%$ greater than EUI required, the realization rate is $90 \%$. The equation written this way allows us to determine the energy realization rate as a function of only the required and measured energy use intensities. In other words, the equation does not require any assumptions about existing building energy use. For example, if the measured EUI is $50 \%$ greater than the required EUI, the ERR is 50\% regardless of the magnitude of the EUI. 
We can manipulate the equation as a function of current energy use. Let $E U I_{E}$ represent the energy use intensity of buildings under some existing building code. Based on the literature, assume that $E U I_{R}$ is $90 \%$ of $E U I_{E}$, such that $E U I_{R}=0.9 E U I_{E}$. Further assume that $E R R=0.9$. Then:

$$
0.9=1+\frac{0.9 E U I_{E}-E U I_{A}}{0.9 E U I_{E}}
$$

Solving for $E U I_{A}$ in terms of $E U I_{E}$ gives:

$$
E U I_{A}=0.99 E U I_{E}=1.1 E U I_{R}
$$

In other words, under these assumptions an energy realization rate of $90 \%$ implies that new construction and major renovation buildings use 10\% more energy than what is required by code, or 9 percentage points greater in terms of existing energy use.

In the moderate abatement scenario, it is assumed that city actions increase the energy realization rate to $100 \%$, such that $E U I_{A}=E U I_{R}=0.9 E U I_{E}$. In other words, the moderate abatement scenario equates to a 9 percentage point reduction in energy use relative to the counterfactual situation $(0.99-0.9=0.09)$. In the high abatement scenario, it is assumed that city actions increase the energy realization rate to $110 \%$, such that $E U I_{A}=1.1 E U I_{R}$. It can be shown that:

$$
1.1=1+\frac{0.9 E U I_{E}-E U I_{A}}{0.9 E U I_{E}} \rightarrow E U I_{A}=0.81 E U I_{E}
$$

That is, an energy realization rate of $110 \%$ in this scenario implies an energy use reduction of 18 percentage points relative to the counterfactual $(0.99-0.81=0.18)$.

\section{A.3 Smart Growth Supplementary Materials: Assumptions for Carbon Intensity of Displaced Travel}

The EIA forecasts that by 2040 about $79 \%$ of vehicles will be powered by gasoline, about $10 \%$ by E85 ethanol, about $5 \%$ by electricity, about $4 \%$ by diesel, and that about $2 \%$ of vehicles will be plug-in hybrids (EIA 2015). Table A-3 summarizes a methodology for a weighted carbon intensity per mile for vehicles in 2035 based on the EIA forecasted vehicle mix in 2040. For the sake of simplicity, we assume about half of plug-in hybrid mileage will be gasoline-powered and about half will be electricity-powered, and we split the plug-in hybrid weight evenly between gasoline and electricity. For gasoline, ethanol, and diesel vehicles, our analysis assumes an average future fuel economy of 44 miles per gallon (mpg). ${ }^{49}$

\footnotetext{
${ }^{49}$ The average fuel efficiency of light-passenger vehicles in the United State has historically been less than $80 \%$ of the prevailing Corporate Average Fuel Economy (CAFE) standard (DOT 2016). The U.S. CAFE standard is set to increase to $55.3 \mathrm{mpg}$ in 2025 for passenger cars. It is assumed that the average fuel efficiency of light passenger vehicles will be about 44 mpg by 2035 or about $80 \%$ of the CAFE standard in 2025 .
} 


\begin{tabular}{|c|c|c|}
\hline Fuel type & Assumptions $^{a}$ & $\begin{array}{l}\text { Weighted carbon } \\
\text { Intensity (kg } \\
\mathrm{CO}_{2} / \text { mile) }\end{array}$ \\
\hline Gasoline & $\begin{array}{l}8.91 \mathrm{~kg} \mathrm{CO} / \text { gallon } \times 0.023 \text { gallons } / \mathrm{mile}= \\
0.20 \mathrm{~kg} \mathrm{CO} / \mathrm{mile}\end{array}$ & $0.8 \times 0.20=0.16$ \\
\hline E85 ethanol & $\begin{array}{l}1.34 \mathrm{~kg} \mathrm{CO} / \text { gallon } \times 0.023 \text { gallons } / \mathrm{mile}= \\
0.03 \mathrm{~kg} \mathrm{CO} / \mathrm{mile}^{50}\end{array}$ & $0.1 \times 0.03=0.003$ \\
\hline Electricity & $\begin{array}{l}\text { The carbon intensity of electric vehicle }(E V) \text { mileage is } \\
\text { a function of the carbon intensity of the local grid where } \\
\text { EVs are charged. For simplicity, it was assumed that } \\
\text { the carbon intensity of an average } E V \text { in the United } \\
\text { States is the equivalent of a gasoline-powered vehicle } \\
\text { achieving } 50 \mathrm{mpg},{ }^{51} \text { or about } 0.18 \mathrm{~kg} \mathrm{CO} \mathrm{CO}_{2} / \mathrm{mile} \text {. }\end{array}$ & $0.06 \times 0.18=0.01$ \\
\hline \multirow[t]{2}{*}{ Diesel } & $\begin{array}{l}10.15 \mathrm{~kg} \mathrm{CO} / \text { gallon } \times 0.023 \text { gallons } / \text { mile }= \\
0.23 \mathrm{~kg} \mathrm{CO} / \mathrm{mile}\end{array}$ & $0.04 \times 0.23=0.009$ \\
\hline & Total weighted carbon intensity & $0.18 \mathrm{~kg} \mathrm{CO}_{2} / \mathrm{mile}$ \\
\hline
\end{tabular}

${ }^{a}$ All emissions factors are based on EIA: Carbon Dioxide Emission Factors for Transportation Fuels

\section{A.4 Solar PV Supplementary Materials: Technical Potential Derate Factor}

According to NREL's nationwide lidar analyses, the average quantity of suitable roof area per suitable small building is 56 square meters. ${ }^{52}$ At a power density of $160 \mathrm{~W} / \mathrm{m} 2$ - which is the average value across all solar PV technologies in a set of over 200,000 systems installed in 2014 (Barbose et. al. 2015) — that corresponds to $9 \mathrm{~kW}$ of technical potential per suitable small building. However, not all that potential is typically utilized. The exact average system size being installed is unknown, but a representative system size is commonly assumed to be $5 \mathrm{~kW}$ for a residential distributed solar PV system. ${ }^{53}$ Therefore, the analysis derates technical potential by a factor of $44 \%$ (4/9) to estimate the amount of technical potential actually deployed due to a change in willingness to adopt solar (see Section 6).

\footnotetext{
${ }^{50}$ This estimate does not include indirect emissions associated with land use changes.

${ }^{51}$ The 50-mpg equivalent does not refer to the equivalent fuel efficiency of the vehicle, which has been estimated at well above $100 \mathrm{mpg}$. Nealer, Reichmuth, and Anair (2015) found that $66 \%$ of Americans live where driving an EV emits the same emissions as driving a gasoline-powered vehicle with $50 \mathrm{mpg}$ or greater fuel economy. This number is likely to increase for several reasons; however, an accurate future estimate of the carbon intensity of EVs is outside the scope of this analysis.

${ }^{52}$ A suitable small building has a footprint of less than 460 square meters and has at least 10 square meters of roof area suitable for solar PV deployment.

${ }^{53}$ As elsewhere in this analysis, we make the simplifying assumption that the behavior of the commercial sector approximately tracks the residential sector.
} 


\section{A.5 Municipal Action Supplementary Materials: Hybrid Adjustment Factor}

Stone et al. (2009) developed a methodology to estimate the carbon abatement potential of fleet hybridization. The study first establishes a formula for baseline fleet emissions based on methods developed by EPA:

$$
\text { base } \mathrm{kgCO}=\frac{\text { total } \mathrm{VMT}}{\mathrm{mpg}} * \frac{8.877 \mathrm{~kg} \mathrm{CO}}{\text { gallon }}
$$

Where total VMT refers to the sum of vehicle miles travelled (VMT) in a given study area of a given period, and $8.877 \mathrm{~kg} \mathrm{CO}_{2} /$ gallon is the EPA emission factor for gasoline. Stone et al. (2009) then developed an emissions adjustment factor for hybrid vehicles:

$$
\text { hybrid adjustment factor }=\frac{m p g_{\text {base }}}{m p g_{\text {hybrid }}} *(1+\text { VMT rebound })
$$

Where $m_{p g} g_{\text {base }}$ is the fuel efficiency of a conventional fleet, $m p g_{\text {hybrid }}$ is the fuel efficiency of a hybridized fleet, and VMT rebound refers to the rebound effect where drivers increase mileage in response to lower marginal travel costs. The rebound effect is typically about $2 \%$ per every $10 \%$ increase in fuel efficiency. The emissions reduction assuming a full fleet hybridization can then be estimated according to:

$$
\mathrm{kgCO} \text { reduction }=\text { base } \mathrm{kgCO} *(1-\text { hybrid adjustment factor })
$$

For the purposes of their study, Stone et al. (2009) calculated a hybrid adjustment factor of 0.82, based on assumed future fuel efficiencies of $25.6 \mathrm{mpg}$ for a non-hybridized fleet and $33 \mathrm{mpg}$ for a hybridized fleet, and a rebound factor of 5.8\%. The hybrid adjustment factor translates to an $18 \%$ reduction in fleet carbon emissions. 


\section{Appendix B. Supplementary Materials: Cost Assumptions Used in Economic Impact Analysis}

\section{B.1 Implementation Cost Assumptions Building Energy Codes}

Cost estimates for actions to improve building code compliance range from $\$ 210$ million, with states bearing about $64 \%$ of the costs, to $\$ 1$ billion per year (Choi Granade et al. 2009). We assume an implementation cost of $36 \%$ (city share $=100-64=36 \%$ ) of the upper bound estimate, $\$ 360$ million per year, or about \$6 billion (adjusted to \$2015) over the study period (2020-2035).

\section{Building Energy Incentives}

Billingsley et al. (2014) estimated the cost of energy efficiency programs for electricity based on reported program costs per unity of energy saved. The study's metric, the levelized cost of lifetime energy savings (LCSE), measures the net present value (NPV) of all program costs relative to lifetime energy savings achieved by the program, written:

$$
\operatorname{LCSE}(\$ / k W h)=\frac{N P V \text { of program cost }(\$)}{\text { lifetime energy savings }(k W h)}
$$

The average LCSE in the study was $\$ 0.018 / \mathrm{kWh}$ for residential programs and $\$ 0.021 / \mathrm{kWh}$ for commercial customers at a discount rate of $6 \%$. We can solve for the NPV of program cost by estimating the lifetime energy savings resulting from the policy scenarios:

$$
N P V \text { of program cost }(\$)=\operatorname{LCSE}\left(\frac{\$}{k W h}\right) * \text { lifetime energy savings }(k W h)
$$

We assume effective useful lifetimes of energy efficiency technologies of 18 years for residential and 15 years for commercial applications. ${ }^{54}$ Table B-1 summarizes estimated lifetime energy savings for the two policy scenarios consistent with the assumptions made in the carbon reduction potential analysis.

Table B-1. Estimated Lifetime Energy Savings (TWh)

\begin{tabular}{lcc} 
Sector & Moderate Abatement Scenario & High Abatement Scenario \\
\hline Residential & 173 & 1,330 \\
Commercial & 1,180 & 2,970 \\
\hline
\end{tabular}

Based on the values in Table B-1 and assumed LCSE of $\$ 0.018 / \mathrm{kWh}$ and $\$ 0.021 / \mathrm{kWh}$ for residential and commercial buildings, respectively, the NPV of program costs in the analysis is

\footnotetext{
${ }^{54}$ The effective useful life refers to the median length of time that an energy efficiency measure is functional. In a review of 70 commercial and 107 residential programs, Hoffman et al. (2015) found that the effective useful life of energy efficiency measures for new construction was 15 years for commercial buildings and 18 years for residential buildings.
} 
assumed to be $\$ 31$ billion in the moderate abatement scenario and $\$ 84$ billion in the high abatement scenario.

\section{Municipal Actions}

\section{Buildings}

The lifetime costs of energy efficiency measures are commonly normalized in terms of negawatthours. A negawatt-hour refers to a $\mathrm{kWh}$ of electricity offset as a result of an energy efficiency measure. Negawatt-hour cost estimates generally measure the full cost of running an energy efficiency program and installing equipment. Gillingham et al. (2006) reviewed negawatt-hour cost estimates from several studies of utility demand-side management programs implementing energy efficiency measures. Negawatt-hour cost estimates ranged from $\$ 0.01$ to $\$ 0.16$ per negawatt-hour ${ }^{55}$ in cost estimates that did not account for free-rider effects. ${ }^{56}$ Based on the cost estimate range, an energy efficiency cost of $\$ 0.10$ per negawatt-hour is assumed.

Total lifetime costs are then the product of the full lifetime energy savings (negawatt-hours) and the negawatt-hour cost. In the analysis, full energy savings (electricity and natural gas) reach 122 billion negawatt-hours (moderate abatement scenario) and 243 billion negawatt-hours (high abatement scenario) in 2035. Assuming constant implementation from 2020 to 2035, consistent with assumptions in the carbon abatement analysis, this equates to annual negawatt-hour changes of 8.1 billion negawatt-hours (moderate) to 16.2 billion negawatt-hours (high). Full lifetime costs can then be calculated:

$$
\begin{aligned}
& \text { lifetime cost (moderate) }=\int_{t=0}^{15} 0.1 *\left(8.1 * 10^{9}\right) t d t=\$ 6.08 B \\
& \text { lifetime cost (high) }=\int_{t=0}^{15} 0.1 *\left(16.2 * 10^{9}\right) t d t=\$ 12.2 B
\end{aligned}
$$

The estimated national costs of municipal building actions are assumed to be $\$ 6.08 \mathrm{~B}$ in the moderate abatement scenario and $\$ 12.2 B$ in the high abatement scenario.

\section{Fleet}

Reductions of greenhouse gas emissions for fleets are based on scenarios in which cities hybridize 50\% (moderate abatement scenario) and $75 \%$ (high) of fleets. Total national municipal fleet VMT equates to 22 billion VMT per year in 2015, rising to 28 billion VMT in the 2035 baseline. $^{57}$

The average annual utilization of municipal vehicles varies by vehicle type from 11,346 VMT/year for typical light-duty vehicles to $15,160 \mathrm{VMT} /$ year for police cars and 25,000 VMT/year for refuse trucks (AFDC 2016). Assuming average annual utilization of 15,000 VMT/year, the baseline estimate of fleet vehicles nationally is 1.5 million in 2015 , rising to 1.8 million vehicles in 2035 . Under the two scenarios, this equates to 0.9 million hybrid vehicles

\footnotetext{
${ }^{55}$ Cost estimates are updated from 2006.

${ }^{56}$ Free rider effects affect the results of utility-led programs that incentivize the private uptake of energy efficiency measures, but they do not apply in the context of municipal action energy efficiency programs.

${ }^{57}$ This assumes municipal fleet VMT comprise $1.5 \%$ of total city VMT. Baseline VMT defined by the reference case based on DOE City Energy Profile Tool data. See Section 7 and Section A.2 in Appendix A for details.
} 
(moderate abatement scenario) to 1.35 million hybrid vehicles (high abatement scenario) procured by 2035 . Hybrid vehicles are currently manufactured at a cost premium of $\$ 2,500$ to $\$ 3,500$ per vehicle (German 2015). Assuming an average price premium of $\$ 3,000 /$ vehicle, the total costs of fleet hybridization are:

$$
\begin{gathered}
\text { total cost }(\text { moderate })=0.9 M \text { vehicles } * \frac{\$ 3,000}{\text { vehicle }}=\$ 2.7 B \\
\text { total cost }(\text { high })=1.35 M \text { vehicles } * \frac{\$ 3,000}{\text { vehicle }}=\$ 4.1 B
\end{gathered}
$$

The national costs of fleet hybridization are assumed to be $\$ 2.7$ billion in the moderate abatement scenario and $\$ 4.1$ billion in the high abatement scenario.

\section{Solar}

Our analysis assumes cities deploy between 50\% (moderate abatement scenario) and 90\% (high abatement scenario) of municipal building technical potential solar PV by 2035. Total municipal building technical potential is estimated at $9.9 \mathrm{GW}^{58}$; therefore, the assumed deployment equates to $4.95 \mathrm{GW}$ (moderate) and $8.91 \mathrm{GW}$ (high). Assuming the capacity is procured continuously from 2020 to 2035, this equates to $0.33 \mathrm{GW} /$ year (moderate) and $0.59 \mathrm{GW} /$ year (high). Distributed solar PV prices are expected to decline by 3\%-12\%/year from 2014 to 2020 and to reach $\$ 1.50-\$ 3.00 / \mathrm{W}$ by 2020 (Feldman et al. 2015). Assuming that mean system prices in 2020 are $\$ 3.00 / \mathrm{W}$ and system prices decline by 3\%/year from 2020 to 2035, total procurement costs in the two scenarios are given:

$$
\begin{gathered}
P V \text { procurement cost }(\text { moderate })=0.99 \int_{t=0}^{15} 0.97^{t} d t=\$ 11.9 B \\
P V \text { procurement cost }(\text { high })=1.77 \int_{t=0}^{15} 0.97^{t} d t=\$ 21.3 B
\end{gathered}
$$

The total national undiscounted costs of municipal solar PV procurement are \$11.9 billion and $\$ 21.3$ billion in the moderate and high abatement scenarios, respectively.

\section{B.2 Input-Output (I-O) Model}

Impact estimates were generated using the IMPLAN I-O model with national-level 2014 data. Each scenario considers different types of impacts. During implementation, economic activity is generated due to demand for construction and planning activities. This comes at a cost, however. Assuming these activities are funded by the population that lives within the affected region (in this case, the United States), and do not displace other economic activities funded by the population, the amount of disposable income for households decreases. Yet, cost savings from reduced energy consumption generate returns and result in increased disposable income over time.

During policy implementation, there are two types of impacts:

\footnotetext{
${ }^{58}$ This figure is based on $1.5 \%$ of total city technical potential. See Section 7.2.
} 
- Jobs and other economic activity supported by construction and planning

- Reduced disposable household income during construction.

Similarly, there are two types of post-implementation impacts that occur during the life span of the policies:

- Increased disposable household income from reduced energy expenditures

- Reduced demand for gas and electricity.

There is considerable precedent for using an I-O based method for net analysis. Anderson et al. (2014) provide an extensive review of economic literature to compare three of the most used types of economic modeling, including I-O, computable general equilibrium modeling, and econometric modeling. The authors (Anderson et al. 2014), who considered both positive and negative impacts of scenarios, found I-O to be the most commonly used of the three.

Similarly, U.S. Bureau of Economic Analysis economists encourage users of its I-O data to estimate net rather than gross impacts, including both new economic activity and displaced activity (Bess and Ambargis 2011). The State of Washington Office of Financial Management also lists using its I-O data for net analysis as a best practice (OFM 2002).

The practice of using net analysis has been published in peer-reviewed journals, dissertations, and theses such as George (2015) and Elder and Butcher (1989).

\section{B.3 Limitations of I-O Methodology}

As do all economic models, I-O analysis has limitations. All production and consumption functions in the model assume perfectly elastic supply. In other words, prices are fixed regardless of the level of a commodity that is consumed. If an apple is $\$ 1$, it will always be $\$ 1$ and apples will always be available regardless of how many apples households purchase.

Low levels of consumption are unlikely to influence prices significantly, and efficiency materials considered in this analysis (for direct effects) are not in short supply and are likely to be available at the levels specified. However, this is only assumed, not explicitly estimated.

Fixed prices also preclude fully representing a possible rebound effect. The rebound effect occurs when a decrease in the quantity of energy demanded results in decreases in energy prices. When these prices decrease, consumers have incentive to consume greater amounts of energy.

The model does account for potential changes in energy use that result from changes in household or business expenditures. For example, if disposable household income increases and results in increased use of automobiles, the model does account for the changes in energy needed to accommodate this consumption.

Neither positive nor negative estimated impact figures necessarily reflect a precise level of economic gains or losses that may actually occur. For example, a retailer may not necessarily increase its workforce size in response to increase in demand. The retailer may simply increase the amount of work that its employees must perform. Similarly, decreased demand for electricity does not necessarily indicate cutbacks of the utility industry workforce. A utility may keep its 
workers - especially those with in-demand skills that are unique to that industry - despite decreases in the use of its products. Both of these are especially relevant when impacts are dispersed nationally and are relatively small at the local level. However, these changes in labor productivity are not considered in the static and linear I-O framework. 